\title{
Exploring the Perceptions of Produce Processors Operating in Non-Profit Commercial Kitchens in West Virginia
}

\author{
Megan Christine Govindan \\ megan.govindan@mail.wvu.edu
}

Follow this and additional works at: https://researchrepository.wvu.edu/etd

Part of the Development Studies Commons, and the Food Studies Commons

\footnotetext{
Recommended Citation

Govindan, Megan Christine, "Exploring the Perceptions of Produce Processors Operating in Non-Profit Commercial Kitchens in West Virginia" (2021). Graduate Theses, Dissertations, and Problem Reports. 8088.

https://researchrepository.wvu.edu/etd/8088

This Dissertation is protected by copyright and/or related rights. It has been brought to you by the The Research Repository @ WVU with permission from the rights-holder(s). You are free to use this Dissertation in any way that is permitted by the copyright and related rights legislation that applies to your use. For other uses you must obtain permission from the rights-holder(s) directly, unless additional rights are indicated by a Creative Commons license in the record and/ or on the work itself. This Dissertation has been accepted for inclusion in WVU Graduate Theses, Dissertations, and Problem Reports collection by an authorized administrator of The Research Repository @ WVU. For more information, please contact researchrepository@mail.wvu.edu.
} 


\title{
Exploring the Perceptions of Produce Processors Operating in Non-Profit Commercial Kitchens in West Virginia
}

\author{
Megan Govindan
}

\author{
Dissertation submitted to the \\ Davis College of Agriculture, Natural Resources and Design \\ at West Virginia University \\ in partial fulfillment of the requirements \\ for the degree of \\ Doctor of Philosophy \\ in \\ Human and Community Development
}

\author{
Cheryl Brown, PhD., Chair \\ Harry N. Boone, Jr., Ph.D. \\ Deborah A. Boone, Ph.D. \\ Nancy M. McIntyre, Ph.D.
}

School of Design and Community Development

Morgantown, West Virginia

2021

Keywords: Food processors, Farm to Institution, Commercial kitchens

Copyright 2021 Megan Govindan 


\title{
ABSTRACT \\ Exploring the Perceptions of Produce Processors Operating in Non-Profit Commercial Kitchens in West Virginia
}

\author{
Megan Govindan
}

According to the Centers for Disease Control and Prevention, 48 million people get sick, 128,000 are hospitalized and 3,000 die each year from foodborne illness. The Food Safety Modernization Act (FSMA) shifted the focus of the Food and Drug Administration from response, to prevention of foodborne illness. The FSMA identified seven rules related to food safety prevention measures, including inspection and compliance, response and enhanced partnerships to ensure food safety along the food system, and employee-training compliance measures. Increasing access to healthy, local foods has economic, public health, and environmental benefits. Farm to Institution policies are becoming more popular nationally, but pose concerns related to food safety, labor and liability, food preparation, sourcing products, cost, and seasonality of local products. The West Virginia Fresh Food Act (HB 2396) requires institutions to purchase a minimum of five percent of fresh produce, meat and poultry products from West Virginia producers and processors. Increasing access requires all food actors to be in compliance with FSMA rules as they relate to their scope of engagement with the food system. Produce processors are required to have advanced food safety training in better process controls to be FSMA compliant. This mixed-methods descriptive research study uses a two-phase, mixed methods design to describe the role of produce processors in food safety as constructed by federal food safety regulations and as perceived by food workers in the context of their everyday lives and work experiences. Produce processors require FSMA compliant education to take advantage of Farm to Institution opportunities associated with HB 2396. This research can inform the development of scale-appropriate food processor education to foster this market opportunity and its contribution to regional food system development. As the demand for local food increases, it is critical to further examine produce processor perspectives related to food safety and local food marketing. This research identified $(n=11)$ commercial food processors operating in non-profit kitchens. The majority of operators were white women, above the age of 45 , in rural towns with annual sales less than $\$ 50,000$. When correcting for college education, there was a significant association between perception of time commitments associated with food safety training and rural environments. Perceived barriers identified include lack of centralized information for food safety, access to environments, and access to Process Control Authority and expertise. The results of this research informed the development of a food safety outreach program entitled The House Food Safety Program for Microprocessors. 


\section{DEDICATION}

This work is dedicated to brown immigrants and their children. 


\section{ACKNOWLEDGEMENTS}

I acknowledge GOD, my creator and savior for the blessings and opportunities to pursue education and contribute to positive change.

I acknowledge the Shawnee, Mingo, Moneton, Osage, Susquehannock, Tutelo, and Tuscarora peoples whose land was stolen and colonized as Virginia, West Virginia, and these parts of Appalachia.

I have been blessed with many mentors lighting my path, who have also been a beacon of hope and change for others. My committee is a wild and wonderful legacy of the transformative power of education and community, and I am indebted to them for their time, expertise and mentorship. I extend my most sincere thanks to my chair and committee members. Thank you, Dr. Cheryl Brown for changing how I see the world, and my own capacity to contribute to positive change. Thank you for being a mentor, a confidant, a friend, and an architect of West Virginia's food system. Thank you, Dr. Nancy McIntyre, for showing me what female leadership in Higher Education looks like, for challenging me to change everything, and helping me believe that I could and I can. Thank you, Dr. Debby Boone, for supporting me in every step of my journey, helping me to refine my thoughts, arguments, and programs to benefit agriculture education in West Virginia. Thank you, Dr. Harry Boone for your support, encouragement, critical review, and for teaching me data collection and presentation, so I can articulate the significant changes I hope to make during my time on this Earth. It is my goal to honor your work and commitment to the great state of West Virginia through the HOUSE food safety outreach program, and provide opportunities for growth for others, just as you have done for me, and countless students and community members who crossed your path.

I recognize and thank those who came before me, including the late Dr. Ruth Kershner and Dr. Cameron Hackney who taught me "public health is not something you do but a way you live", and that food safety is a precedent to healthy communities.

I acknowledge and thank my ancestors, known and unknown from Bolivia and India, for dreaming of me. This work would not have been possible without the love and support of my parents Anna Maria Rivero de Govindan and Srinivasan Govindan, and the guidance and encouragement of my older sisters Elizabeth and Vanessa, and the promise of the next generation, my nephew Anthony and niece Lilly. I acknowledge and thank my loving partner Christopher, who shouldered every burden, celebrated every success, and continually motivated me to step into my power.

Thank you to my friends, and colleagues for always cheering me on, and loving me, as I am. Thank you to my local food \& farm community, and study participants for sharing your stories, work and passion with me. I am motivated and inspired to continue to make this road by walking with you all, to build a more just, equitable, sustainable, and resilient food system. 


\section{TABLE OF CONTENTS}

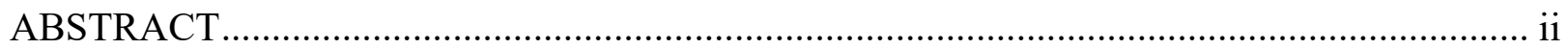

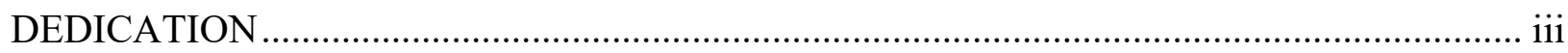

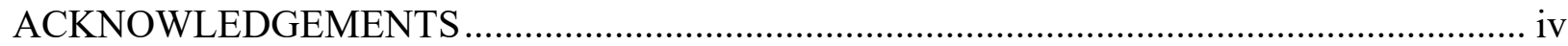

LIST OF TABLES ................................................................................................... vii

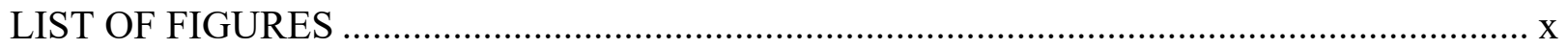

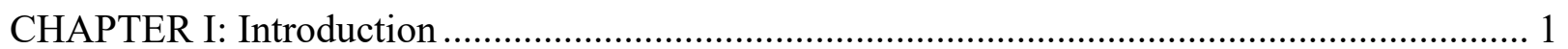

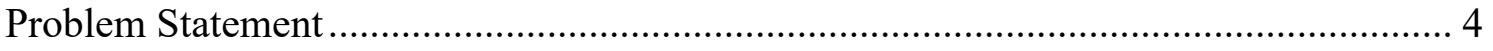

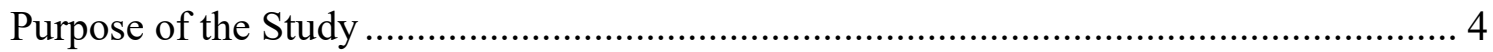

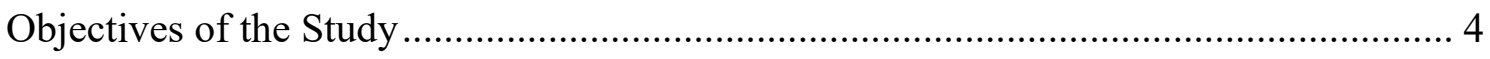

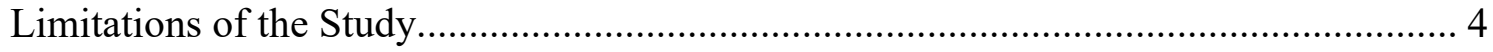

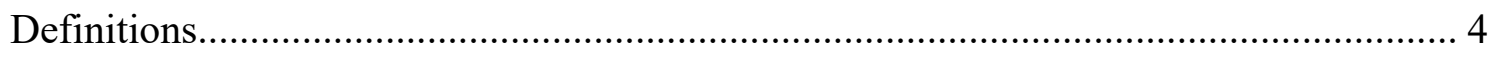

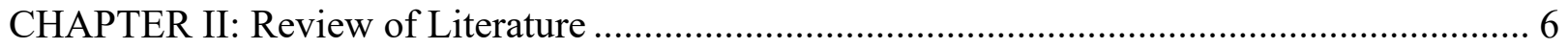

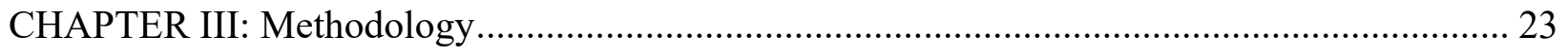

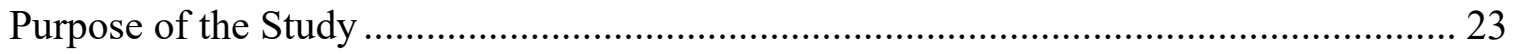

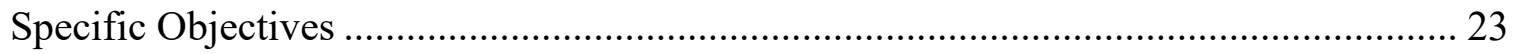

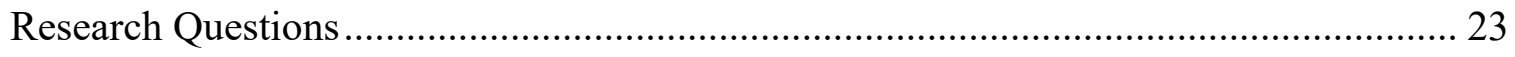

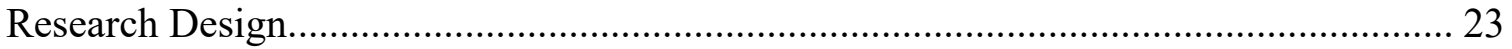

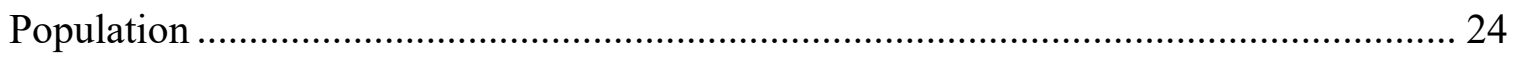

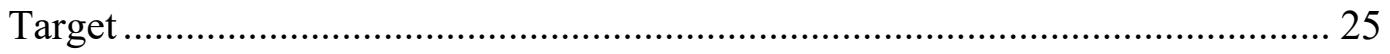

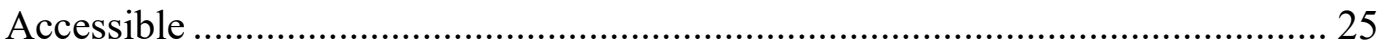

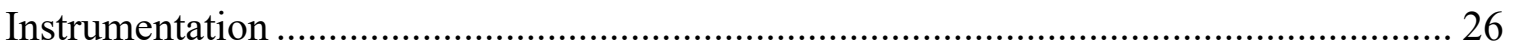

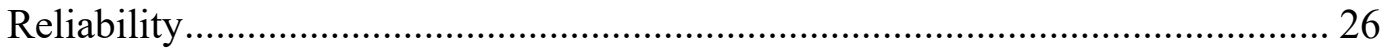


Validity

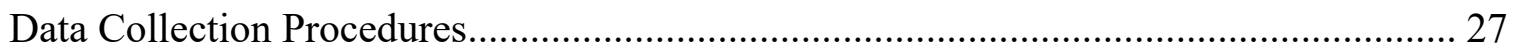

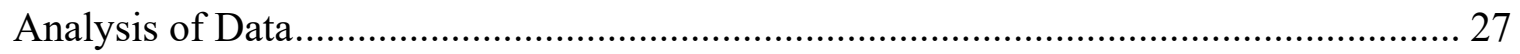

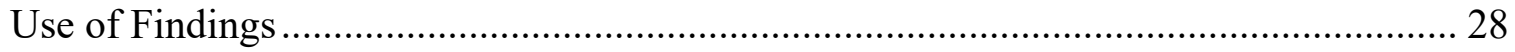

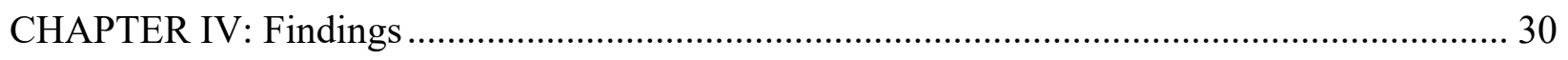

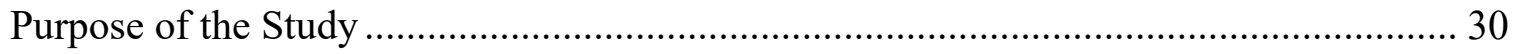

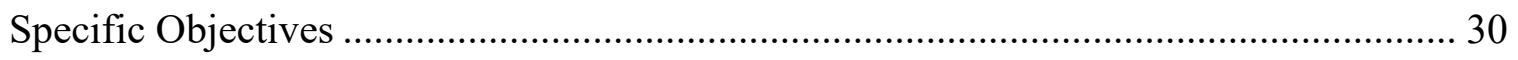

Research Questions ................................................................................................... 30

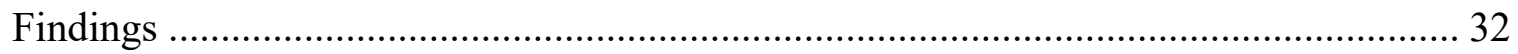

CHAPTER V: Summary, Conclusions, and Recommendations ............................................... 43

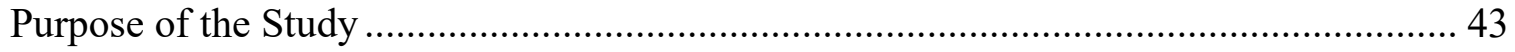

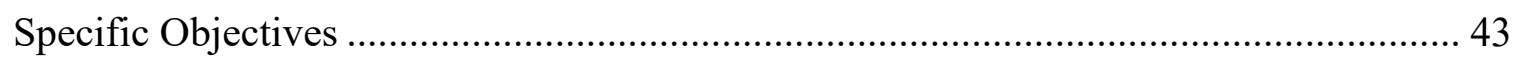

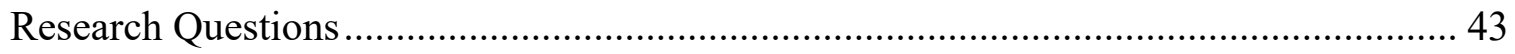

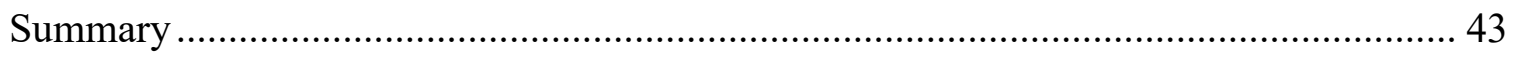

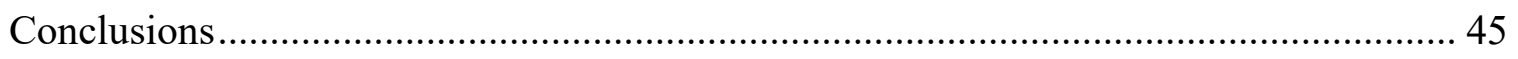

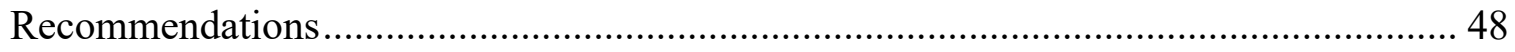

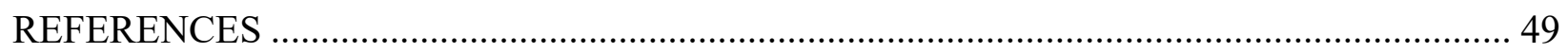

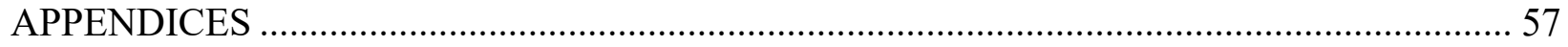

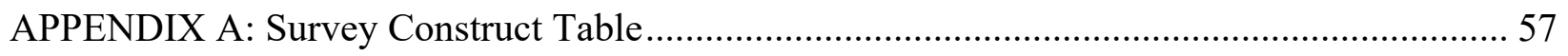

APPENDIX B: Cover Letter for Survey - First Request ........................................................... 59

APPENDIX C: Cover Letter for Survey - First Follow Up ....................................................... 61

APPENDIX D: Cover Letter for Survey - Second Follow Up .................................................... 65 


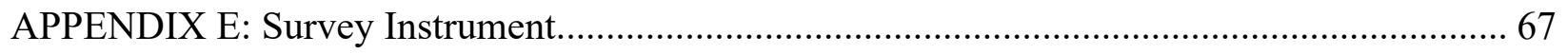

APPENDIX F: Focus Group Facilitation Outline ....................................................... 81

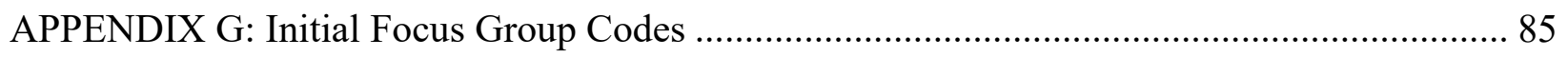

APPENDIX H: Food Safety Outreach Program Development and Program Evaluation ............ 87

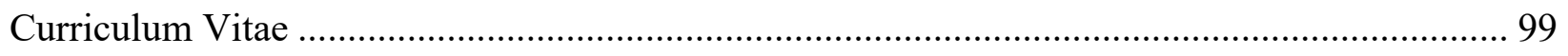




\section{LIST OF TABLES}

Table Title Page

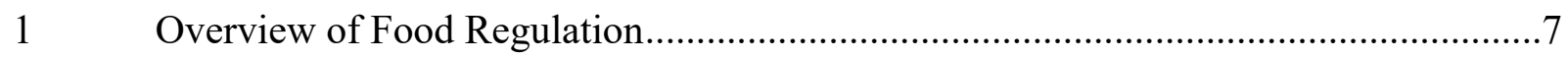

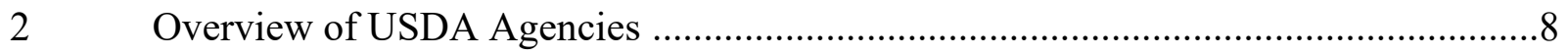

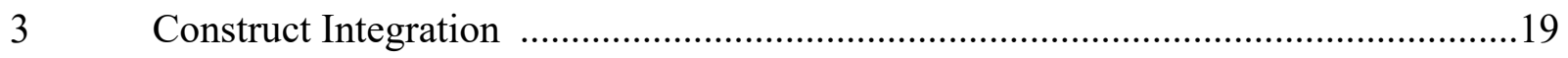

$4 \quad$ Methods for Increasing Self-efficacy, Adapted from Bandura...............................21

$5 \quad$ Non-Profit Kitchens Identified by Community Food Systems LINK .....................25

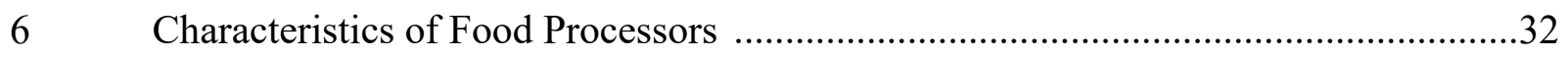

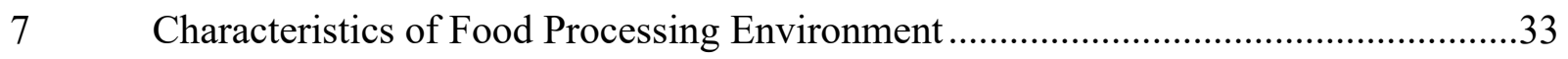

8 Fisher's Exact Test: Association of Variables and BPCS Completion .....................33

9 Fisher's Exact Test and CMH: Association of Variables and BPCS completion and

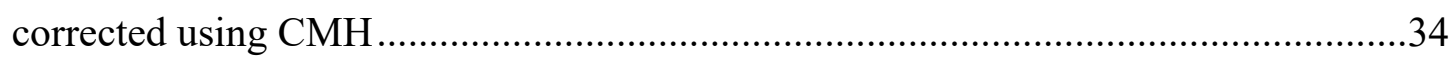

10 Fisher's Exact Test: Association of completion of College and perception...............35

11 Fisher's Exact Test and CMH: Association of completion of College with food safety training Variables and controlled for rural/urban environments using $\mathrm{CMH}$................35

12 Fisher's Exact Test: Variables Compared by Rural and Urban Environments ..........36

13 Fisher's Exact Test: Variables Compared by Total Sales .....................................37

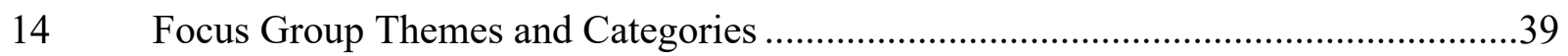

15 Focus Group Quotes Applied to Social Cognitive Theory Concepts ........................40

16 Methods for Increasing Self-efficacy Applied to the HOUSE program ...................43

17 HOUSE Pilot - Participating Organizations .....................................................93

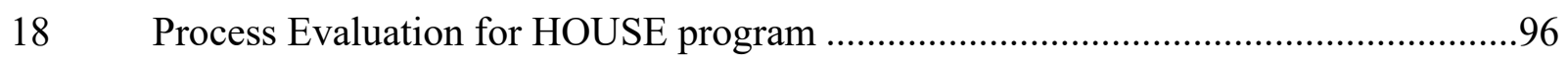

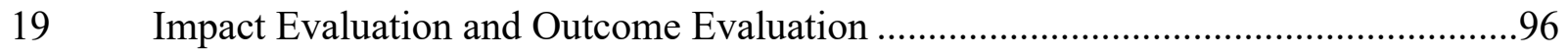




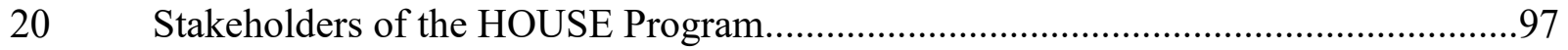

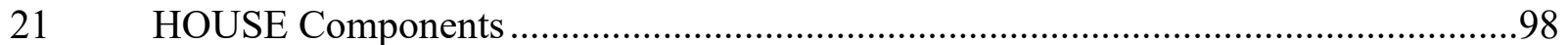




\section{LIST OF FIGURES}

Figure Title Page

1 Theory of Planned Behavior.............................................. 15

2 Conceptual Framework of Food Processor to Adopt Food Safety Certification.........21

3 Local Social Entrepreneurship Process of Knowledge Conversion ........................... 46

4 Local Social Entrepreneurship Process of Knowledge Conversion Applied to the........

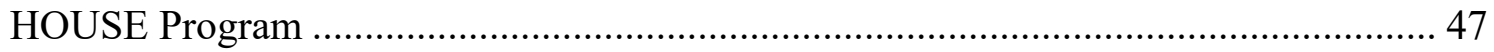

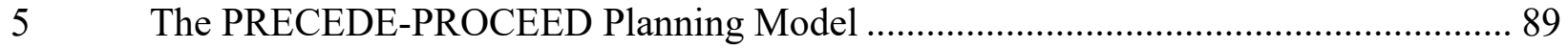

$6 \quad$ Logic Model: The HOUSE Program ................................................................... 93

7 Application of the PRECEDE-PROCEED Model to the HOUSE .............................. 95 


\section{CHAPTER I}

\section{Introduction}

\section{Background}

According to recent data from the Centers for Disease Control and Prevention (CDC) approximately 48 million people get sick, 128,000 are hospitalized and 3,000 die each year from foodborne illness (CDC, 2018). This represents a significant public health problem, and a threat to the economic well-being of the food system that is largely preventable. Based on this, the Food and Drug Administration (FDA), the authority responsible for addressing this problem, created the Food Safety Modernization Act in 2011. In this chapter, the history of this act is discussed, along with how compliance is achieved, the training that is required, how food is sold directly from farms, barriers for food processors, and how West Virginia responded to the act. West Virginia received an "F" from the Center for Science in Public Interest in their 10-year review of state outbreak reports (Center for Science in Public Interest, 2011). The findings suggest the state lacks funding for public health services, leading to health departments that are overburdened and understaffed. The result is decreased outbreak investigation, and detection and reporting. The last report associated with potentially hazardous food was in 1973, with a Botulism outbreak that was linked to a commercial food product, peppers, a low acid food (Barker et al., 1977) West Virginia lacks a Process Control Authority, a food safety position that is typically housed in a Land Grant Institution. Processing authorities are individuals who possess expert knowledge in thermal processing requirements for low-acid and acidified foods.

\section{Food Safety in the United States and the Food Safety Modernization Act (FSMA)}

The Food Safety Modernization Act (FSMA) was signed into law on January 4th, 2011 by President Obama, giving the FDA the authority to enforce prevention-based controls to regulate growing, harvesting, packing and holding of fresh fruits and vegetables (FDA, 2018a). It is the most sweeping reform of the United States' food safety laws in over 70 years and transforms the nation's food system from being reactive to proactive, with core elements of prevention, surveillance, and response and recovery (FDA, 2018a). The FDA finalized seven rules to implement FSMA to ensure responsibility among different points in the global supply chain for both human and animal food. The seven core FSMA rules are designed to clarify specific actions that must be taken at each of these points to prevent contamination and adulteration of food. The seven core rules are:

1) Produce Safety Rule,

2) Preventive Controls for Human Food,

3) Preventive Controls for Animal Food,

4) Foreign Supplier Verification Programs,

5) Accreditation of Third-Party Auditors/Certification Bodies

6) Sanitary Transportation of Human and Animal Food, and

7) Prevention of Intentional Contamination/Adulteration (FDA, 2018a).

These rules each require training of qualified individuals and employees and mandate the education and training experience to perform specific tasks along the supply chain. 


\section{Ensuring FSMA Compliance Through Public Private Partnerships}

The final seven FSMA Rules were published in the Federal Register on November 27, 2015, and the regulation became effective 60 days after the publishing date January 26, 2016 (Cornell, 2019). The FDA then formed three public/private partnerships to develop education and training to ensure FSMA compliance. These partnerships formed the Produce Safety Alliance, the Preventive Controls Alliance and the Sprout Safety Alliance. Led by Cornell University, the Produce Safety Alliance curriculum meets the requirements for the FSMA Produce Safety Rule (Cornell, 2019). This requires operational changes to meet standards associated with agricultural water, biological soil amendments, domesticated and wild animals, employee training and health and hygiene, and equipment, tools, buildings and sanitation. This is typically completed by food producers, farmers, aggregators, and other agricultural actors verifying Good Agricultural Practices (GAP) (USDA, 2020).

The Illinois Institute of Technology's Institute for Food Safety and Health created the Food Safety Preventive Control Alliance to develop training courses and technical information for prevention of contamination of food for both humans and animals during production (Illinois Institute of Technology, 2020a). These include Preventive Controls for Human Food, Preventative Controls for Animal Food, Foreign Supplier Verification Program and Strategies Against Intentional Adulteration. Training in these programs represents advanced food safety training for food processors and verifies current Good Manufacturing Practices (cGMP) to ensure safe manufacturing/processing, packing and holding of food products for human (and animal) consumption in the United States. The Illinois Institute of Technology also coordinates the Sprout Safety Alliance (Illinois Institute of Technology, 2020b). These public/private partnerships developed a spectrum of train-the-trainer curriculum. Expert trainers receive the food safety training to deliver at the state and county level to food workers, such as food processors.

\section{FSMA Training Requirements for Food Processors}

Navigating food safety agencies, federal and state laws, and requirements can be challenging for all food system actors operating in a variety of environments. Employee food safety training varies in duration, delivery and cost. In order to be FSMA compliant, food producers and processors must verify compliance with GAP and cGMP, and verification of employee training of their food workers (FDA, 2018a). FSMA requires food processors to complete training in Preventive Controls for Human Food, developed by the Food Safety Preventive Control Alliance. The educational program verifies federal compliance and is entitled Better Process Control School (BPCS) (Illinois Institute of Technology, 2020a). These trainings are commonly available through Cooperative Extension, in conjunction with State Departments of Agriculture and Public Health. Verification of federal food safety employee training BPCS allows commercial kitchen environments to process food for institutional consumers and markets.

\section{Direct Farm Sales of Food}

The 2015 Local Food Marketing survey conducted by the USDA's National Agricultural Statistics Service (USDA, 2019), provided benchmark data about local food marketing practices (USDA, 2016a). This survey found that 167,009 U.S. farms produced and sold $\$ 8.7$ billion of edible food commodities directly to institutions, retailers, consumers and a variety of local food 
intermediaries such as distributors and wholesalers (USDA, 2016a). Farm direct marketing involves selling a product from the farm, directly to the customers. Direct farm sales included both fresh and processed or value-added products. Consumers made up 35\% of direct sales, while retailers and institutions and local intermediary businesses comprised $27 \%$ and $39 \%$ of direct sales respectively (USDA, 2016a).

Institutional procurement of local food is increasing thanks to the Healthy, Hunger-Free Kids Act of 2010, which established \$5 million annually to be used for Farm to School (FTS) grants (National FTS Network, 2020). The USDA FTS Grant program increases local foods in schools and has boosted farm income and economic opportunities (National FTS Network, 2020). The 2015 USDA FTS Census indicated that nearly $\$ 790$ million worth of local food was purchased from farmers, ranchers, fishermen, food processors and manufacturers in the school year 2013-2014, representing a 105\% increase from the 2011-2012 school year (USDA FTS, 2016). Forty-seven percent of districts surveyed plan to purchase more food in future school years (USDA FTS, 2016). The positive impacts extend beyond the school cafeteria as school spending on local food drives over $\$ 1$ billion in local economic activity (USDA FTS, 2016). The Farm to School Census reported that schools are purchasing local food from distributors, individual food producers, food processors and manufacturers, USDA foods, and Department of Defense Fresh Program vendors. (USDA FTS, 2016). Other institutions such as colleges, universities, hospitals and prisons can also source local food using these outlets. Many wholesale buyers require food suppliers to comply with food safety protocols such as GAP and cGMP, in addition to carrying liability insurance to protect against economic loss from food-borne illness attributed to the food producer/processor's product (Harris et al., 2012). The costs of adopting food safety standards can be prohibitive for some small, mid-scale and organic producers - thus eliminating them from some markets. Despite the number of schools participating in FTS, few studies have sought to examine the perspectives of primary stakeholders, the producers and processors (Izumi et al., 2010; Joshi et al., 2008).

FTS is a specialized form of Farm to Institution (FTI) (Harris et al., 2012). FTI policies at the local, state, and federal level are a strategy for increasing access to healthy local and regional foods by leveraging purchasing power (Harris et al., 2012). Farm to Institution practices and programs can vary from basic to comprehensive initiatives including procurement of food (fresh, processed and value-added products), food literacy education, access programs (farmers markets, worksite wellness) in a variety of environments (schools, colleges and universities, prisons, and early childhood education centers) (Harris et al., 2012). Agricultural practices related to FTI pose a promise to address health disparities by aligning instructional resources with health and sustainability guidelines from the United States Department of Health and Human Services (Harris et al., 2012).

\section{The West Virginia Fresh Food Act - House Bill 2396 (HB 2396)}

The West Virginia Fresh Food Act, HB 2396 requires state institutions to purchase at least $5 \%$ of their product from West Virginia Producers (WV Legislature, 2019). Beginning July 1st, 2019, all state-funded institutions including schools, colleges, correctional facilities, government agencies and state parks, shall purchase a minimum of $5 \%$ of their food purchases from in-state producers (when available). 
West Virginia leads the nation with $95 \%$ of the farms being family-owned farms (USDA, 2019). There is room for economic growth as approximately $80 \%$ of West Virginia's 20,600 farms have an annual income of less than $\$ 10,000$ (UDSA, 2019). The 2015 United States Department of Agriculture Farm to School census reported that 82\% of school districts surveyed in West Virginia participated in FTS programming, with $12 \%$ the average of total food budget spent on local food (USDA, 2016a). In order to take advantage of the opportunities provided by HB 2396, food producers and processors must be FSMA compliant.

\section{Statement of the Problem}

As the demand for locally produced foods increases in West Virginia, Extension educators and other community development practitioners are eager to enable processors to take advantage of new opportunities for income generation. Due to FSMA regulations, and pressure from buyers for processed foods, it appears that commercial food processors (regardless of size) may need FDA-approved, advanced food safety education and certification to sell to institutions and certain markets. Given the federal mandates, and economic opportunity at hand, it is necessary to comprehend the food processor's intention to adopt the BPCS.

\section{Purpose of the Study}

The purpose of this two-phase, mixed-methods descriptive research study was to learn more about and describe food workers, specifically produce processors operating in WV commercial kitchens, and gain an understanding of their perception of the FDA regulations as well as their intentions to seek food safety training

\section{Objectives of the Study}

1. To understand the social-psychological motivations (behavioral intention, attitude, perceived norm, personal agency) that shape $\mathrm{WV}$ produce processors' intention to complete additional food safety training BPCS.

a. RQ1: What are the characteristics of WV produce processors operating in nonprofit commercial kitchens?

b. RQ2: What beliefs or attitudes influence intention to obtain food safety BPCS certification?

2. To assess the educational programming preferences and delivery formats preferred by WV fruit and vegetable local food processors.

a. RQ3: What key issues do WV produce processors face related to accessing food safety information?

\section{Limitations of the Study}

This study does not include processing of meat and poultry products. This study also does not include produce processing that occurs on the farm. It does not focus on food handlers who are governed by the FDA Food Code in the retail environment.

\section{Definition of Terms}

Listed below are the definitions of key terms used in this study. 
Better Process Control School (BPCS): The BPCS was established by the Food and Drug Administration (FDA) for operating supervisors of commercial food canning operations. The BPCS provides instruction which fulfills the FDA and USDA Good Manufacturing Practice (GMP) requirements to certify the supervisors of acidification, thermal processing, and container closure evaluation operations during the canning of low-acid, acidified foods (Cornell, 2019).

Foodborne illness: A disease that is carried by or transmitted to people through food (National Restaurant Association Educational Foundation, 2010).

Good Agricultural Practices (GAP): GAP is a voluntary audit that verifies that fruit and vegetables are produced, packed, handled, and stored as safely as possible to minimize risks of microbial food safety hazards (USDA, 2020).

Good Manufacturing Practices: cGMP refers to the current Good Manufacturing Practice regulations enforced by the FDA. cGMPs provide for systems that assure proper design, monitoring, and control of manufacturing processes and facilities (FDA, 2018b).

Community Kitchen: The term "community kitchen" encompasses various concepts but is generally used to describe kitchens that serve the community at large (which may include food businesses) and are not for the exclusive use of for-profit businesses (The Food Corridor, 2017).

Commissary Kitchen: A kitchen whose business model is to rent out kitchen time, equipment, and storage (The Food Corridor, 2017).

Incubator Kitchen: A kitchen whose business model is to rent out kitchen time, equipment and storage; with the addition of business development assistance and access to unique channel opportunities (The Food Corridor, 2017).

Shared kitchen: Shared-use kitchens are co-working spaces, where renters or members can rent existing infrastructure for hourly or daily time blocks. There are two types of shared-use kitchens emerging as valuable models in this sector: (1) Commissary kitchens, and (2) Incubator kitchens. The terms "shared kitchen" and "incubator kitchen" are often used interchangeably, but there is an important distinction - whether the entrepreneurial ecosystem services are provided (The Food Corridor, 2017).

Value-Added Products: Value-added products are defined by the USDA as having a change in the physical state or form of the product, the production of a product in a manner that enhances its value, and the physical segregation of an agricultural commodity or product in such a manner that results in the enhancement of the value of that commodity or product (USDA, 2020). 


\section{CHAPTER II}

\section{Review of Literature}

This Review of Literature is divided into three sections. The first section examines the history of food safety regulation in the United States, federal, state and local oversight, with a focus on training requirements for food processors and the environments they operate in. It describes Farm to Institution policy types, West Virginia's Fresh Food Act, and the role of commercial kitchens in community development. In section two, social entrepreneurship is explored. In section three, the theoretical and conceptual framework describing the theories of change and their function are discussed. This section examines Lewin's 3-step theory of change, the theory of planned behavior, and social cognitive theory.

\section{Section One}

\section{History of Food Safety Regulation in the United States}

Federal oversight of food safety can be traced back to the 1906 Pure Food and Drugs Act. Laying the foundation for the Food and Drug Administration (FDA, 2018b), this act prohibited the sale of misbranded or adulterated food and drugs in interstate commerce (FDA, 2018b). The 1938 Federal Food, Drug, and Cosmetics Act brought cosmetics and medical devices under federal control and required pre-approval for drugs to ensure safety and efficacy. In the mid1960s the FDA decided to clarify the Food, Drugs, and Cosmetics Act through regulation of GMP. These regulations were finalized in 1969 and revised in 1986. In 2004, the FDA announced an effort to modernize the GMPs, and in 2011 the Food Safety Modernization Act (FSMA) was passed to enforce this modernization through training developed by public/private partnerships. In 2015, the publication of the final rule, entitled "Current Good Manufacturing Practices and Hazard Analysis and Risk-Based Preventive Controls for Human Food" was published. In order to be FSMA compliant, food processors must complete Better Process Control School, an advanced food safety training certification (Cornell, 2019).

President Obama signed the FSMA into law on January 4th, 2011, transforming the nation's food system from being reactive to proactive, with core elements of prevention, surveillance, and response and recovery (FDA, 2018a). The enactment of FSMA gave the FDA the authority to enforce prevention-based controls to regulate growing, harvesting, packing and holding of fresh fruits and vegetables, processed foods, and supplier verification. As noted above, they created rules to ensure that safe food is a shared responsibility among different points in the global supply chain for both human and animal food (FDA, 2020d). These rules affect the entire food system and each actor in the food system differently. Compliance to federal law is based on sales, and the FDA started routine inspections in 2019. All farms, regardless of size, location, or commodities grown, can reduce food safety risks. Even if a producer is exempt from federal regulation inspections, they are not exempt from personal liability if their product is found to be unsafe. Each year one in six Americans get sick from eating contaminated food (CDC, 2018). Being implicated in a food safety outbreak can dramatically impact the financial viability of the farm. 


\section{Federal, State, and Local Oversight - Jurisdiction and Authority of Food Safety Regulation}

Food Safety regulations are dictated by the United States government, who sets standards and enforces regulations through licensing. The jurisdiction over food safety regulations and licensing is divided amongst several different government agencies. The Food and Drug Administration (FDA) and the United States Department of Agriculture (USDA) provide jurisdiction at the federal level and have the authority to make and enforce regulations on food, see Table 1 (USDA, 2019).

\section{Table 1}

Overview of Food Regulation

\begin{tabular}{ll}
\hline Food \& Drug Administration (FDA) & United States Department of Agriculture (USDA) \\
\hline Food (but not meat) & Grading of raw fruit \& vegetables \\
Dietary supplements & Meat and poultry \\
Bottled water & Eggs, processing, and grading \\
Seafood & Certifying organic production \\
Wild game ("exotic” meat) & \\
Eggs in shell &
\end{tabular}

The USDA develops and manages products and markets for U.S. agriculture, which includes food, fiber, forest and horticulture. The USDA intertwines risk mitigation, credit access and market/production data. Market data can be used in a variety of ways, including demonstrating and validating the economic importance of a sector, evaluating program support, and studying trends and informing decisions (USDA, 2019). The USDA is home to the Agricultural Marketing Service (AMS), the Animal and Plant Health Inspection service (APHIS) and the Food Safety and Inspection Service (FSIS), shown in Table 2. Food safety regulation falls primarily under the USDA FSIS, and the FDA and FSIS have overlapping authority for making and enforcing food safety standards (USDA, 2019). 
Table 2

Overview of USDA Agencies

\begin{tabular}{ll}
\hline USDA Agency & Scope \\
\hline $\begin{array}{l}\text { Agricultural } \\
\text { Marketing }\end{array}$ & $\begin{array}{l}\text { Specific programs for dairy, poultry, fruits and vegetables (Good } \\
\text { Agricultural Practices or GAP), livestock \& seed, organic standards }\end{array}$ \\
Animal \& Plant & $\begin{array}{l}\text { How animals/plants are grown, where they come from, how } \\
\text { illnesses are treated, how identified, tagged or labeled NAIS } \\
\text { Health }\end{array}$ \\
$\begin{array}{l}\text { (National Animal Identification System) } \\
\text { Service (APHIS) }\end{array}$ & \\
Food Safety \& & $\begin{array}{l}\text { Oversees domestic \& imported meat, poultry and eggs, plus foods } \\
\text { where they are an ingredient. }\end{array}$ \\
Inspection & Hazard Analysis \& Critical Control Point Program (HACCP) \\
Service (FSIS) & Regulates meat and poultry from farm to table \\
\end{tabular}

The FDA and USDA share federal jurisdiction. Food produced in one state and sold in another state is termed "interstate commerce" and these foods must meet the requirements of the FDA and/or USDA. Food sold retail or wholesale must come from "an approved source" as defined by government regulations, such as FSMA. Each state has a Department of Agriculture and Department of Public Health which are required under federal law to adopt and enforce food safety standards. Enforcement must be at least equal to federal standards. States may be more restrictive than federal standards, but not less restrictive. Federal standards are dictated in legislation, such as the Federal Meat Inspection Act, which may be amended or re-interpreted over the years. Many states choose to adopt federal regulations into their respective state legal code "by reference." This allows states to refer to the federal law by name only, as being incorporated into state law. This results in food processors needing to have working knowledge of federal regulations in order to comprehend and comply with state regulations. For example, adoption of the FDA Food Code by states. A common example is state adoption of the food code. West Virginia is currently under the 2007 Food Code, while other states that have more progressive agricultural policies are under more recent food codes.

At the local level food systems regulation becomes even more complex. Each state may vary where the burden of regulation lies (Department of Agriculture or Department of Public Health), and regulation may vary by county or municipality. Food safety inspection requirements may vary based on production processes and food products, and their educational training varies widely. This spectrum of employee training requirements for food processors can lead to confusion in obtaining, applying, and verifying advanced food safety training.

\section{Employee Training requirements - Produce Processors}

Employee food safety training is not a one-size fits all approach, as many food system actors have overlapping roles. Food processors have options to verify their FSMA compliance. 
Food Safety training varies in duration, delivery, and cost. Food producers and processors can turn to their state department of agriculture and cooperative extension office for guidance on training availability and potential cost subsidy. State food safety teams can elect to deliver curriculum from the three food safety alliances to train their supervisors. The Produce Safety Alliance provides training verification on the Produce Safety Rule. The Food Safety Preventive Control Alliance provides training verification on Preventive Controls for Human Food. These trainings can be used to verify compliance with Good Agricultural Practices and current Good Manufacturing Processes, respectively. While these advanced food safety certifications verify federal compliance in the individual, they do not apply to the environment of the commercial kitchen facility. Additional permits and/or training, may be required at the state and local level.

\section{Farm to Institution Policy}

FTI policies can be enacted at the federal, state, and local level to support a spectrum of activities centered on increasing access to, and education about, local food. Leveraging institutional purchasing power, FTI policies support increasing access to fresh produce and other products from local and regional farms, to a variety of institutional environments such as worksites, schools, higher education, hospitals, prisons, parks and museums, and faith-based organizations. Comprehensive policies may incorporate point of service education about local foods and producers, cooking nutrition, agriculture, and sustainability. FTI efforts are widely seen as fostering closer community ties and engagement around food issues (Schafft, Hinrichs, \& Bloom, 2010). A popular and specialized form of FTI is Farm to School (FTS) programs, which provide students with experiential learning activities such as school gardens, farm visits from food producers, nutrition and culinary education and salad bars.

The needs and practices of institutions vary, and cultures and attributes of communities are distinct. Advancing FTI policy requires a range of policies and strategies. The most common policies include purchasing preferences, small purchase thresholds, FTS programs, and support for state food policy councils. These policies use different approaches to support procurement through advocate positions, incentives, aid, small purchase thresholds, and celebration. Institutions are broadly categorized as either self-operated or contracted, meaning the institution either runs their own internal food service program or they enter into contract with a food service management company (FSMC) to manage their meal service programs for them. Whether an institution's food program is self-operated or managed by an FSMC, most institutional purchasing is governed by contracts. In order for food producers and processors to supply food service management companies, they must meet liability insurance and follow food safety standards.

\section{West Virginia House Bill 2396: The West Virginia Fresh Food Act}

The West Virginia Fresh Food Act, House Bill 2396 (HB 2396), requires state institutions to purchase at least $5 \%$ of their product from West Virginia Producers (WV Legislature, 2019), provided that such produce, meat and poultry products are available from instate agents. Beginning July 1, 2019, all state-funded institutions such as schools, colleges, correctional facilities, government agencies and state parks, shall purchase a minimum of 5\% from in-state producers. This bill aims to stimulate the agricultural economy through procurement preferences and agricultural activities to spur self-sufficiency. State schools alone 
purchase \$100 million of food from out-of-state sources (WV Legislature, 2019). While the Commissioner of Agriculture is charged with the enforcement and authority of rules and administration of this article, food producers and processors must meet federal requirements such as FSMA to access this market opportunity.

\section{The Role of Commercial Kitchens in Community Development}

Food is a driving force in creating equitable economic opportunities. The scaling up of local food is commonly limited by an enterprise's access to critical infrastructure, such as a commercial kitchen (Palkova \& Palko, 2017). The lack of access to food grade workspace is a barrier to entry for industry growth. Kitchen incubators can provide a strong foundation for the creation and expansion of food businesses and jobs by helping communities with vocational and educational training. Underutilized properties in public and private ownership can be reimagined as kitchen incubators, and have the potential to spur productive, inclusive and sustainable economic development (Palkova \& Palko, 2017). Incubator kitchens provide licensed kitchen space, equipment, and varying levels of other services for food business entrepreneurs who want to focus their start-up capital on proving the product and market. These spaces can combat social inequality by offering the prospect of expanding employment in the food sector through educational opportunities for disadvantaged populations (Palkova \& Palko, 2017).

Shared-use kitchens and kitchen incubators play unique roles in food and entrepreneurial ecosystems. Shared-use kitchens refer to legally licensed, commercial kitchen spaces that are certified for the production of value-added food products. These spaces can create positive social, economic, environmental, and health effects for communities (Conover et al., 2015). They can significantly reduce capital costs and risks of starting a food business, while fostering flexible entrepreneurial jobs in both urban and rural areas (Dent, 2008). The success of these spaces is highly dependent on demographic considerations including population, racial diversity, per capita income, and education level (Conover et al., 2015). In order for operators to engage in commercial kitchens, they must have appropriate food safety training to ensure state and federal compliance.

\section{Food Safety Outreach}

West Virginia food producers and processors have repeatedly voiced concerns about challenges accessing consistent information about laws, regulations, food safety concerns, the lack of information for food processing, and where to turn for information that is accurate, reproducible and administered in a timely fashion (Oldham, 2013). The lack of centralized information has created confusion among want-to-be manufacturers, placed large barriers to entry into the agribusiness marketplace, and driven producers out of state in order to find and utilize resources elsewhere (Stroud et al., 2015). In West Virginia, in addition to being FSMA compliant, food processors must possess a food manufacturers license in order to sell their prepared foods and value-added products to other businesses. The lack of guidance on how to produce, process and sell local food is a limiting factor for WV food producers and processors. This leads many businesses to cross state lines to purchase prepared foods for resale, and ultimately a loss of market share for small businesses. The WV Food and Farm Coalition surveyed over 1,064 producers impacting 31 counties in WV during the summer of 2017 to 
identify over two million dollars in local food sales. This is a strong indicator that local foods are a worthy economic driver in the state (WV Legislature, 2018).

In 2018, researchers at West Virginia University were awarded a \$148,462 USDA Food Safety Outreach program to address this knowledge gap. The Commercial-Kitchens, HomeKitchens, Incubator Kitchens and Food Producers (CHIP) project was selected as one of 31 food safety outreach programs to facilitate the integration of FSMA. The long-term goal of this project was to support infrastructure for food processors in the state by addressing a knowledge gap in food processing education and outreach which contribute to understanding food safety rules and regulations. Shedding light on rules, regulations, and requirements allows food processors to operate more efficiently, and ensures food safety while increasing access to direct and indirect markets. Food Safety outreach materials were developed to increase self-efficacy among food processors. In order to refine and implement these materials, it is crucial to understand the intention of food processors to adopt additional food safety training.

\section{Section Two}

This section examines the differences between entrepreneurs and social entrepreneurs as well as examining the positive theory of social entrepreneurship and neglected positive externalities. It also explores the role of food entrepreneurs and examples of social enterprisefocused, food safety outreach programs.

\section{Social Entrepreneurship}

Entrepreneurial theory is framed in two ways, the classic economist approach, which includes more critical works by Schumpeter and other economists, and the more holistic approach, which includes entrepreneurial ecosystem assessment, supply chain management, and intersections with sustainability (Kline, 2014). Social entrepreneurs are a subset of entrepreneurs that can be defined as socially conscious individuals who devise and incorporate innovative business models and address social issues often overlooked by other organizations (Zahra et al., 2009, Ergul \& Johnson, 2011). Social entrepreneurs aim to create social change in education, health, environment and enterprise improvement. While entrepreneurs are focused on financial gain, emphasizing creativity and innovation to create new businesses, social entrepreneurs take responsibility and risk for civil society needs. Systemic change is the most important objective in social entrepreneurship, gaining support from the community and eliminating the problem through disseminating solutions (Basar, 2018). Partnerships with universities and other stakeholders can contribute to the efficiency of the innovation. Social enterprise must be constructed as a social organizational identity, as social capital is an important determinant for business support (Johnsen, 2015).

A social entrepreneur can be defined as one who uses business principles to solve social problems. Other definitions suggest a continuum extending from those with a purely social mission to hybrid models that include the profit motive to different degrees (Lee \& Jay, 2015, Volkmann, et al., 2012). Bornstein (2007) states that social entrepreneurs "combine the savvy, opportunism, optimism and resourcefulness of business entrepreneurs with the devotion and pursuit of 'social profit' rather than 'business profit,' but these definitions barely touch on the more profound social transformation that is the intended outcome of social entrepreneurship" 
(p.1). In 1977, Chamberlin argued to use the term to include a broader philosophical approach: "for me social entrepreneurship is grounded in social rationality - a completely different philosophical perspective that prioritizes human relationships above task efficiency" (Chamberlin, 1977, p. 2). Zahra et al. (2009) developed a typology of social entrepreneurs including Social Bricoleurs, who focus on addressing small-scale local social needs; Social Constructionists, who exploit "market failures by filling gaps to underserved clients in order to introduce reforms and innovations to the broader social system" and Social Engineers, who address systemic problems within existing structure by destroying the outdated system and introducing revolutionary change.

\section{The Positive Theory of Social Entrepreneurship and Neglected Positive Externalities}

In 2014, Kline et al., examined the potential application of the Positive Theory of Social Entrepreneurship (PTSE) to understand food entrepreneurs and their operations. A principal philosophy in the PTSE is that social entrepreneurs rise up to address an issue that governments do not have the resources to address and in which profit-driven businesses have no interest (Kline et al., 2014). Social entrepreneurs differ from private sector entrepreneurs because of their passion for, and generation of, innovations in the public or nonprofit sectors (Thompson et al., 2020). According to Santos and Moraes (2009), social entrepreneurs can also be in the private sector, but operate on business models that address basic human needs. Social entrepreneurs fulfill a role in the economy when governments and markets simultaneously fail and support the four propositions about social enterprise within PTSE (Santos \& Moraes, 2009). These propositions include (1) Addressing problems involving neglected positive externalities in the distinctive domain of action of social entrepreneurs; (2) Social entrepreneurs are more likely to operate in areas with localized positive externalities that benefit a powerless segment of the population; (3) Social entrepreneurs are more likely to seek sustainable solutions that seek sustainable advantages; (4) Social entrepreneurs are more likely to develop a solution built on the logic of empowerment than on the logic of control (Santos \& Moraes, 2009, Kline et al., 2014).

PTSE notes that social entrepreneurs address "neglected positive externalities" (NPE) (Santos \& Moraes, 2009), which are the positive impacts that could be generated from a business beyond profit but are neglected because the government has multiple roles and scarce resources and because other entrepreneurs are focusing on value appropriation. Santos indicates that NPE are the "distinctive domain" of the social entrepreneur, and because of this they raise awareness regarding the importance of the issues for our society. Food entrepreneurs can generate social, economic and public health NPE, including but not limited to, healthier lifestyles from eating local organic foods, farm to table initiatives - increasing access to local food and decreasing food miles, access to less processed and more nutritious natural and local products, and education of stakeholders and consumers (Kline et al., 2014).

Social entrepreneurship is one of the fastest growing social movements in our time. Growing global awareness that 'business as usual' capitalism and individual self-interest are leading us towards potentially catastrophic environments and social consequences has set the stage for social entrepreneurship to catalyze into a movement (Sheldon \& Daniele, 2017). A recent strategy of food entrepreneurs to increase business activity is to embrace competition through networking, identifying areas of collaboration and cooperation (Novelli et al., 2006) (Kline et al., 2014). 


\section{Strengthening food safety outreach through social entrepreneurship}

In 2017, researchers examined the advances and challenges faced by the formation of the Solidarity Kitchen, a social enterprise that targeted post-harvest losses and the promotion of food safety in vulnerable communities in the city of San Salvador, Brazil. The Solidarity Kitchen was formed to address social vulnerability stemming from poverty, food insecurity and the simultaneous high rates of food loss (Soledade et al., 2017). Seeking to mitigate these problems, this social enterprise sought to guarantee a minimum amount of food for the least privileged, through organized participation in impacted communities (Soledade et al., 2017).

This new model of economic organization of collective work was established in response to the State's inability to solve the problem of poverty. These efforts supported the development of a solidarity economy, as a new modality that encourages defense against social exclusion and operates as a mechanism of socioeconomic integration (Arcoverde et al., 2006). The solidarity economy is understood to be effective for consolidating a different type of work organization, recognizing working individuals as the center of the organization they undertake (Soledade et al., 2017). In the solidarity economy, the principles of collective work include cooperation, solidarity, valuing of community feelings, reciprocity, and democratic, participatory, and selfmanaged organizations (Arcoverde et al., 2006). In Brazil, the solidarity economy has been presented as a response in favor of social inclusion (Cruz \& Santos, 2010).

Soledade et al. (2017) evaluated the Solidarity Kitchen in different aspects of interest, including social mobilization for collective work, the formation, access, and use of the kitchen space, and training in hygiene and food production and commercialization, which allowed for monitoring, processing and discussion of the adjustments for improving the conduct of the activities. This intervention study applied an analysis matrix to assess activities in four areas: popular mobilization to work in a solidarity economy, formation of the workspace, training in food hygiene and production, and marketing of food. Social mobilization and training of the workers emphasized that the issues were identified from the community, not outside agents. According to Franca Filho (Soledade et al., 2017) the establishment of socio-productive activities occurs due to real demands expressed by the residents in a given territory politically debating their common problems. Challenges observed included the mobilization and formation of the group, internal conflicts, the flow of production and the formalization of the activity (Soledade et al., 2017).

In 2018, Basar conducted a case study on Unilever's Trusted Hands Food Safety Online Training Program. This program engaged the public and private sectors including Unilever Foods and Turkey's Union of Cooks, Food Security Association, Food Industry Association, and Tourism Restaurant Investors and Businesses Association. Trusted Hands targeted 30,000 chefs and kitchen teams over three years and sought to develop a curriculum that could be launched in other countries via Unilever. Raising awareness about the impacts of food borne illness outbreaks and preventative measures, this program delivered five online modules which were accessible through scanning quick response (QR) bar codes on various Unilever Food products. The Unilever Food Solution framework sought to awaken consciousness in society and in the sector by increasing the reach of food safety training by using food as an entry point for education. Unilever Food Solutions continues to provide free, online training to build the skills of culinary professionals, while reinforcing food safety principles. This social entrepreneurship 
effort aimed to provide solutions-focused, experiential transformations, by strengthening social capital and constructing social enterprise as a social organizational identity and business model through Unilever Food Solutions (Basar, 2018).

In the United States, Avetisyan and Ross (2019) conducted a comparative case study of food hubs in Michigan, finding that they all could be considered social enterprises, creating both social and economic value. They conclude that: "Social value is created by addressing the needs of small- and medium-sized farmers to access larger markets, establishing scale-appropriate infrastructure and food safety procedures, improving healthy food access in local communities, preserving family farms, maintaining farm identity, and/or strengthening local and regional systems as a whole" (Avetisyan \& Ross, 2019, p. 103).

\section{Section Three}

This section explores the main theories and situates the work. It discusses the theoretical and conceptual framework describing the theories of change and their function. This section examines Lewin's 3-step theory of change, the theory of planned behavior, and social cognitive theory as the theoretical framework for the research study.

\section{Theory of Planned Behavior and Theory of Reasoned Action}

The theoretical framework that was used for this research study is the Theory of Planned Behavior (TPB). Developed in 1991 by Icek Ajzen, TPB was derived from the Theory of Reasoned Action (TRA), proposed by Ajzen and Fishbein (1980). Both theories are concerned with defining behavior through determinants that may be described as motivational factors of the individual (Glanz et al., 2008). The TRA utilizes four attitudinal constructs to determine the attitude toward the behavior and the perceived subjective norm. Attitude towards behavior is determined by two factors: 1) the behavioral belief and 2) the evaluation of the behavioral outcome. The perceived subjective norm is determined by two factors: 1) normative beliefs and 2) motivation to comply. The TRA did not predict behaviors well, particularly when the behaviors were not fully under the individual's control (Glanz et al., 2008). An individual may be motivated by attitudes and subjective norms to perform the behavior, but they may not actually execute the behavior because of certain surrounding circumstances. The inability of the TRA to predict behavior was amongst one of the important reasons another construct was added to this theory, to become the TPB (Glanz et al., 2008).

Ajzen and colleagues added perceived behavioral control to TRA to account for factors outside of individual control that may affect intentions and behaviors. With this addition, TPB was developed (Glanz et al., 2008). The TPB seeks to explain how beliefs develop the foundations that determine behavior (Ajzen, 2011). Beliefs play a key role in determining behavior, and may come from inaccuracy, bias, or lack of knowledge. A key factor in TPB is the intention of the individual as a predictor to perform a certain behavior. Intention is determined by attitude toward the behavior and social normative perceptions regarding the behavior. The theory postulates that perceived control is an independent determinant of behavioral intention, along with attitudes towards the behavior and subjective norms (Ajzen, 2011). In this study, intention was defined as the food processor's intention to adopt the Better Process Control School (BPCS) food safety certification. A conceptual framework is shown in Figure 1 below. 
Icek Ajzen first introduced the TPB, which seeks to explain how beliefs develop the foundations that determine behavior (Ajzen, 1991). This theory exhibits a focus on the individual's intention to display the desired behavior, and the ability of the individual to act on the desired behavior - known as volitional control. Attitude, subjective norms, and perceived behavioral control are three factors included in the TPB as a precursor to behavior. These factors interact with each other to form intent, which can eventually lead to desired behavioral outcomes (Ajzen, 1991).

\section{Figure 1}

Theory of Planned Behavior (Source: Modified from Glanz et al., 2008)

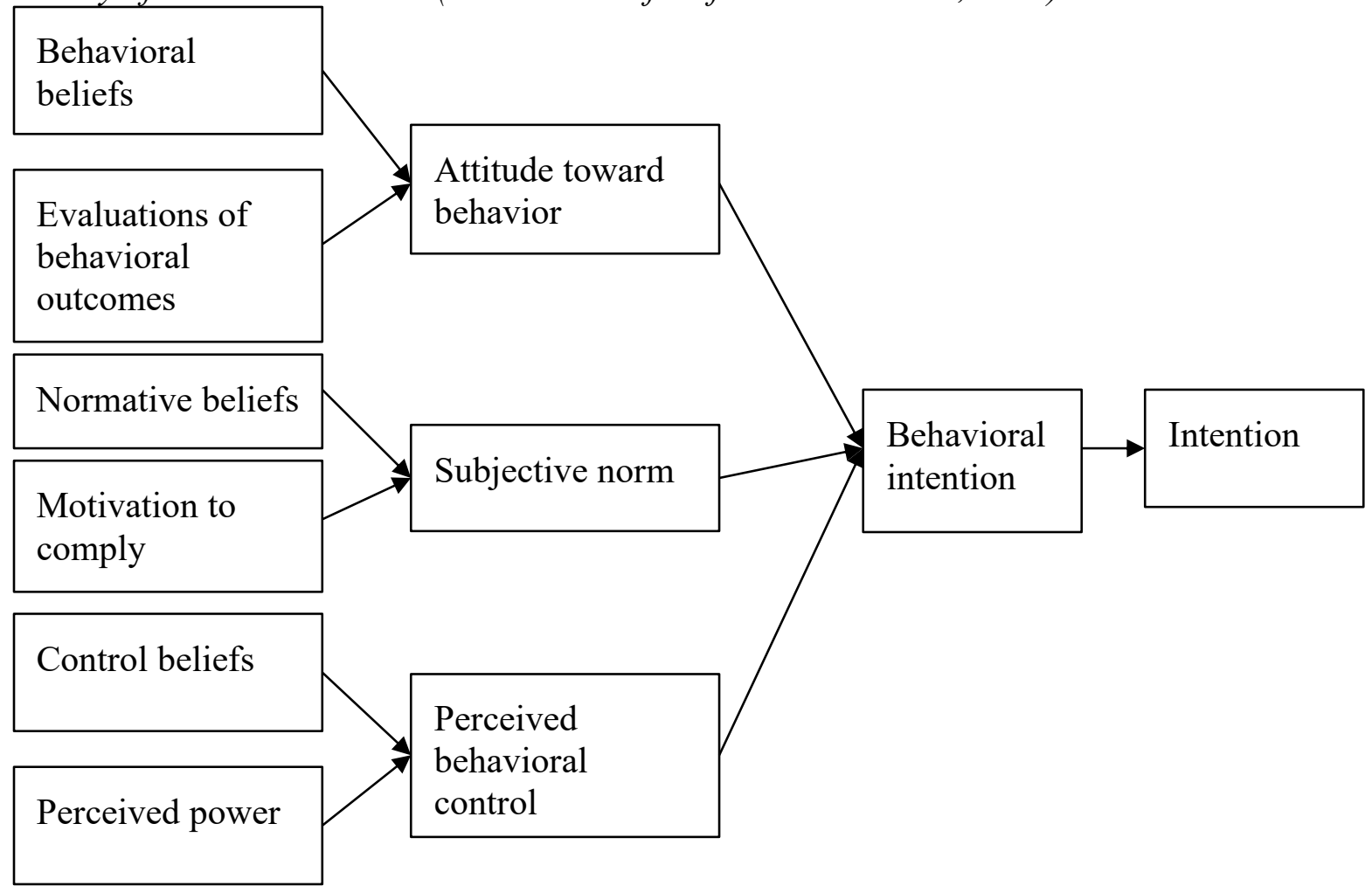

Individuals exhibit certain attitudes associated with specific behaviors (Ajzen, 1991). Attitudes are reflective of an individual's summary evaluation of psychological concepts or objects described in such paradigms as likable-dislikeable, harmful-beneficial, good-bad, and pleasant-unpleasant (Ajzen, 2006). The second factor is subjective norms, which are described as the perceived social pressures influencing individuals to act on a behavior (Ajzen, 1991). Subjective norms can impact the intention of individuals to act on specific behaviors (Sheeran et al., 2001). The third factor is perceived behavioral control, which is described as an individual's perceived ease or difficulty in taking part in a specific behavior (Ajzen, 1991). Perceived behavioral control is associated with experiences and the expected complications of performing a new behavior and can play a role in affecting behavior directly (Ajzen, 1991). 


\section{Kurt Lewin's Stage Model - a Three-step Model of Change}

The foundation for action research and modern organizational change theories is Kurt Lewin's model, which consists of three stages: (1) unfreezing of past behavior and attitudes within the organization, (2) moving by exposure to new information, attitudes, and theories, and (3) refreezing through processes of reinforcement, confirmation, and support for the change (Lewin, 1951).

According to Lewin, the first step in the process of changing behavior is to unfreeze the existing situation. This status quo is considered the equilibrium state, and a state of disequilibrium (unfreezing) must be created to overcome the strains of individual resistance and group conformity. For Lewin, human behavior was based on a quasi-stationary equilibrium supported by a complex field of forces (Burnes, 2004). Driving forces can facilitate change through these stages, as they can push individuals in the desired direction. Restraining forces can hinder change as they push individuals in the opposite direction. Most research on stage theory has focused on activities that occur within each stage, rather than the factors that influence how an organization moves from one stage to the next (Steckler et al., 2001). Unfreezing can be achieved by increasing driving forces that direct behavior away from the existing situation and decreasing the restraining forces that negatively affect the movement from the existing equilibrium. This can undermine the self-satisfaction feeling created by group norms of acceptance (Schein, 1996). Motivating participants by preparing them for change and building trust and recognition for the need for change so individuals can actively participate in recognizing problems and brainstorming solutions within a group, can assist in unfreezing (Robbins, 2003).

Lewin's second step in the process of changing behavior is movement. Unfreezing is not an end to itself, but rather it "...creates motivation to learn but does not necessarily control or predict the direction" (Schein, 1996, p. 62). This involves identifying desired and undesired (unproductive) behavioral patterns. A transition stage is needed to move toward the change. Glew et al. (1995, p. 0) defined Employee Involvement (EI) as "Employee involvement seeks to increase members' input into decisions that affect organizational performance and employee well-being." Employee involvement is the oldest and most effective strategy for overcoming the resistance to organizational change, and planning and implementing change. The participation of employees can lead to high quality change and prevail over the resistance experience in the implementation stage (Vroom \& Yetton, 1973). This is crucial as organizational processes and structures may be required to implement the change. Encouraging change promoters and removing change resistance agents' roles may be redefined, organizational relationships may change, and skills and competencies may need to be developed. Lewin viewed successful change as a group activity, and that requires changes to policies, practices, and norms in the organizational culture (Cummings \& Worley, 2001).

The third step of Lewin's model is refreezing. Refreezing stabilizes the new equilibrium resulting from the change by balancing the driving and restraining forces to ensure the new behaviors are safe from regression (Burnes, 2004). It is possible to achieve behavior change by acting upon the group norms enforcing it and identifying and acting upon the values upholding the attitudes of affiliation to group norms (Condreanu, 2010). New patterns warrant reinforcement through formal and informal mechanisms, such as policies and procedures, to 
institutionalize new behavior (Robbins, 2003). Change then occurs by altering the driving and resisting forces, thereby facilitating the movement of the organization to a new equilibrium (Zand \& Sorensen, 1975).

\section{Social Cognitive Theory}

Social cognitive theory (SCT) is important as a way of understanding behavior and planning interventions to change behavior. It presents an interpersonal-level perspective, examining how behaviors are affected by the interaction of personal factors, behaviors, the environment and relationships (Glanz et al., 2008). It subscribes to a model of emergent interactive agency, and concepts can be grouped into 5 categories: (1) psychological determinants of behavior, (2) observational learning, (3) environmental determinants of behavior, (4) self-regulation, and (5) moral disengagement (Bandura, 1986). Core features of human agency include intentionality, forethought, self-reactiveness, and self-reflectiveness (Bandura, 2001). The way human agency operates has been conceptualized as an autonomous agency, mechanical agency, and emergent interactive agency. This theory emphasizes reciprocal determinism in the interaction between people and their environments, which suggests that human agency and the environment interact and influence each other, leading to individual and social change (Glanz et al., 2008).

Psychological determinants of behavior in SCT include outcome expectations, social outcome expectations, self-evaluative outcome expectations, self-efficacy, and collective efficacy. These individual-level psychological determinants examine how the individual feels about the behavior, how others feel about the behavior, and the individual's capacity to change the behavior (Bandura, 1986). Observational learning is central to SCT. Four processes govern observational learning: (1) attention, (2) retention, (3) production, and (4) motivation (Bandura 2001). Peer modeling is well-recognized as a method for influencing behavior, as many studies have shown that models are imitated more frequently when observers perceive the models as similar to themselves (Schunk, 1987).

Environments can have powerful influences on behavior. SCT hypothesizes that no amount of observational learning will lead to behavior change unless the environment supports the change (Bandura, 2001). Incentive motivation can be used to change the environment, as well as the provision of new structure or resources to facilitate the behaviors to make them easier to perform (Bandura, 1986). Bandura (2001) identified six ways self-regulation can be achieved: (1) self-monitoring, (2) goal setting, (3) feedback, (4) self-reward, (5) self-instruction, and (6) enlistment of social support. Self-regulation allows for the individuals to discount the cost of behaviors that lead to a more distant goal. Or more simply put - short term pain, for long-term success.

SCT describes how people can learn moral standards for self-regulation which can lead them to avoid violence and cruelty to others (Glanz et al., 2008). Moral standards can be violated through mechanisms of moral disengagement which include euphemistic labeling, dehumanization and attribution of blame, the diffusion and displacement of responsibility and perceived moral justification. An individual's behavior is the result of their learning history, environmental perceptions, and physical and intellectual capacities. Therefore, behavior can be 
changed through new learning experiences, adjustment and maintenance of perspectives, and support for capacity development.

While Lewin's model provides a goal and plan-oriented framework, it lacks consideration of personal factors - human feelings and experiences which can have negative consequences and resistance to change. On the contrary, the TPB considers self-efficacy, which is a characteristic of both the TPB and SCT. SCT proposes that behavior change is affected by environmental influences, personal factors, and attributes of the behavior itself. SCT considers external and internal conditions. Self-efficacy is having the confidence in the ability to act and persist in the action. Self-efficacy must be present for the TPB and SCT to be applied, resulting in successful behavior change. These theories can be linked with Lewin's three-step model to provide an integrated framework.

Armenakis et al., (1993) proposed a three-step model that incorporates elements of Social Learning Theory (Bandura, 1986). In this "unfreezing" stage, readiness is enhanced, and resistance is decreased. Applying the theory of planned behavior, unfreezing may be achieved by creating the readiness for change (Armenakis et al., 1993). This allows for the behavior to refreeze once the organization has reached the desired state (Bakari \& Hunjra, 2017). Social networks and agents of change are crucial in the change process. For readiness to change to occur, the mindset and motivations must change. This requires disintegrating an individual's contemplation of the existing situation, creating dissatisfaction in the status quo, creating an appealing future vision, and enhancing self-efficacy and optimism that the future state will be more beneficial with greater long-term benefits (Armenakis et al., 1993).

Cultivating individual change, by utilizing agents of change, can promote an increased locus of control in employees to promote systemic change across the organization, counteracting restraining forces. Authentic leadership can facilitate readiness for change as leaders communicate the need for change and employee behaviors are altered (Bakari \& Hunjra, 2017). The mindset that binds a person to the target of change may reflect an effective commitment to change, continuous commitment to change, and normative commitment to change (Bakari \& Hunjra, 2017). An integration and comparison of these theories is shown in Table 3. 
Table 3

Integration of Constructs Associated with the Theory of Planned Behavior and Social Cognitive Theory, applied to Lewin's Framework

\begin{tabular}{|c|c|c|c|}
\hline Theory & $\begin{array}{l}\text { Stage } 1 \\
\text { Unfreezing }\end{array}$ & $\begin{array}{l}\text { Stage } 2 \\
\text { Moving }\end{array}$ & $\begin{array}{l}\text { Stage } 3 \\
\text { Refreezing }\end{array}$ \\
\hline $\begin{array}{l}\text { Lewin } \\
3 \text { Stage } \\
\text { Theory }\end{array}$ & Readiness & Adoption & Institutionalization \\
\hline $\begin{array}{l}\text { Theory } \\
\text { of } \\
\text { Planned } \\
\text { Behavior }\end{array}$ & $\begin{array}{l}\text { Attitude } \\
\text { Experiential } \\
\text { Attitude } \\
\text { Behavioral Belief } \\
\text { Instrumental Attitude }\end{array}$ & $\begin{array}{l}\text { Perceived Norm } \\
\text { Subjective Norm } \\
\text { Normative Belief } \\
\text { Motivation to Comply }\end{array}$ & $\begin{array}{l}\text { Personal Agency } \\
\text { Perceived Behavioral } \\
\text { Control } \\
\text { Control Belief } \\
\text { Perceived Power }\end{array}$ \\
\hline $\begin{array}{l}\text { Social } \\
\text { Cognitive } \\
\text { Theory }\end{array}$ & $\begin{array}{l}\text { Psychological } \\
\text { determinants } \\
\text { of behavior }\end{array}$ & $\begin{array}{l}\text { Observational } \\
\text { Learning } \\
\text { Environmental } \\
\text { determinants of } \\
\text { behavior }\end{array}$ & $\begin{array}{l}\text { Reciprocal determinism } \\
\text { Self-Regulation } \\
\text { Moral disengagement }\end{array}$ \\
\hline
\end{tabular}

\section{Applying the Theory of Planned Behavior}

The TPB describes measures of attitudes and social normative perceptions of a specified behavior that lead to intention to perform the behavior (Montano \& Kasprzyk, 2001). It seeks to address individual motivational factors within unique contexts to explain the overall execution of a specific behavior (Ajzen, 1991). It provides a framework to identify key behavioral, normative, and control beliefs affecting behaviors. Interventions can be designed to target and change these beliefs, or the value placed on them, thereby affecting attitude, subjective norm, or perceived control and leading to changes in intentions and behaviors (Glanz et al., 2008).

The TPB seeks to address individual available factors within unique contexts to explain the overall execution of a specific behavior (Ajzen,1991). It is assumed that intentions will capture motivational factors that influence behavior, following that an intention is an indication both of how hard a person is willing to work and how much effort a person is willing to exert to perform the behavior (Ajzen, 1991). Ajzen suggests generally, the stronger a person's intention to engage in behavior, the more likely the behavior will be performed (Ajzen, 1991). However, the behavior must be under a person's volitional control, or will to decide, if they are to perform the behavior (Ajzen, 1991). Attitudes are shaped by the individual's positive or negative judgement of the expected outcomes related to performing the behavior (Ajzen, 2011).

Behavioral belief is the individual's perception of the consequences associated with the behavior (Ajzen, 2011). Perceived behavior control differs from locus of control in that it can vary across 
situations and actions, rather than remaining stable across situations and forms of action (Ajzen, 1991). Perceived behavior is like Bandura's concept of perceived self-efficacy which "is concerned with judgements of how well one can execute courses of action required to deal with prospective situations" (Bandura, 1986). The concept of self-efficacy differs from perceived behavior control in that self-efficacy is concerned with an individual's ability to perform behavior regardless of how much control over performing a behavior or how easy or difficult it is to perform the behavior (Hayden, 2014).

\section{Applying TPB, SCT and Lewin's Three Step Model to Food Processors in West Virginia}

A prospective study design is recommended to discern relationships between constructs, with attitudes, subjective norms, perceived control, and intentions measured at one time point and behavior measured following a time interval (Glanz et al., 2008). In this study intention was defined as the food processor's intention to complete food safety training. A conceptual framework, applying TPB is shown in Figure 2. Ajzen's inclusion of perceived control (Ajzen, 1991) was founded in part on the idea that behavioral performance is determined jointly by motivation (intention) and ability (behavioral control). 


\section{Figure 2}

Conceptual framework of food processor intention to adopt food safety certification (Source: Modified from Glanz et al., 2008)

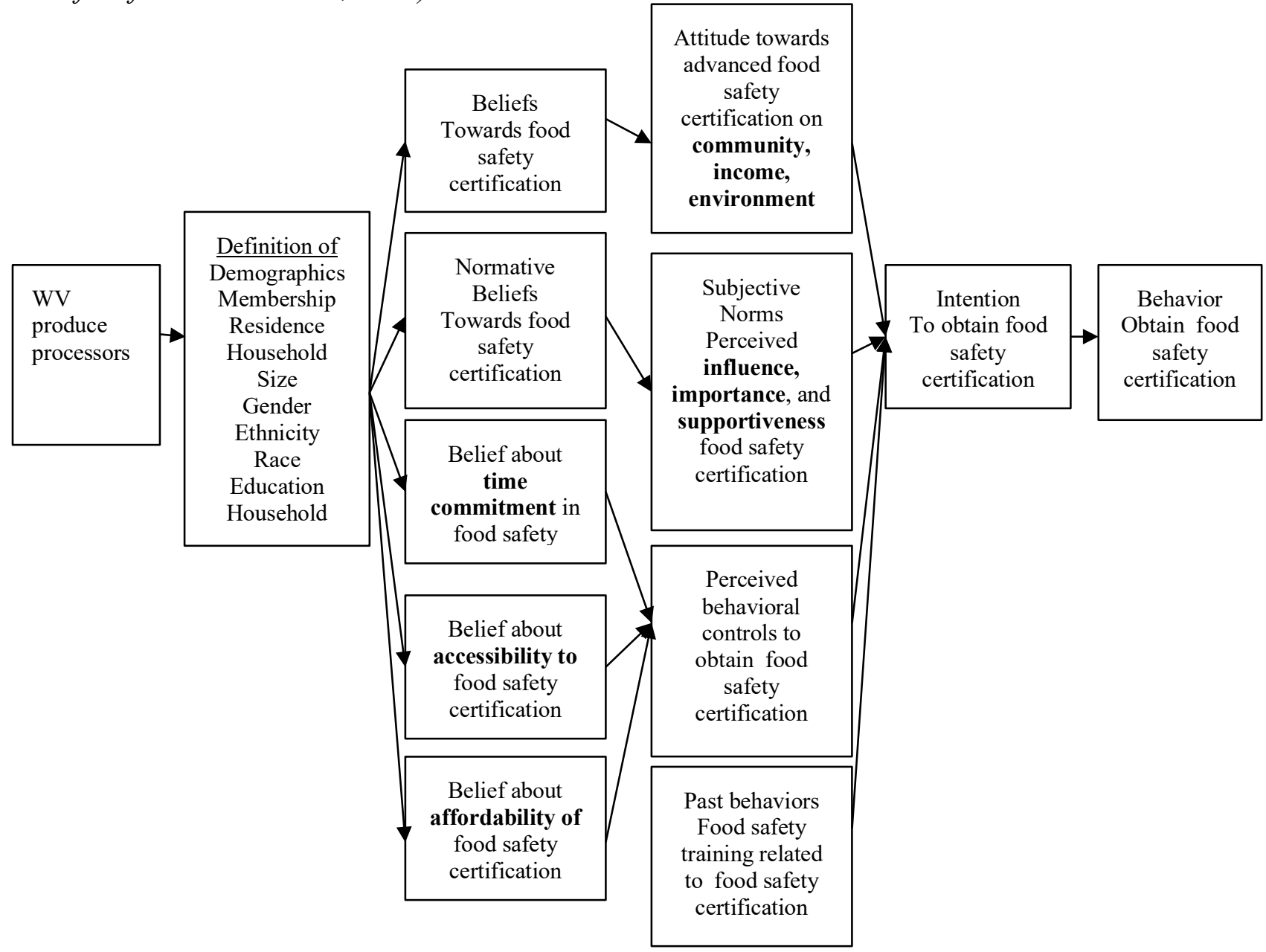

This research informed the development of a food safety outreach program in WV. Materials through this program seek to increase the ability of food processors to process food safely and improve self-efficacy. Shown in Table 4, the SCT identifies four major ways in which self-efficacy can be developed (Bandura, 2001). 


\section{Table 4}

Methods for Increasing Self-efficacy, adapted from Bandura (1986)

Sources of self-efficacy Description

Mastery experience Enabling the person to succeed in attainable but increasingly challenging performances of desired behaviors. The experience of performance mastery is the strongest influence on self-efficacy belief.

Social modeling Showing the person that others like themselves can do it. This should include detailed demonstrations of the small steps taken in the attainment of a complex objective.

Improving physical and Making sure people are well-rested and relaxed before attempting a emotional states new behavior. This can include efforts to reduce stress and depression while building positive emotions- as when "fear" is relabeled as "excitement"

Verbal persuasion $\quad$ Telling the person that he or she can do it. Strong encouragement can boost confidence enough to induce the first efforts toward behavior change. 


\section{CHAPTER III}

\section{Methodology}

The purpose of this chapter is to introduce the research methodology for this descriptive, mixed methods study. The research design, methodology, study participants, data collection and analysis are presented.

\section{Purpose of the Study}

The purpose of this mixed methods, two-phase descriptive research study was to better understand and describe the perceptions of produce processors operating in WV non-profit commercial kitchens. This study describes food processors, commercial kitchen operators, the commercial kitchen operation, and perspectives on employee food safety. It provides the perspectives of these food workers, who directly are responsible for the food safety practices in these activities. This approach allowed for a deeper understanding of food processor experiences and provided a way to connect theory to the data in order to understand motivations of these food workers to participate in advanced food safety training.

\section{Research Questions}

Three research questions guided the study:

RQ1: What are the characteristics of produce processors operating in commercial kitchens?

RQ2: What beliefs or attitudes influence intention to obtain BPCS?

RQ3: What key issues do produce processors face related to accessing food safety information?

\section{Specific Objectives}

1. To understand the social-psychological motivations (behavioral intention, attitude, perceived norm, personal agency) that shape WV produce processors' intention to complete advanced food safety training.

a. RQ1: What are the characteristics of WV produce processors, and their commercial kitchen operations?

b. RQ2: What beliefs or attitudes influence intention to obtain BPCS?

2. Assess the educational programming preferences and delivery formats preferred by $\mathrm{WV}$ produce processors.

b. RQ3: What key issues do WV produce processors face related to accessing food safety information?

Limitations: This study does not focus on meat and poultry processors, restaurants, or institutional food handlers. It does not focus on for-profit produce processors and is limited to non-profit commercial kitchen environments.

\section{Research Design}

A two-phase, mixed methods research design was employed, targeting 11 produce processors operating in commercial kitchens in WV. The respondents from phase one served as the target population for phase two. In phase one, an original survey instrument was developed and used to collect empirical data on the food processor, the commercial kitchen operation, and 
perceptions towards advanced food safety certification. In phase two, a focus group was employed to understand what key issues food processors face related to accessing food safety information.

\section{Phase 1: Development of original survey instrument}

In phase one, an original survey instrument was developed to examine the relationship between food processor practices (perceptions, motivations, barriers), food safety training (participation, certification issues and benefits), and the overall needs of food processors. Appendix A shows Theory of Planned Behavior (TPB) constructs applied to survey questions on food safety training intention. The cover letter is shown in Appendix B, and the instrument, shown in Appendix C, has 45 questions describing the food processing operation, employees, processing practices, and perceptions on food safety.

\section{Population}

In 2020, the WVU Center for Resilient Communities identified food and agricultural producers, processors, aggregators, distributors, support agencies and institutions in the West Virginia agricultural asset mapping project, Community Food Systems LINK (WVU Center for Resilient Communities, 2020). In West Virginia, the food processing sector alone is made up of over 468 operations processing various agricultural products including produce, animal products, and alcohol. This does not include food service outlets such as restaurants. Produce processors operating in commercial kitchens are 158 of the 468 operations, and it is estimated that approximately 11 of these operations are non-profit, social-enterprise-focused operations. 


\section{Table 5}

Non-profit Kitchen Identified in Community Food Systems LINK

Non-profit Name Location

$\begin{array}{ll}\text { ACCESS WV } & \text { Wayne, WV } \\ \text { Fruits of Labor } & \text { Rainelle, WV } \\ \text { Greenville Farm Kitchen } & \text { Greenville, WV } \\ \text { Heart \& Hand House } & \text { Phillippi, WV } \\ \text { La Casa de la Amistad } & \text { Mineral Wells, WV } \\ \text { Pollen } 8 & \text { Charleston, WV } \\ \text { Potomac Highlands Market } & \text { Davis, WV } \\ \text { Preston County Workshop } & \text { Reedsville, WV } \\ \text { Public Market } & \text { Wheeling, WV } \\ \text { Wardensville Garden Market } & \text { Hardensville, WV } \\ \text { Wild Ramp } & \text { Hunton, WV }\end{array}$

\section{Target}

Food workers in this sector were included according to a criteria-based selection strategy (Maxwell, 2005). Exclusion criteria included for-profit organizations, those processing dairy, meat and poultry, alcohol production, and bakeries. Inclusion criteria was limited to non-profits processing produce in commercial kitchens for different outlets and purposes, including direct to consumer, retail market, value-added products, institutional education programs such as ProStart ${ }^{\circledR}$, technical and agricultural education, and county and/or community processing. The resulting 11 operations were identified for purposive sampling.

\section{Accessible}

The target population included 11 produce processors operating in commercial kitchens in West Virginia. These produce processors were further categorized as operating in urban or rural environments, workforce development and ProStart ${ }^{\circledR}$ programs operating in high schools, 
community and technical colleges, and institutional education programs including correctional facilities, childcare, and the WV School for the Deaf. In order to access the population, the Processing, Aggregation and Distribution (PAD) network was contacted. The PAD network was born out of years of groundwork laid by the former WV Aggregation and Distribution Working Group; one official working group organized by the WV Food and Farm Coalition. Since 2017, the network has been coordinated by the Value Chain Cluster Initiative, which is funded by the Natural Capital Investment Fund. The Value Chain Cluster Initiative provides hands-on business development and coaching services to strengthen expanding local food and farm business in four regions in West Virginia. They have supported over 270 food and farm businesses to scale up and build the local food economy, resulting in over 220 new jobs and investment of over $\$ 3$ million dollars in private funds.

Purposive sampling was used based on criterion-based selection. This type of sampling served as an efficient approach for identifying workers that may provide information needed to inform study aims. These food workers are regulated by the FDA Food Code at the state level, and by FSMA at the federal level, which may triangulate workers' food safety perceptions to the way in which they are described and regulated within food safety legislation, which inform and shape the FDA food code. By selecting workers who directly handle food, the study may include the perspectives of those who are most directly tied to food safety as a part of their responsibilities.

\section{Instrumentation}

The 45-question survey included an informational letter, which clarified the study's purpose, procedures, risks, confidentiality, benefits, explanation, an offer to answer questions, compensation, voluntary participation, IRB approval statement, and investigator statement.

The first portion of the instrument had six questions, asking participants demographic questions including age, education, and past food safety training. The second section asked 14 questions about food processor practices related to employee food safety training and the commercial kitchen environment, the commercial kitchen, processing activities, and markets. The third seven-question section asked questions related to marketing practices. The fourth section had 16 questions to determine attitudes of respondents towards food safety certification. The rating scale was a bipolar adjective measurement, with 3 representing the most positive attitudes, and -3 representing the most negative. Participants were asked to select appropriate reactions describing their attitude and behavioral control toward the statements regarding BPCS certification. Applications of the TPB suggest that control beliefs regarding each factor should be measured on a bipolar likelihood of occurrence scale score -3 to +3 (Glanz, 2008). Participants were asked to respond to questions regarding their beliefs, attitudes, and behaviors related to obtaining food safety processing certification. Items were informed by previous studies with surveys that applied the TPB model to alternative agriculture topics (Arvola et al., 2008).

\section{Reliability}

The instrument was pilot tested by Board members from the WV Farmers Market Association, and comments integrated. The group was not part of the final study. To ensure consistency of scale items within the survey, Cronbach's alpha was used for item scores with a 
range of values, including Likert and bipolar attitude scales. Likert items were combined into a composite scale.

\section{Validity}

A panel of experts from faculty in agricultural education, hospitality and tourism, and professionals from the WV Department of Agriculture reviewed the items in the instrument to determine face, construct, and content validity.

\section{Data Collection Procedures}

This study used an online descriptive survey administered with cover letters via Qualtrics (Appendices B, C, D, E). Online survey research is quantitative in nature and effective for collecting, organizing and analyzing data. Advantages include low cost, lack of geographic limitations, lack of time constraints on participants, and flexibility in data collection. Participants for the study were recruited from the state Processing Aggregation and Distribution (PAD) network, and by emailing the participants directly to participate.

\section{Procedures}

1. The researcher requested the survey to be delivered by the WV PAD network to the listserv, representing over 100 fruit and vegetable processors, eight of which are social enterprise, non-profit food processors.

a. An initial email request was sent to the listserv.

b. First email reminder was sent five days after the initial email contact.

c. Second email reminder was sent 14 days after the initial email contact.

2. The researcher contacted the email list of the accessible population.

a. The first email introduced the study, requested participation, explained why they were selected, how to access the surveys, ensured the voluntary and confidential nature of the study, privacy rights, compensation, and researcher contact information.

b. The first email reminder was sent five days after the initial email contact.

c. The second email reminder was sent 14 days after the initial email contact.

3. The survey was readministered to participants after three months

a. The first email reminder was sent five days after the initial email contact.

b. The second email reminder was sent 14 days after the initial email contact.

\section{Analysis of Data}

The data were analyzed using descriptive statistics. Linear regression and measures of central tendency could not be performed due to the lack of continuous variables. Discrete categorical variables were used, allowing for frequency analysis to describe the data. Fisher's exact test was used due to the small sample size. Like the chi-square test for fourfold (two by two) tables, Fisher's exact test examines the relationship between the two dimensions of the table, classifying rows vs. classification into columns. The null hypothesis is that these two classifications are not different. The $\mathrm{P}$ values in this test are computed by considering all possible tables that could give the row and column totals observed (Conover, 1999). 
The Cochran-Mantel-Haenszel (CMH) test was also calculated. $\mathrm{CMH}$ is an inferential test for the association between two variables, while controlling for a third confounding nominal variable (Cochran 1954; Mantel \& Haenszel 1959). The CMH test examines the weighted association of a set of two by two tables, and it allows for stratification on additional variables. $\mathrm{CMH}$ Chi-square was used to assess correlations between attending college, and respondents in urban and rural environments. The researcher explored the relationship of a food processor's intention to complete food safety training as a dependent variable to independent variables such as a food processor's demographic profile, awareness, knowledge and the three major factors in the TPB: attitudes towards the behavior indicating a favorable/unfavorable evaluation of the behavior, subjective norms indicating perceived social pressure to perform or not to perform the behavior, and perceived behavioral control for perceived capacity to perform the behavior (Ajzen, 2011).

\section{Use of Findings}

Findings are being used to inform a food safety outreach program with food processors in West Virginia.

\section{Phase 2: Focus group}

In phase two, a focus group was employed, recruiting participants from phase one. Focus group interviews were conducted to evaluate agriculture and food safety education materials, specifically a curriculum for food processors to process acidified/low-acid foods cooperatively in West Virginia. The education materials were shared with participants two weeks prior to the focus group facilitation. Focus groups confirm not just the facts (as in the survey method) but the meaning behind the facts, to produce insight, and give participants the opportunity to interact and share opinions (Morgan, 1998). When participants can share information with the group, it gives them the opportunity to engage in feedback with others, promoting deeper thought into the issue (Morgan, 1998).

Focus group objectives

1. Assess the food safety competencies and needs of produce processors.

2. Assess the educational programming preferences of produce processors.

3. Identify the information delivery formats preferred by produce processors.

\section{Population}

\section{Target}

The target population included 11 who responded to the original survey in phase one, consisting of food processors operating in non-profit, commercial kitchens.

\section{Accessible}

Focus group participants were recruited based on their participation in the phase one survey, where demographics and behavior were assessed.

\section{Instrumentation}

The Focus Group Guide is shown in Appendix F. The guide was designed for two moderators to facilitate a 70-minute focus group session for approximately 8-12 individuals per 
group. Standards of rigor for this qualitative research study addressed credibility via triangulation and evidence based on structural corroboration, as well as evidence based on consensus, and evidence based on theoretical adequacy. In quantitative research, an important question is whether the data are valid and reliable. Standards for rigor for research are upheld with issues addressed for truth value, generalizability, consistency, and neutrality. Qualitative researchers speak of dependability, rather than reliability. Purposive sampling from respondents who participated in phase one allowed for evidence based on structural corroboration, consensus and interpretive and theoretical adequacy.

\section{Data Collection Procedures}

Data collection included recording of Zoom conference calls and transcription. The forms of data collected included: 1) conversation, including tone, 2) silences (words and issues), and 3) body language. Formats for reporting included selected quotations and analysis of reported themes.

Due to the small sample size, only one focus group discussion was conducted to evaluate key issues of food processors. The targeted size for the group was 8-12 participants. Focus group participants were selected individuals who completed the survey used in phase one. Convenience sampling was used to choose individuals to participate in the focus group. In this inquiry, the intent was not to generalize a broad audience (Lincoln \& Guba, 1985). To allow participants appropriate time to read related draft curriculum materials and formulate comments, materials were mailed two weeks prior to the discussion.

To preclude the introduction of bias into the discussion, it is necessary for the primary moderator to have no formal association with the project (Nordstrom et al., 2000). The focus group was conducted by a moderator and assistant moderator. The materials to be evaluated, focus group guide, and list of focus group questions were provided to moderators two weeks prior to the scheduled discussion. To allow first-hand knowledge of the discussion, the assistant moderator was one of the project researchers who subsequently would be involved in data analysis. The focus group discussions were audio and video recorded, and the assistant moderator took notes. After the focus group the moderator and assistant moderator reviewed the discussion and notes.

\section{Analysis of Data}

Analysis of the focus group data started with considering the original intent of the study, which is to assess what key issues produce processors face related to accessing food safety information. What are their preferences for educational programming and delivery? Analysis of focus group data must follow a prescribed, verifiable process that permits the researchers to arrive at similar conclusions (Krueger, 1988). The data files and notes were transcribed to identify similar themes and ideas. Themes were considered verified when two or more individuals include it in their discussion (Morgan, 1998). A summary report was compiled from the transcript review.

Validity of the study was established by data triangulation and theory triangulation. To obtain data triangulation, the group members were categorized by the number of years they have worked as a food processor. Categories include: 1) 1-3 years, 2) 4-6 years, 3) 7-9 years, and 4) 
10 or more years. Data triangulation occurred by looking for outcomes that are agreed upon by the participants. Theory triangulation involves the use of multiple professional perspectives to interpret a single set of data/information, and entails using professionals outside of your field of study. Theory triangulation occurred by sharing transcripts with professionals outside of the Davis College, such as Administrative Faculty from other WVU Colleges, utilizing the Krueger (1988) framework. In addition to helping emergent themes be situated in a more meaningful context (enhancing representation), this process can also help validate inferences made about the level of consensus (Onwuegbuzie et al., 2009).

Trustworthiness of the data were addressed by the creation of an audit trail of the transcripts and by using a "memoing" process (Hesse-Biber \& Leavy, 2011). The memoing process included reflective notes from the researcher recording concepts and their relationships. 


\section{CHAPTER IV}

\section{Purpose of the Study}

\section{Findings}

The purpose of this mixed methods, two-phase descriptive research study was to better understand and describe the perceptions of produce processors operating in WV non-profit commercial kitchens. This study describes food processors, commercial kitchen operators, the commercial kitchen operation, and perspectives on employee food safety. It provides the perspectives of these food workers, who directly are responsible for the food safety practices in these activities. This approach allowed for a deeper understanding of food processor experiences and provided a way to connect theory to the data in order to understand motivations of these food workers to participate in advanced food safety training.

\section{Phase 1}

The 45-question survey that makes up phase one was broken down into five sections: 1) Demographics, 2) Employee Food Processor Practices, 3) Environment Food Processor Practices, 4) Marketing Practices, and 5) Attitudes on Food Safety. The in-depth discussion of results follows the description of how missing data were addressed, the discussion of the sample demographics, and how data screening was processed.

\section{Specific Objectives}

1. To understand the social-psychological motivations (behavioral intention, attitude, perceived norm, personal agency) that shape WV produce processors' intention to complete advanced food safety training.

a. RQ1: What are the characteristics of WV produce processors, and their commercial kitchen operations?

b. RQ2: What beliefs or attitudes influence intention to obtain BPCS?

\section{Missing data}

A total of 29 individuals responded to the email request to participate in the survey and submitted their responses. After analyzing these responses, 16 respondents were removed due to ineligibility because they were not processing in a commercial kitchen. Two additional respondents were removed because their submissions were blank. Even though the sample size was already small, it was appropriate to eliminate those additional participants from the overall analysis; thus, reducing the sample size to 11 participants. Once the missing data were addressed as mentioned above, each of the other variables were investigated for outliers and abnormalities. Data were cleaned to ensure consistency among reporting. This included standardization of data values for dollar amounts reported, capitalization, and investigating outliers and abnormalities.

\section{Data Analysis}

Quantitative data were analyzed in JMP and SAS (JMP®, Version Pro 12.2, SAS Institute Inc, Cary, NC, Copyright ${ }^{\circledR} 2015$; Version 9.4, SAS Institute Inc., Cary, NC, Copyright (C)2002-2012). Quantitative analyses included descriptive analysis, frequency analysis, Fisher's exact test, and Cochran-Mantel-Haenszel $(\mathrm{CMH})$ statistics. In all statistical analyses, significance criterion alpha for all tests was 0.05 , and a statistical trend was declared when $\mathrm{p}<0.1$. 


\section{Demographics}

The 11 survey respondents in the study were categorized by the following demographics: $90.9 \%$ female, $9.09 \%$ male, $100 \%$ Caucasian, $18.1 \%$ were ages $25-34,9.09 \%$ were ages $35-44$, $36.36 \%$ were ages $45-54$, and $36.36 \%$ were ages 55-64. The highest level of education completed by survey respondents included $9.09 \%$ high school graduates, $9.09 \%$ completed some college, $18.18 \%$ had two-year degrees, $27.27 \%$ had four-year degrees, and $36.36 \%$ had completed professional degrees.

\section{Data Screening}

Due to the small sample size, in order to conduct statistical analysis, data were further screened for groups that could be collapsed among observations to facilitate stronger insights. Five-category Likert scales were collapsed into three-category Likert scales. Binary variables were used to indicate college experience (completion of two-year, four-year, and professional degrees), and completion of Better Process Control School (BPCS yes or no).

Total sales, age in years, and years of experience were also collapsed and reclassified based on responses. Reported sales were collapsed into two categories: annual sales valued at $<\$ 50,000$ or $>\$ 100,000$, as there were no sales reported between $\$ 50,000-\$ 100,000$. Age was collapsed into $<45$ years of age or $\geq 45$ years of age. Food service management experience collapsed into $\leq$ six years of experience or $>$ seven years of experience.

\section{Characteristics of Food Processors and their Environments}

Frequency distributions for food processor characteristics are shown in Table 6, The majority of participants were women, over the age of 45, with less than six years of food processing experience, who had completed college.

\section{Table 6}

Characteristics of Food Processors

\begin{tabular}{lll}
\hline Variable & $\mathrm{N}=11$ & Percent \\
\hline Women & 10 & $90.00 \%$ \\
$\leq 45$ years of Age & 4 & $36.36 \%$ \\
$>45$ years of Age & 7 & $63.64 \%$ \\
Years of experience $\leq 6$ years & 7 & $63.64 \%$ \\
Years of experience $>7$ years & 4 & $36.36 \%$ \\
Completed college & 9 & $81.18 \%$ \\
No college completed & 2 & $18.18 \%$ \\
Title: Educator/Instructor & 5 & $45.45 \%$ \\
Title: Foodservice Manager & 6 & $54.54 \%$ \\
\hline
\end{tabular}


Characteristics of the food processing environment are shown in Table 7. The majority of respondents operated in a rural area, with the majority of their market targeting direct to consumer sales, generating less than $\$ 50,000$ annually.

\section{Table 7}

Characteristics of Food Processing Environment

\begin{tabular}{lll}
\hline Variable & $\mathrm{N}=11$ & Percent \\
\hline $\begin{array}{l}\text { Rural town (places with fewer than 2,500 } \\
\text { people) }\end{array}$ & 8 & $72.73 \%$ \\
Urban (places with populations 2,500 - 49,999) & 3 & $27.27 \%$ \\
Direct to consumer & 8 & $72.73 \%$ \\
Direct to retail & 3 & $27.27 \%$ \\
Direct to institutions & 2 & $18.18 \%$ \\
Direct to intermediate & 2 & $18.18 \%$ \\
Total sales $<\$ 50,000$ & 8 & $72.73 \%$ \\
Total sales $\$ 100,000+$ & 3 & $27.27 \%$ \\
\hline
\end{tabular}

Fisher's exact test was used to assess relationships between variables of age, urban/rural environment, college completion, and total sales, and BPCS. Listed in Table 8, these results were not significant.

\section{Table 8}

\begin{tabular}{lccl}
\multicolumn{3}{l}{ Fisher's Exact Test: Association of Variables and BPCS completion } \\
\hline Variable & $\mathrm{N}$ & $\begin{array}{l}\text { Degrees of } \\
\text { Freedom }\end{array}$ & $\begin{array}{l}\text { Fisher's } \\
\text { Exact Test } \\
\text { p-value }\end{array}$ \\
\hline Age: Over the age of 45 & 11 & 1 & 0.6515 \\
Urban/Rural Environment & 11 & 1 & 0.5758 \\
Completion of college & 11 & 1 & 1.0000 \\
Total sales & 11 & 1 & 0.5758 \\
\hline
\end{tabular}

Fisher's exact test was used to assess relationships between variables of years of experience, title in operation, preparation of potentially hazardous food (identified by canning 
and fermenting) and institutional and intermediary sales. Shown in Table 9, these variables were corrected for college, years of experience, and rural/urban environments. These results indicated no significance.

\section{Table 9}

Fisher's Exact Test and CMH: Association of: Variables and BPCS completion and corrected using $C M H$

\begin{tabular}{lclllll}
\hline Variable & $\mathrm{N}$ & $\begin{array}{l}\text { Degrees } \\
\text { of } \\
\text { Freedom }\end{array}$ & $\begin{array}{l}\text { Fisher's } \\
\text { Exact Test } \\
\text { p-value }\end{array}$ & $\begin{array}{l}\text { CMH } \\
\text { Chi- } \\
\text { Square }\end{array}$ & $\begin{array}{l}\text { CMH } \\
\text { p-value }\end{array}$ & $\begin{array}{l}\text { CMH } \\
\text { correction }\end{array}$ \\
\hline Years of experience & 11 & 1 & 0.9848 & 0.9800 & 0.3222 & college \\
Canning & 11 & 1 & 0.1753 & 0.8008 & 0.3711 & college \\
Fermenting & 11 & 1 & 0.2727 & 1.2503 & 0.2636 & college \\
Title in operation & 11 & 1 & 0.3918 & 0.6279 & 0.4281 & $\begin{array}{l}\text { years of } \\
\text { experience }\end{array}$ \\
Institutional sales & 11 & 1 & 0.8182 & 0.0000 & 1.0000 & rural/urban \\
Intermediary sales & 11 & 1 & 0.8182 & 0.0000 & 1.0000 & rural/urban \\
\hline
\end{tabular}

\section{Attitudes towards Food Safety Training}

Respondents were asked 14 questions regarding their attitudes towards food safety training. As previously indicated, five category Likert scales were collapsed into three categories for stronger statistical tests. Due to the small sample size, some questions did not show any difference amongst respondents, therefore seven out of 14 questions were selected for statistical analysis. Seven variables were not analyzed as participants shared the same opinion. For example $100 \%$ of respondents indicated they could complete food safety training.

Fisher's exact test was used to assess relationships between perceptions and college completion, total sales, and operating in rural and urban environments. As shown in Tables 1013 , these results indicated no significance. 
Table 10

Fisher's Exact Test: Association of Completion of College and Perception Variables

\begin{tabular}{lllll} 
Variable - Perception & $\mathrm{N}$ & $\begin{array}{l}\text { Degrees of } \\
\text { Freedom }\end{array}$ & $\begin{array}{l}\text { Fisher's } \\
\text { Exact Test } \\
\text { p-value }\end{array}$ \\
\hline $\begin{array}{l}\text { Food safety training takes a lot of time } \\
\text { My staff wants me to do food safety }\end{array}$ & 11 & 11 & 1 & 0.0946 \\
training & & 11 & 1 & 0.3818 \\
$\begin{array}{l}\text { I want food safety training } \\
\begin{array}{l}\text { I intend to do additional food safety } \\
\text { training }\end{array}\end{array} \quad 11$ & 1 & 0.8182 \\
$\begin{array}{l}\text { Food safety training is expensive } \\
\text { Food safety training is cost prohibitive }\end{array}$ & 11 & 2 & 0.6545 \\
\hline
\end{tabular}

Fisher's exact test was used to assess relationships between perceptions and college completion, correcting for rural and urban environments, see Table 11. These results showed no significance.

\section{Table 11}

Fisher's Exact Test and CMH: Association of Completion of College with Food Safety Training Variables and Controlled for Rural/urban Using CMH

\begin{tabular}{|c|c|c|c|c|c|c|}
\hline Variable & $\mathrm{N}$ & $\mathrm{DF}$ & $\begin{array}{l}\text { Fisher's } \\
\text { Exact Test } \\
\text { p-value }\end{array}$ & $\begin{array}{l}\text { CMH } \\
\text { Chi- } \\
\text { Square }\end{array}$ & $\begin{array}{l}\mathrm{CMH} \\
\mathrm{p}- \\
\text { value }\end{array}$ & $\begin{array}{l}\mathrm{CMH} \\
\text { correction }\end{array}$ \\
\hline $\begin{array}{l}\text { Food safety training is } \\
\text { beneficial to my operation }\end{array}$ & 11 & 1 & 0.8182 & 0.1556 & 0.6933 & rural/urban \\
\hline $\begin{array}{l}\text { My staff thinks they should } \\
\text { complete food safety training }\end{array}$ & 11 & 2 & 0.3818 & 0.7778 & 0.3778 & rural/urban \\
\hline $\begin{array}{l}\text { I am confident I can complete } \\
\text { food safety training } \\
\text { successfully }\end{array}$ & 11 & 1 & 0.8182 & 0.0000 & 1.0000 & rural/urban \\
\hline
\end{tabular}

Fisher's exact test was used to assess relationships between perceptions and rural/urban environments, correcting for college, shown in Table 12. The majority of these correlations showed no evidence of a relationship. However, the majority of respondents $(87.50 \%)$ operating in rural environments agreed that food safety training took a lot of time, compared to those 
(33.33\%) operating in urban environments. A Fisher's exact test assessed the relationship between perception of time commitments of food safety training, and rural vs. urban environments. There was an insignificant association between the two variables $(n=11, D F=1$, $\mathrm{p}=0.1515$ ). When correcting for college experience using $\mathrm{CMH}$, the association of perception of time commitments of food safety training, and rural vs. urban environments was significant (CMH Chi-square 45.5714, $\mathrm{p}=0.0325$ ). Participants in rural environments perceived food safety training as taking a lot of time, independent of college completion.

Table 12

Fisher's Exact Test: Variables Compared by Rural/Urban Environments

\begin{tabular}{|c|c|c|c|c|c|c|c|}
\hline Variable & $\mathrm{N}$ & $\begin{array}{l}\text { Degrees } \\
\text { of } \\
\text { Freedom }\end{array}$ & $\begin{array}{l}\text { Fisher's } \\
\text { Exact } \\
\text { Test P }\end{array}$ & $\begin{array}{l}\text { Table } \\
\text { probability }\end{array}$ & $\begin{array}{l}\text { CMH } \\
\text { Chi } \\
\text { Square }\end{array}$ & $\begin{array}{l}\mathrm{CMH} \\
\mathrm{p}\end{array}$ & $\begin{array}{l}\mathrm{CMH} \\
\text { correction }\end{array}$ \\
\hline $\begin{array}{l}\text { Food safety training is } \\
\text { expensive }\end{array}$ & 11 & 2 & 0.1212 & 0.1212 & 2.0000 & 0.1573 & college \\
\hline $\begin{array}{l}\text { Food safety training } \\
\text { takes a lot of time }\end{array}$ & 11 & 1 & 0.1515 & 0.1454 & 45.5714 & 0.0325 & college \\
\hline $\begin{array}{l}\text { It is difficult to do food } \\
\text { safety training }\end{array}$ & 11 & 2 & 0.2727 & 0.2727 & 0.6667 & 0.7165 & college \\
\hline $\begin{array}{l}\text { My staff is supportive of } \\
\text { food safety training }\end{array}$ & 11 & 1 & 0.2788 & 0.2545 & 0.8000 & 0.3711 & college \\
\hline $\begin{array}{l}\text { I want to complete food } \\
\text { safety training }\end{array}$ & 11 & 1 & 1.0000 & 0.7272 & 0.5000 & 0.4795 & college \\
\hline $\begin{array}{l}\text { Food safety training } \\
\text { costs a lot of money }\end{array}$ & 11 & 1 & 2.0000 & 0.2545 & 0.6667 & 0.7165 & college \\
\hline $\begin{array}{l}\text { I intend to do food safety } \\
\text { training }\end{array}$ & 11 & 1 & 1.00 & 0.5090 & 1.1429 & 0.2850 & college \\
\hline
\end{tabular}

Fisher's exact test was used to assess relationships between perceptions and total sales, shown in Table 13. These results showed no significance. 


\section{Table 13}

Fisher's Exact Test: Variables Compared by Total Sales

\begin{tabular}{lllll} 
Variable & $\mathrm{N}$ & $\mathrm{DF}$ & Fisher's Exact Test P & Table probability \\
\hline I intend to complete food safety training & 11 & 1 & 1.0000 & 0.5090 \\
Food safety training takes a lot of time & 11 & 1 & 0.6606 & 0.5090 \\
$\begin{array}{l}\text { My staff is supportive of food safety } \\
\text { training }\end{array}$ & 11 & 1 & 1.0000 & 0.2121 \\
\hline
\end{tabular}

Phase 2

\section{Purpose of the Study}

The purpose of phase two was to describe the perspectives of food processors by utilizing a focus group. This approach allowed for a deeper understanding of food processor experiences and provided a way to connect theory to the data in order to understand motivations of these food workers to participate in advanced food safety training. It also provided information on how best to develop the outreach component that is a follow-up to this research.

\section{Specific Objectives}

1. To assess the educational programming preferences and delivery formats preferred by WV fruit and vegetable local food processors.

a. RQ3: What key issues do WV produce processors face related to accessing food safety information?

\section{Data Analysis}

After obtaining written consent of the participants, the focus group was video/audio recorded and discussions were transcribed. The analytical process included categorization of answers, extraction of general concepts, and synthesis of the topics. To achieve a more direct connection with the data, the researcher personally carried out the processes of transcription, categorization, and synthesis. Transcription was done immediately following the focus group. This process allowed the researcher to review group dynamics, opinions of participants, and the effectiveness of the questions used before starting analysis.

There are a number of approaches that can be taken to analyze qualitative data. The advantage of the Krueger approach (1988) is a clear series of steps, which can assist first-time researchers in analyzing complex, qualitative data. Krueger provides eight established criteria, which suggest the following headings as a framework for interpreting coded data: 1) words, 2) context, 3) internal consistency, 4) frequency, 5) extensiveness of comments, 6) specificity of comments, 7) intensity of comments, and 8) big ideas.

Focus group analysis used deductive and thematic coding. Thematic coding in qualitative research consists of a series of processes that enable collected data from interactions to be sorted 
and categorized, which allows for the construction of meaning behind the data, providing thematic directionality towards categorizing data (Williams \& Moser, 2019).

Three rounds of coding took place. In the first round, distinct concepts and themes were identified (Appendix G). Axial coding took place in the second round, where themes were refined and categorized into overarching categories, following detailed review of transcriptions. The third and final stage of coding included selective coding, in which the data from the axial coding phase were refined into meaningful themes that could support arguments presented in the research study. Krueger and Casey's (2000) practical steps for managing and sorting out data were used to facilitate the coding process. This involved numbering each line of the transcript, printing two copies, and cutting the document into strips. The researcher reviewed each question from the focus group, and answered the following four questions:

1) Did the participant answer the question that was asked? If yes, go to question 3; if no, go to question 2; if don't know, set it aside and review it later.

2) Does the comment answer a different question in the focus group? If yes, move it to the appropriate question; if no, go to question 3.

3) Does the comment say something of importance about the topic? If yes, put it under the appropriate question; if no, set it aside.

4) Is it something that has been said earlier? If yes, start grouping like quotes together; if no, start a separate pile.

Trustworthiness of the focus group transcript was addressed by the creation of an audit trail of the transcripts and of the research process using a "memoing" process, which included reflective notes accumulating ideas and records about concepts and their relationship (HesseBiber \& Leavy, 2011, Krueger \& Casey, 2000).

\section{Participants}

Due to the small sample size, only one focus group was conducted with the participants. Out of the 11 participants who completed the survey, eight respondents engaged in the focus group; $100 \%$ of the participants were white females managing non-profit food processing operations, $37.5 \%$ under the age of 45 years old, $62.5 \%$ over 45 years old, and they represented eight WV counties. Education backgrounds differed amongst participants as $25 \%$ held a twoyear degree, $25 \%$ had completed a four-year degree, $37.5 \%$ completed a professional degree, and $12.5 \%$ had completed some college.

Years of experience varied amongst participants with $62.5 \%$ indicating less than or equal to 6 years of experience and $37.5 \%$ indicating they had over seven years of experience in foodservice. The majority of participants $(75 \%)$ operated in rural environments compared to urban environments (25\%). The majority (90\%) of participants reported annual sales less than $\$ 50,000$, compared to those $(10 \%)$ reporting sales over $\$ 100,000$. 


\section{Results}

Although, of the original 11 survey respondents only eight participated in the focus group, the sample size was deemed adequate because saturation was reached (Krueger \& Casey 2000.) Shown in Table 14, emergent themes were categorized then subcategorized into social cognitive theory concepts.

\section{Table 14}

Focus Group Themes and Categories

\begin{tabular}{|c|c|c|c|}
\hline $\begin{array}{l}\text { Question } \\
\text { theme }\end{array}$ & Emergent themes & Categories & $\begin{array}{l}\text { Subcategories reflective of } \\
\text { social cognitive theory } \\
\text { concepts }\end{array}$ \\
\hline $\begin{array}{l}\text { Benefits } \\
\text { processing } \\
\text { food }\end{array}$ & $\begin{array}{l}\text { Beauty in nature/Circle of } \\
\text { life } \\
\text { Connecting community } \\
\text { Building connections } \\
\text { Life cycle of food } \\
\text { Supporting non-profit } \\
\text { Community investment } \\
\text { Joy in work }\end{array}$ & $\begin{array}{l}\text { Healing } \\
\text { Connection } \\
\text { Empowerment } \\
\text { Resiliency } \\
\text { Wealth-building } \\
\text { Motives and drivers }\end{array}$ & $\begin{array}{l}\text { Outcome expectations } \\
\text { Collective efficacy }\end{array}$ \\
\hline $\begin{array}{l}\text { Barriers } \\
\text { processing } \\
\text { food }\end{array}$ & $\begin{array}{l}\text { Rural landscape/Internet } \\
\text { access } \\
\text { Lack of centralized } \\
\text { information } \\
\text { Multiple rules for different } \\
\text { types of products, markets, } \\
\text { sales outlets } \\
\text { Fear of reprimanding }\end{array}$ & $\begin{array}{l}\text { Communication } \\
\text { Confusion } \\
\text { Equipment access } \\
\text { Labeling } \\
\text { Service providers } \\
\text { Mixed messages } \\
\text { Services }\end{array}$ & $\begin{array}{l}\text { Moral disengagement } \\
\text { Incentive motivation } \\
\text { Outcome expectations }\end{array}$ \\
\hline $\begin{array}{l}\text { Accessing } \\
\text { food safety } \\
\text { rules and } \\
\text { regulations }\end{array}$ & $\begin{array}{l}\text { Technical jargon } \\
\text { No WV-specific } \\
\text { information } \\
\text { Inherited knowledge } \\
\text { Broadband access }\end{array}$ & $\begin{array}{l}\text { Guidance } \\
\text { Hands on } \\
\text { Web-based } \\
\text { Multiple formats } \\
\text { print }\end{array}$ & $\begin{array}{l}\text { Self-regulation } \\
\text { Interpretation/social } \\
\text { modeling }\end{array}$ \\
\hline $\begin{array}{l}\text { Desired } \\
\text { food safety } \\
\text { training }\end{array}$ & $\begin{array}{l}\text { Information specific to } \\
\text { WV } \\
\text { Information specific for } \\
\text { "little guys" } \\
\text { Accessibility even when } \\
\text { willing to invest in } \\
\text { driving/gas/time }\end{array}$ & $\begin{array}{l}\text { Upward mobility } \\
\text { Meeting demands of } \\
\text { Non-profit board } \\
\text { Gear }\end{array}$ & $\begin{array}{l}\text { Incentive motivation } \\
\text { Reciprocal determinism }\end{array}$ \\
\hline
\end{tabular}


Quotes were aligned to social cognitive theory concepts in Table 15. Data were interpreted using criteria from Krueger (1988) to identify words, context, internal consistency, frequency, extensiveness, specificity and intensity of comments and big ideas.

\section{Table 15}

Focus Group Quotes Applied to Social Cognitive Theory Concepts

Social cognitive theory Selected quotes from focus group concepts

Outcome expectations

"We participated in the Farmacy program this past year. It seemed to be so impactful and made a difference in the way people look at their food."

"I love the idea of getting local food into local bellies."

"I know I am having an impact on my community and helping farmers make it."

Collective efficacy "I like helping people connect to food, we used frozen carrots, so they know the farmer, and the location where they were grown, rather than God knows where they came from. I feel like we (my organization) make a difference."

Moral disengagement

"My Maw Maw taught me how to put up food. I don't need to pay to learn how to do that."

"I've been to the training put on by the state, but it didn't teach me how to process local food. I learned how to can fish, which I will never do. What's the point of telling my employees to go? They won't learn nothing."

"I have the book (FDA code book), and I have little doubt that it has a lot of beneficial information in it, but honestly, it's like stereo instructions. This is not something that I can immediately use as a reference..it's overwritten..it's for people that work in bureaucracy."

Incentive motivation "I don't want to feel like I'm going to let some slip through the cracks and poison people."

"I feel like my county health inspector gives me the run around. Every time I call a state agency, I get a different answer. Now I don't bother to call. I wait until someone tells me I've done something wrong."

Self-

regulation

"I want to sell my product out-of-state, but I can't find anyone to help me out. I keep getting told to get the services out of state, but it 
is expensive. When I do call Virginia (Virginia Tech), they tell me that they have to take care of their state first, and it will be a long time before they can get to me."

"I check up what I'm doing with this chart, but I don't know where the old manager got it from."

"I look for stuff online, all the time...but none of it is from here

(West Virginia). I don't know if it's accurate, but it's all I have to go by."

Social modeling "My background is in business. I rely on the old kitchen manager to tell me what I need to know."

"I inherited this place from a lady who got it up and running in 1992. She gave me a handbook that's all dog-eared, but it's all I got."

Reciprocal determinism

"I want to make my board happy, but I don't know how to make the food products they want to keep them happy."

\section{Words}

The researcher considered the actual words used, and their meaning. Many participants used the term "rules," "regulation," "policies," and "procedures," while it became evident in their actual experience, there was little understanding about the difference between rules at the county, state, and federal level. There is also a belief that attending food safety training did not clarify rules and regulations for these various levels, and the level of enforcement varied based on rural and urban environments. The majority of participants also expressed fear of being reprimanded and financial losses for their organizations for "getting in trouble." The participants understood that there were issues surrounding non-compliance but were not clear on how to be in compliance to avoid negative consequences.

\section{Context}

The wording of the moderator's questions and subsequent comments made by others in the group influences the context within which comments are made. The respondents are never asked directly to talk about issues stemming from non-compliance, although when asked about barriers in accessing food safety materials, the majority of participants indicated fear of being reprimanded, and negatively impacting their communities.

\section{Internal Consistency}

The researcher considered any changes in opinion or position by the participants. This also showed how participant engagement with one another influences responses. It was noted that participants expressed using FDA guidance materials once other participants acknowledged use. Inherited knowledge was also noted. Participants indicated they relied on past and present employees to verify compliance and gain understanding on how to process food safely. 


\section{Frequency and Extensiveness of Comments}

All participants talked at length about their experiences processing food and navigating available resources online. The majority of participants also indicated they made efforts to access information online but did not know where to go to get clear, accurate, updated information. All participants indicated that the materials they were using were not specific to West Virginia, and the majority were from unverified or unknown sources.

\section{Specificity of Comments}

Greater attention was placed on responses referring to personal experience, as opposed to hypothetical situations. The majority of participants indicated they had completed food safety training and expressed concern in not learning appropriate rules and regulations for county, state, and federal requirements. Participants indicated they understood there were rules for different marketing outlets, and had the desire to be in compliance, but did not have resources to ensure compliance.

\section{Intensity of Comments}

The researcher considered the depth of the feeling in which the comments were expressed. There was use of more negative terms when describing accessibility of information, reliability of information available, and updated materials. Positive terms were used in describing motives for work, the impact the work had on their community, and their contributions to feeding their community and supporting farmers.

\section{Big Ideas}

To identify big ideas, the researcher considered the larger trends or concepts that emerged from accumulation of evidence. This included lack of state-specific information, support from agri-service providers and health department officials, examples to ensure compliance, and communication with regulatory officials.

The results allowed for assessing educational programming preferences and delivery formats preferred by WV fruit and vegetable local food processors and key issues they face accessing food safety information. 


\section{CHAPTER V}

\section{Summary, Conclusions, and Recommendations}

\section{Summary}

\section{Purpose of the Study}

The purpose of this study was to describe food processors operating in non-profit commercial kitchens in West Virginia. Eleven food processors completed the phase one survey, and of those participants, eight engaged in the focus group in phase two.

\section{Specific Objectives}

1. To understand the social-psychological motivations (behavioral intention, attitude, perceived norm, personal agency) that shape WV produce processors' intention to complete advanced food safety training.

2. Assess the educational programming preferences and delivery formats preferred by WV produce processors.

\section{Research Questions}

1. RQ1: What are the characteristics of WV produce processors, and their commercial kitchen operations?

2. RQ2: What beliefs or attitudes influence intention to obtain BPCS?

3. RQ3: What key issues do WV produce processors face related to accessing food safety information?

The results of this study describe the small population of white, female, food processors in rural West Virginia. The two-phase, mixed-methods approach, used a survey to address objective one and a focus group to address objective two. Due to the small sample size, the majority of statistical analyses were not significant, with the exception of the perception of time and food safety training for processors operating in rural environments.

\section{RQ1: Characteristics of WV produce processors, and their commercial kitchen operations?}

Of the participants surveyed, the majority of operators were women, over 45 years old, with less than six years of experience working in commercial kitchen environments. The majority had college experience and operated in rural areas as food service managers. Their operations predominately served direct to consumer markets, with annual sales less than $\$ 50,000$. When processing potentially hazardous foods, the majority of participants indicated they had BPCS training.

\section{RQ2: Beliefs or attitudes influencing intention to obtain BPCS}

The majority of statistical tests resulted in insignificant results with the exception of the perception of time associated with food safety training. The majority of respondents $(87.50 \%)$ operating in rural environments agreed that food safety training took a lot of time, compared to $(33.33 \%)$ operating in urban environments. A Fisher's exact test assessed the relationship between perception of time commitments of food safety training, and rural vs. urban environments. There was an insignificant association between the two variables $(n=11, D F=1$, 
$\mathrm{p}=0.1515)$. However, when correcting for college experience using $\mathrm{CMH}$, the association of perception of time commitments of food safety training, and rural vs. urban environments was significant (CMH Chi-square 45.5714, $\mathrm{p}=0.0325$ ). The factors of time and difficulty may be attributed to long travel times for individuals in rural environments, where obtaining food safety training may involve overnight stays, in addition to taking time off of work. Both time perception and difficulty were indirect measures of behavioral belief, which can influence attitudes toward behavior, behavioral intention, and intention.

\section{RQ3: Key issues facing WV Produce Processors related to accessing food safety information}

Results from this study indicate participants identified the lack of centralized, accurate, state-specific food safety information for the state as a barrier. Information is not readily available from West Virginia sources. One respondent stated, "I often have to utilize Virginia Tech (University) as a source of information."

\section{Educational programming preferences and accessing food safety education}

Focus group themes associated with the benefits of processing of food were categorized into healing, connection, empowerment, wealth-building and resiliency. These themes were reflective of outcome expectations and collective efficacy.

Themes related to barriers to processing food were categorized into communication, confusion, access to equipment and services such as labeling and process review, and receiving mixed messages. These themes were reflective of social cognitive theory concepts related to moral disengagement, incentive motivation, and outcome expectations.

Participants expressed need for guidance, hands-on experience, and resources in multiple formats including print and online, reflective of social cognitive theory themes related to selfregulation, interpretation and social modeling. Desired food safety training focused on upward mobility, meeting the demands of nonprofits and quelling fears from rules and regulations reflective of social cognitive theory themes related to incentive motivation and reciprocal determinism.

\section{Access to Service Providers}

West Virginia lacks a Better Process Control Authority, who would provide guidance to processors, to ensure food safety and to have upward mobility as processors. This is a barrier to market and causes processors to seek these services from out of state. The State Food Safety Team promotes FSMA compliance including BPCS training, but the lack of access to commercial kitchen facilities leads many processors to prepare food in their homes as cottage foods. Even with production in this environment, processors must have verification of the recipe process to sell at the farmers market.

\section{Access to Environments}

The state has only one co-packing facility, and limited options for accessing commercial kitchens through shared-use agreements. Processors are able to access these environments through non-profits, who participate in shared-use. Of the surveyed participants $(n=11), 3$ provide shared-use renting space to the community. Processors must verify their BPCS training and show documentation of their recipes as verified by a Process Control Authority. 


\section{Conclusions}

The results of this study were used to inform the development of a food safety outreach program. Participants noted the lack of available, accurate, and consistent information for local, state and federal governance. Food Safety outreach programs can address these issues as they build capacities in communities, using concepts of social cognitive theory to support social entrepreneurship.

\section{Using Social Cognitive Theory to Build Self-Efficacy}

Social Cognitive Theory (SCT) was used as the theoretical framework for analyzing the survey and focus group results. Based on the concept of self-efficacy, this theory proposes that individuals develop and create self-perceptions as a part of human behavior (Usher \& Pajares, 2008). These self-perceptions, in turn, become the means by which people follow their goals and recognize what they are capable of doing to control their environments. SCT provides opportunities for social support through instilling expectations of self-efficacy and using observational learning and other reinforcements to change behavior. Perceived self-efficacy affects behavior by 1) influencing what the individual chooses to pursue; 2) being a source of intrinsic motivation or demotivation, 3) determining the effort devoted to instructional strategies, and 4) predicting how long the individual will persevere in carrying out the activities (Bandura, 2001). These constructs can be used in the development of a food safety outreach program to develop self-efficacy, as shown in Table 16.

\section{Table 16}

Methods for Increasing Self-efficacy, Applied to Food Safety Outreach Program, adapted from Bandura (1986)

\begin{tabular}{ll}
\hline Self-efficacy construct & Method to increase self-efficacy through food safety outreach \\
\hline Mastery experience & $\begin{array}{l}\text { Increasing access to open source resources to be able to perform } \\
\text { the behavior. Engagement with a group collaboration to achieve } \\
\text { mastery in safe food processing. }\end{array}$ \\
\hline
\end{tabular}

Social modeling Training processors in cohorts, using online and in-person skill development on specific processes outlined in the food safety outreach program.

Improving physical and emotional states
Hosting cycles of communication to facilitate communication amongst food processors to identify questions, concerns, and areas of clarification. Recognition as part of the WV Department of Agriculture marketing bulletin and local food program (WV Grown)

Verbal persuasion
Promotion of processors and kitchens and recipes through WV Grown program, highlighting efforts at WVU Small Farms Conference and WV Farmers Market platforms. ${ }^{1}$

\footnotetext{
1 The WVU Small Farms Conference is a state conference for agri-service providers The West Virginia Farmers Market Association is a state direct market grower group.
} 


\section{Moving from Insights to Action: Applying New Knowledge to Develop Social Enterprise}

The results of this research project were used to inform a social-enterprise focused, food safety outreach program that seeks to create systemic change in West Virginia's agriculture system by addressing the problem of lack of food processing in the state, through access to resources, building social capital and educating potential partners. West Virginia lacks a process control authority, causing processors to go out of state for services, and poses a rate-limiting factor for the growth of the local food sector. While the state facilitates a cost subsidy for BPCS training, the lack of infrastructure limits growth of the agriculture sector.

To address this social problem, resources must be aligned to forge trust amongst actors by building capacities through education and experiences (Figure 3). Allowing for upward mobility by addressing gaps in knowledge and resources, a food safety outreach program can engage state and local partners with complementary competencies to create an innovative approach to health promotion through a holistic, integrated, locally-focused approach.

\section{Figure 3}

Local Social Entrepreneurship Process of Knowledge Conversion (Source: Modified from Heinze et al., 2016)

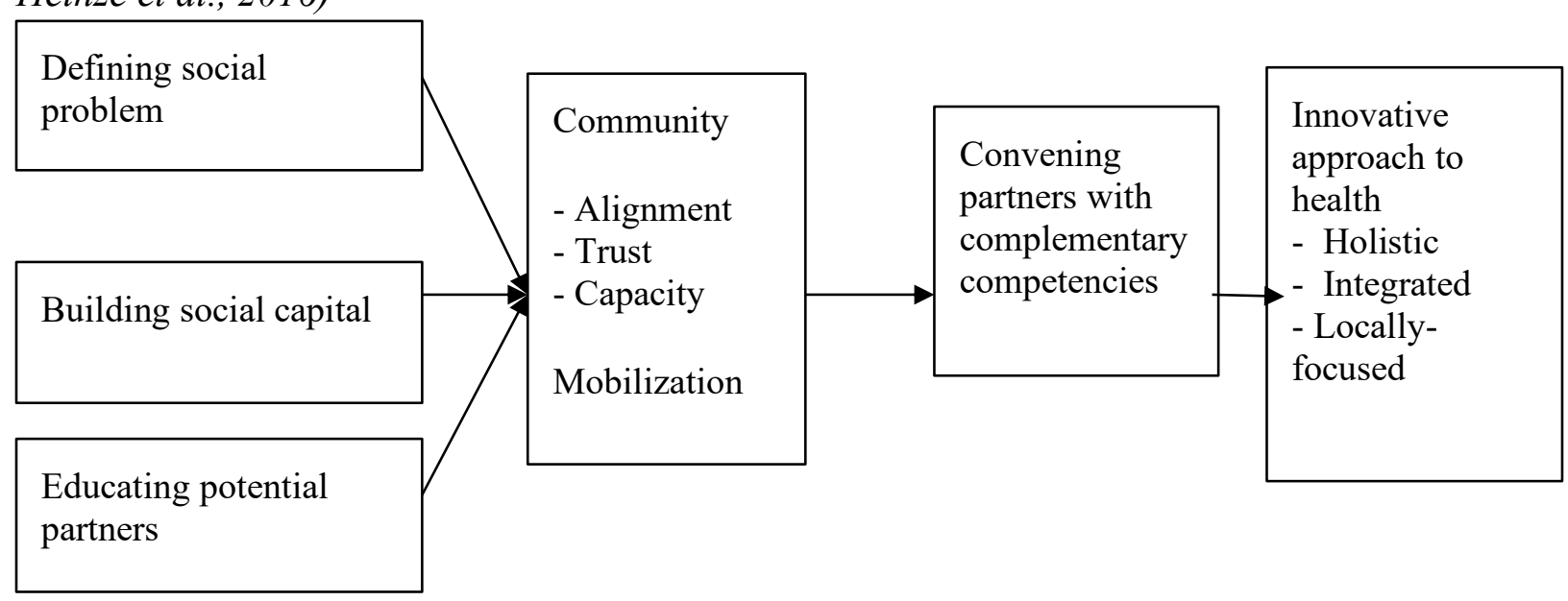

A principal philosophy in the positive theory of social entrepreneurship is that social entrepreneurs rise up to address an issue that governments do not have the resources to address, and that profit-driven business have no interest in (Santos, 2009). Social enterprises fulfill a role in the economy when market and government simultaneously fail (Santos, 2009). Non-profits represent a mechanism that can move resources towards a more just allocation of resources and economic outcomes. The combination of not-for-profit and for-profit activities can play a crucial role in ensuring the economic viability of the local and regional food networks (Dunning, 2013). 
The resulting social enterprise program, entitled the HOUSE food safety outreach program (Appendix H), builds social capital amongst non-profit food processors. By facilitating cohort training, access to resources, shared marketing and promotion, this food safety outreach program aims to increase self-efficacy in food processors through mastery of experience, social modeling, improving physical and emotional states, and verbal persuasion. The program uses the PRECEDE-PROCEED (Predisposing, Reinforcing, and Enabling Constructs in Educational Diagnosis and Evaluation. Policy, Regulatory, and Organizational Constructs in Educational and Environmental Development) planning model, to increase access to open-source food safety resources.

\section{Figure 4}

Local Social Entrepreneurship Process of Knowledge Conversion Applied to the HOUSE Program (Source: Modified from Heinze et al., 2016)

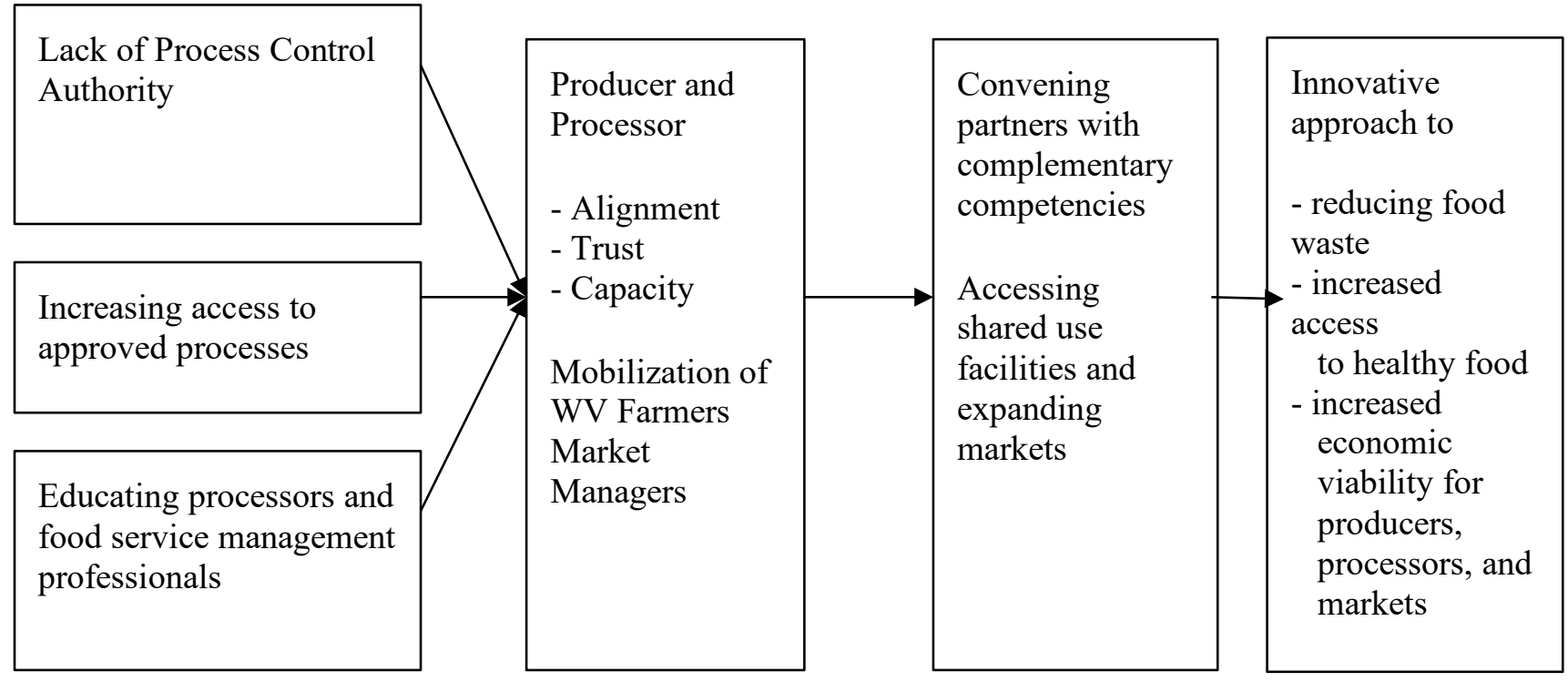




\section{Recommendations}

This study contributed to the knowledge of food processors and increased understanding of the challenges they face when accessing food safety information. It has implications for human and community development in West Virginia. Participants noted the lack of centralized, food safety information as a barrier, and indicated preferences for online and print training.

\section{Support for Process Control Authority}

The state of West Virginia should look to engage expertise at the WVU Davis College of Agriculture, Natural Resources and Design and the WV Department of Agriculture to support a joint position to reinstate a Process Control Authority. This would provide access to services to ensure food safety, as well as regulatory oversight of new product development. It would also develop a new revenue stream as food entrepreneurs would not have to go out of state for these services, and it would strengthen the agriculture sector.

\section{Centralized information for food processors}

Stakeholders should work together to create a centralized source for state-specific information for food processors. This information should be updated regularly to ensure that food processors have easy access to reliable, current information.

\section{Adoption of new food safety outreach programs relevant to the population}

The WV Department of Agriculture and the West Virginia Farmers Market Association should support the adoption of the HOUSE Food Safety Outreach program, which addresses barriers in the agriculture ecosystem and can alleviate food borne illness outbreak concerns stemming from the lack of resources, and increase producer profitability.

\section{Future research}

Future research should facilitate a phase three, participant follow up, to assess changes in knowledge, attitudes, and beliefs. Due to time constraints, this phase was not executed in the current research study. Phase three would allow for follow-up engagement with the participants to assess changes in attitude, behavior, and attaining BPCS training, after the food safety training outreach material was delivered. The target population should include respondents who completed phase one (survey) and phase two (focus group), representing eight food processors, operating in eight counties. The instrument would be the original 45 -question survey used in phase one, which would re-assess the participants six months after the original survey was delivered. Data collection procedures would replicate phase one with consistent data analysis, utilizing Fisher's exact test as well as $\mathrm{CMH}$ to assess correlations six months after program completion. 


\section{REFERENCES}

Ajzen, I. (1991). The theory of planned behavior. Organizational behavior and human decision processes, 50(2), 179-211.

Ajzen, I. (2001). Nature and operation of attitudes. Annual Review of Psychology, 52(1), 27-58.

Ajzen, I. (2006). Constructing a theory of planned behavior questionnaire. Retrieved from the University of Massachusetts website:

https://people.umass.edu/aizen/pdf/tpb.measurement.pdf

Ajzen, I. (2011). Behavioral interventions: Design and evaluation guided by the theory of planned behavior. Social Psychology for Program and Policy Evaluation. Guilford, New York, pp: 74-100.

Ajzen, I., \& Fishbein, M. (1980). Understanding attitudes and predicting social behavior. Englewood Cliffs, NJ: Prentice-Hall.

Arcoverde, ACB., Souza, IL., \& Fragoso, NM. (2006). Economia solidaria en pernambuco: Alternativa de emancipacao frente ao desemprego e a exclusvio social? Acoes em Redes Coordenas no Universo Social-ARCUS, Revista da ABET, VI(2):72-93

Armenakis, A., Harris, S., \&Mossholder, K. (1993). Creating readiness for organizational change. Sage Journals.

Arvola, A., Vassallo, M., Dean, P., Lampila, A., Saba, L. Lähteenmäki, \& R. Shepherd. (2008). Predicting intentions to purchase organic food: The role of affective and moral attitudes in the theory of planned behavior. Appetite, 50:443-454.

Avetisyan, T., \& Ross, B. (2019). The intersection of social and economic value creation in social entrepreneurship: A comparative case study of food hubs. Journal of Food Distribution Research, 50(1): 97-104.

Bakari, H., \& Hunjra, A. (2017). How does authentic leadership influence planned organizational change? The role of employees' perceptions. Journal of Change Management, 17(2).

Bandura, A. (1986). Social foundations of thought and action: A social cognitive theory. Englewood Cliffs, NJ: Prentice-Hall.

Bandura, A. (2001). Social cognitive theory; An agentic perspective. Annu Rev Psychology, 52: 
$1-26$.

Barker, WH., Weissman, J., Dowell, V., Gutmann, K., \& Kautter, D. (1977). Type B Botulism outbreak caused by a commercial food product: West Virginia and Pennsylvania. Journal of the American Medical Association, 237(5): 456-9.

Basar, P. (2018). Social entrepreneurship: Case study in Unilever food solutions' trusted hands food safety online training program. Entrepreneurship - Trends and Challenges, 145 - 158 .

Bornstein, D. (2007). How to change the world: Social entrepreneurship and the power of new ideas. Oxford, Oxford University Press.

Burnes, B. (2004). Kurt Lewin and complexity theories: Back to the future? Journal of Change Management, 4(3): 309-325.

Center for Disease Control and Prevention (CDC). (2018). Estimates of foodborne illness in the United States. Retrieved from https://www.cdc.gov/foodborneburden

Center for Science in the Public Interest. (2015). All over the map: A 10-year review of state outbreak reporting. Retrieved from the Center for Science in the Public Interest website: https://cspinet.org/sites/default/files/attachment/alloverthemap.pdf

Chamberlain, N. (1977). Remaking American values. New York. Basic Books.

Condreanu, A. (2010). Organizational change: A matter of individual and group behavior transformation. Journal of Defense Resources Management, 1(1): 49-56.

Cochran, I. (1954). Some methods for strengthening common $\mathrm{X}^{2}$ tests. Biometrics, 10 (4): 417-451.

Conover, E., Rubchinuk, E., Smith, S., \& Yarisamar, C. (2015). History of shared-use kitchens: A case study analysis of kitchen success. Community engaged research reports, 30.

Conover, W.J. (1999). Practical nonparametric statistics. Willey \& Sons., New York, 428-433.

Cornell University (2019). Produce safety alliance - Timelines. Retrieved From the Produce Safety Alliance website: https://producesafetyalliance.cornell.edu/food-safetymodernization-act/produce-safety-rule-compliance-dates-timeline/ 
Cruz, ZG., \& Santos, LML. (2009). Economia solidaria: potencialidades e desafios dos empreendimentos solidarios em Londrina. Londrina, (10), 224.

Cummings, T., \& Worley, C. (2001). Organization development and change. $7^{\text {th }}$ Edition, South-Western College Publishing, Mason, OH.

Dent, B. (2008). The potential for kitchen incubators to assist food-processing enterprises. International Journal of Entrepreneurship and Small Business, 6(3), 496-512.

Ergul, M., \& Johnson, C. (2011). Social entrepreneurship in the hospitality and tourism industry: an exploratory approach. Consortium Journal of Hospitality \& Tourism, 16(2), 40-46.

Food Corridor. (2017). Shared-use kitchen industry report. Retrieved from the Food Corridor website: https://www.thefoodcorridor.com/resources/

Food \& Drug Administration. (2018a). Background on the FDA food safety modernization act (FSMA). The Food and Drug Administration website: https:/www.fda.gov/food/foodsafety-modernization-act-fsma/background-fda-food-safety-modernization-act-fsma

Food \& Drug Administration. (2018b). The history of the FDA's fight for consumer protection. Retrieved from the Food and Drug Administration website: https://www.fda.gov/about-fda/fdas-evolving-regulatory-powers/part-v-consumerprotection-late- $20^{\text {th }}$-century

Food \& Drug Administration. (2018c). The Preventive controls alliance. Retrieved from the Food and Drug Administration website: https:/www.fda.gov/food/food-safetymodernization-act-fsma/food-safety-preventive-controls-alliance

Food \& Drug Administration. (2018d). FSMA compliance dates. Retrieved from the Food and Drug Administration website: https://www.fda.gov/food/food-safety-modernization-act-fsma/fsma-complianc e-dates

Food \& Drug Administration. (2019). Food Safety Modernization Act (FSMA) Retrieved from the Food and Drug Administration website: https://www.fda.gov/food/guidanceregulation-food-and-dietary-supplements/food-safety-modernization-act-fsma

Glanz, K., Rimer, B., \& Viswanath, K. (Eds.). (2008). Health behavior and health education: Theory, research, and practice, ( ${ }^{\text {th }}$ ed.). San Francisco, CA, US: Jossey-Bass.

Glew, D., Leary-Kelly, A., Griffin, R., \& Van Fleet, D. (1995). Participation in organizations: A preview of the issues and proposed framework for future analysis. Journal of Management, 21(3), 395-421. 
Green, L., \& Kreuter, M. (2005). Health program planning: An educational and ecological approach, $4^{\text {th }}$ edition. New York, NY: McGraw-Hill.

Harris, D., Lott, M., Lakins, V., Bowden, B., \& Kimmons, J. (2012). Farm to Institution: Creating access to healthy local and regional foods. Advances in Nutrition, 3(3), 343-349.

Hayden, J. (2014). Introduction to health behavior and theory. Sudbury, Mass; Jones and Bartlett.

Heinze, K., Banaszak-Holl, J., \& Babiak, K. (2016). Social entrepreneurship in communities: Examining the collaborative process of health conversion foundations. Nonprofit Management and Leadership, (26): 3

Hesse-Biber, S., \& Leavy, P. (2011). The practice of qualitative research. Los Angeles: SAGE. Harvard (18 ${ }^{\text {th }}$ ed.)

Illinois Institute of Technology. (2020a). Food safety preventive controls alliance. Retrieved from https://www.ifsh.iit.edu/fspca

Illinois Institute of Technology. (2020b). Sprout safety alliance. Retrieved from the Illinois Institute of Technology website: https://www.ifsh.iit.edu/ssa

Izumi, B.T., Wright, D.W., \& Hamm, M. (2010). Market diversification and social benefits: Motivations of farmers participating in farm to school programs. Journal of Rural Studies, 36 (4), 374-382.

Johnsen, S. (2015). Revisiting the concept of social enterprise in a gulf cooperation council (GCC) context: a social constructionist view, CIRIEC-Universite de Liege.

Joshi, A., Azuma, A., \& Feenstra, G. (2008). Do Farm-to-School programs make a difference? Findings and future research needs. Journal of Hunger \& Environmental Nutrition, 3(23), 229-246.

Kline, C., Shah, N., \& Rubright, H. (2014). Applying the positive theory of social entrepreneurship to understand food entrepreneurs and their operations. Tourism Planning \& Development, 11(3), 330-342.

Krueger, R. (1988). Focus groups. A practical guide for applied research. Newbury Park, CA. Sage Publications.

Krueger, R., \& Casey, MA. (2000). Focus Groups: A Practical Guide for Applied Research, 3rd ed. 
Thousand Oaks, CA: Sage Publications.

Lewin, K. (1951). Field theory in social science: Selected theoretical papers. (Edited by Dorwin Cartwright.).

Lee, M., \& Jay, J. (2015). Strategic responses to hybrid social ventures. California Management Review, 57(3), 26-148.

Lincoln, Y., \& Guba, E. (1985). Naturalistic inquiry. Beverly Hills, CA: Sage Publications. p.210.

Mantel, N., \& Haenszel, W. (1959). Statistical aspects of the analysis of data from retrospective studies of disease". Journal of the National Cancer Institute, 22(4), 719748.

Maxwell, J.A. (2005). Qualitative research design: An interactive approach. J.A. Maxwell

Montano, D., \& Kasprzyk, D. (2001). Theory of reasoned action, theory of planned behavior, and the integrated behavioral model. In K. Glanz, B. Rimer, \& K. Viswanath (Eds.), Health behavior and health education: Theory, research and practice. $3^{\text {rd }}$ Edition. San Francisco, CA, US: Jossey-Bass.

Morgan, D. (1998). Focus groups as qualitative research. Sage University Paper Series on Qualitative Research Methods, Vol. 16. Beverly Hills: Sage.

National Farm to School Network. (2020). Farm to School Policies. Retrieved from the National Farm to School Network website: http://www.farmtoschool.org/policy\#

National Restaurant Association Education Foundation. (2010). Serv Safe. Retrieved from the National Restaurant Association Education Foundation website: https://restaurant.org

Nordstrom, P., Wilson, L., Kelsey, T., Maretzki, A., \& Pitts, C. (2000). The use of focus group interviews to evaluate agriculture educational materials for students, teachers, and consumers. Journal of Extension, 38(5), 14-20.

Novelli, M., Schmitz, B., \& Spencer, T. (2006). Networks, clusters and innovation in tourism: A UK experience. Tourism Management, 27(6), 1141-1152.

Oldham, RM. (2013). Meeting the demand for local good in West Virginia: An analysis of factors influencing producers' market participation and expansion decisions. [Unpublished master's thesis]. West Virginia University, Morgantown, WV. 
Onwuegbuzie, A., Dickinson, W., Leech, N., \& Zoran, A. (2009). A qualitative framework for collecting and analyzing data in focus group research. International Journal of Qualitative Methods, (9), 1-21.

Palkova, Z., \& Palko, T. (2017). Food incubators for sustainable development of regions. Management, economic engineering in agriculture \& rural development. 17 (2), 263-267.

Robbins, S. (2003). Organizational behavior. $10^{\text {th }}$ ed. Upper Saddle River, NJ: Prentice Hall.

Santos, P., \& Moraes, F. (2009).Empreendedorismo na incubadora da UFRPE: Uma reflexao sobre empresas criadas por inciativas de alunos e docentes. $R O C$; 10(20): 371-406.

Schafft, K., Hinrichs, C., \& Bloom, J. (2010). "Pennsylvania farm-to-school programs and the articulation of local context." Journal of Hunger and Environmental Nutrition, 5 (1), 2340 .

Schein, E. (1996). Kurt Lewin's change theory in the field and in the classroom: Notes toward a model of managed learning. Systems Practice, No. 9, p. 28

Schunk, D.H. (1987). Peer models and children's behavior change. Review of Educational Research, 57(2), 149-174.

Sheeran, P., Conner, M., \& Norman, P. (2001). Can the theory of planned behavior explain patterns of health behavior change? Health Psychology, 20(1), 12-19.

Sheldon, P., \& Daniele, R. (2017). Social Entrepreneurship and Tourism: Philosophy and Practice. Springer International Publishing AG.

Soledade, J., Cardosa, R., Pena, L., Figueiredo, K., \& Oliveira, T. (2017). Formation of a solidarity kitchen, use of post-harvest losses, and food safety: advances and challenges in addressing social vulnerability. Demetra: Food, Nutrition \& Health, 12(4), 2285-1202.

Steckler, A., Goodman, R.M., \& Kegler, M. (2001). Mobilizing organizations for health enhancement: Theories of organizational change. In K. Glanz, B. Rimer, \& K. Viswanath (Eds.), Health behavior and health education: Theory, research and practice. $3^{\text {rd }}$ Edition. San Francisco, CA, US: Jossey-Bass.

Stroud, A., Boettner, F., Gilmer, B., \& Betcher, M. (2015). West Virginia food hub feasibility assessment. Retrieved from: 
http://www.downstreamstrategies.com/documents/reports_publication/wv-food-hubfinal-report_1-23-15.pdf

Thompson, J., Alvy, G., \& Lees, A. (2000). Social entrepreneurship: A new look at the people and the potential. Management Decision, 38(5), 328-338.

United States Department of Agriculture. (2016). Farm to school works to stimulate local economies. Retrieved from: https://farmtoschoolcensus.fns.usda.gov

United States Department of Agriculture. (2016a). Local Food Marketing Practices Survey. Retrieved from the United States Department of Agriculture website: https://www.nass.usda.gov/Publications/Highlights/2016/LocalFoodsMarketingPractices _Highlights.pdf

United States Department of Agriculture. (2019). Overview of West Virginia agricultural statistics. Retrieved from the United States Department of Agriculture website: https://www.nass.usda.gov/Quick_Stats/Ag_Overview/stateOverview.php?state=west $\% 2$ 0virginia

United States Department of Agriculture (2020). Good Agricultural Practices. Retrieved from: https://www.ams.usda.gov/services/auditing/gap-ghp

Usher, E.L., \& Pajares, F. (2008.) Sources of self-efficacy in school: Critical review of the literature and future directions. Review of educational research, 78(4) 751-796.

Volkmann, C., Tokarski, K., \& Ernst, K. (2012). Social entrepreneurship and social business: An introduction and discussion with case studies. Wiesbaden: Springer.

Vroom, V., \& Yetton, P. (1973). Leadership and decision-making (Vol. 110). University of Pittsburgh Press.

West Virginia University (WVU) Center for Resilient Communities. (2020). Community food systems link. Accessible at https://www.cfslinkwv.com

Williams, M., \& Moser, T. (2019). The art of coding and thematic exploration in qualitative research. International Management Review, (15), 45.

Zahra S.A., Gedajlovic, E., Neubaum D., \& Shulman, J. (2009) A typology of social entrepreneurs: Motives, search processes and ethical challenges. Journal of Business Venturing, 24(5), 519-532. 
Zand, D., \& Sorensen, R. (1975) .Theory of change and the effective use of management science. Administrative Science Quarterly, 20(4), 532-545. 
APPENDIX A

Survey Construct Table 


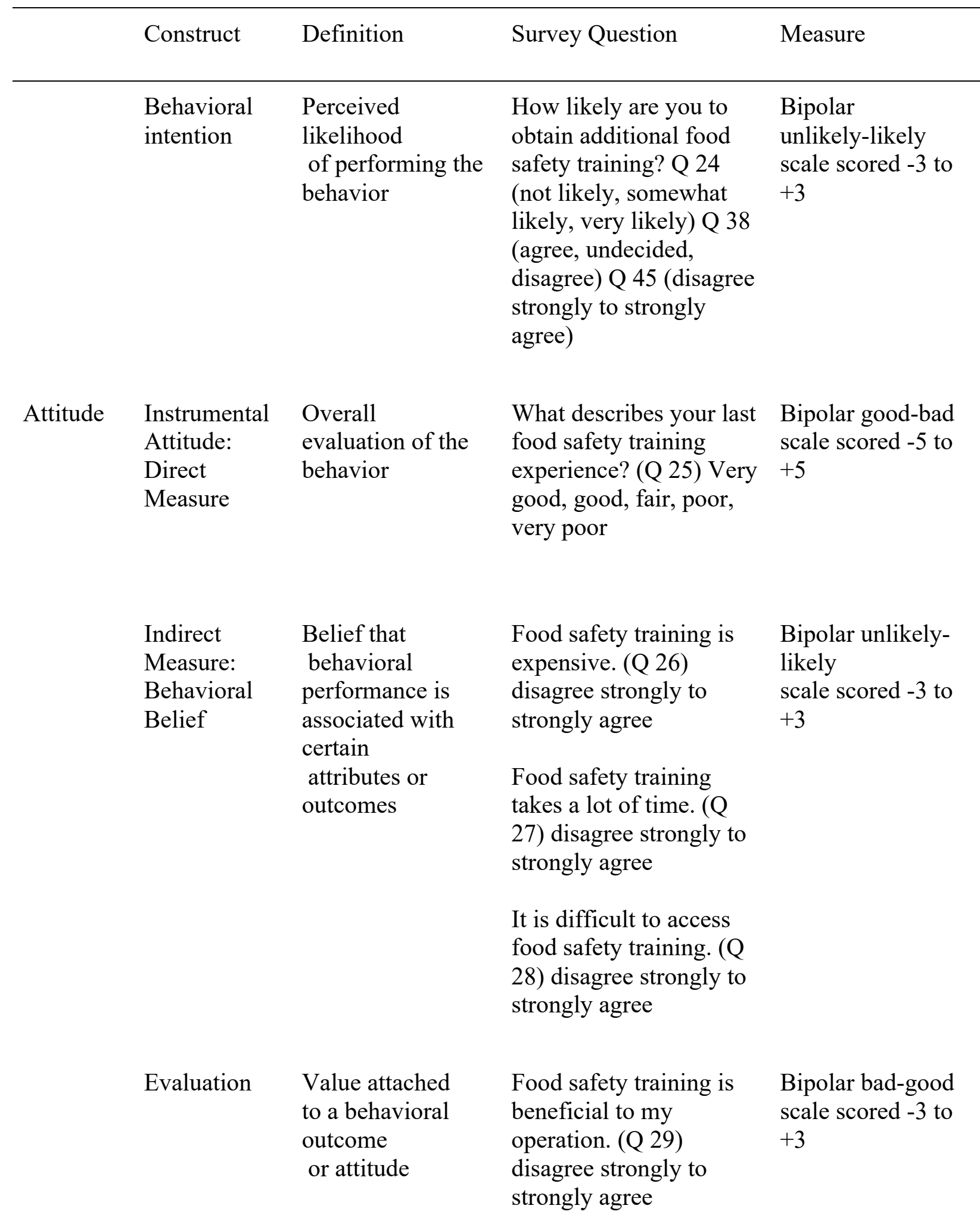




\begin{tabular}{|c|c|c|c|c|}
\hline \multirow[t]{3}{*}{$\begin{array}{l}\text { Perceived } \\
\text { Norm }\end{array}$} & $\begin{array}{l}\text { Subjective } \\
\text { (Injunctive) } \\
\text { Norm Direct } \\
\text { Measure: }\end{array}$ & $\begin{array}{l}\text { Belief about } \\
\text { Whether most } \\
\text { people } \\
\text { approve or } \\
\text { disapprove } \\
\text { of behavior }\end{array}$ & $\begin{array}{l}\text { Most of my staff think I } \\
\text { should complete food } \\
\text { safety training. (Q 30) } \\
\text { disagree strongly to } \\
\text { strongly agree }\end{array}$ & $\begin{array}{l}\text { Bipolar disagree- } \\
\text { agree } \\
\text { scale scored }-3 \text { to } \\
+3\end{array}$ \\
\hline & $\begin{array}{l}\text { Indirect } \\
\text { Measure: } \\
\text { Normative } \\
\text { belief }\end{array}$ & $\begin{array}{l}\text { Belief about } \\
\text { whether each } \\
\text { referent } \\
\text { approves or } \\
\text { disapproves } \\
\text { of the behavior }\end{array}$ & $\begin{array}{l}\text { Most of my staff thinks } \\
\text { they should complete } \\
\text { food safety training. (Q } \\
\text { 31) disagree strongly to } \\
\text { strongly agree }\end{array}$ & $\begin{array}{l}\text { Bipolar disagree- } \\
\text { agree } \\
\text { scale scored }-3 \text { to } \\
+3\end{array}$ \\
\hline & $\begin{array}{l}\text { Motivation to } \\
\text { comply }\end{array}$ & $\begin{array}{l}\text { Motivation to do } \\
\text { what each referent } \\
\text { thinks }\end{array}$ & $\begin{array}{l}\text { Generally, I want to } \\
\text { complete advanced food } \\
\text { safety training. (Q 32) } \\
\text { Agree, undecided, } \\
\text { disagree }\end{array}$ & $\begin{array}{l}\text { Bipolar disagree- } \\
\text { agree } \\
\text { scale scored }-3 \text { to } \\
+3\end{array}$ \\
\hline \multirow[t]{3}{*}{$\begin{array}{l}\text { Personal } \\
\text { Agency }\end{array}$} & $\begin{array}{l}\text { Perceived } \\
\text { Behavioral } \\
\text { Control } \\
\text { Direct } \\
\text { Measure: }\end{array}$ & $\begin{array}{l}\text { Overall measure } \\
\text { of perceived } \\
\text { control } \\
\text { over the behavior }\end{array}$ & $\begin{array}{l}\text { I can complete advanced } \\
\text { food safety training. (Q } \\
\text { 33) disagree strongly to } \\
\text { strongly agree }\end{array}$ & $\begin{array}{l}\text { Semantic } \\
\text { differential scales. } \\
\text { For example, } \\
\text { under my control- } \\
\text { not under my } \\
\text { control; easy - } \\
\text { difficult }\end{array}$ \\
\hline & $\begin{array}{l}\text { Indirect } \\
\text { Measure: } \\
\text { Control } \\
\text { Belief }\end{array}$ & $\begin{array}{l}\text { Perceived } \\
\text { likelihood } \\
\text { of occurrence of } \\
\text { each } \\
\text { facilitating or } \\
\text { constraining } \\
\text { condition }\end{array}$ & $\begin{array}{l}\text { food safety training is } \\
\text { cost-prohibitive. (Q 34) } \\
\text { disagree strongly to } \\
\text { strongly agree }\end{array}$ & $\begin{array}{l}\text { Unlikely-likely } \\
\text { scale. } \\
\text { Score }-3 \text { to }+3\end{array}$ \\
\hline & $\begin{array}{l}\text { Perceived } \\
\text { Power }\end{array}$ & $\begin{array}{l}\text { Perceived effect of } \\
\text { each } \\
\text { condition in } \\
\text { making } \\
\text { behavioral } \\
\text { performance } \\
\text { difficult or easy }\end{array}$ & $\begin{array}{l}\text { Food safety training is } \\
\text { difficult to complete. (Q } \\
\text { 35) disagree strongly to } \\
\text { strongly agree } \\
\text { I can implement } \\
\text { advanced food safety } \\
\text { protocols in my } \\
\text { operation. (Q 36) } \\
\text { disagree strongly to } \\
\text { strongly agree }\end{array}$ & $\begin{array}{l}\text { Bipolar difficult- } \\
\text { easy scale. } \\
\text { Scored }-3 \text { to }+3\end{array}$ \\
\hline
\end{tabular}




\begin{tabular}{|c|c|c|c|}
\hline $\begin{array}{l}\text { Self-Efficacy } \\
\text { Direct } \\
\text { Measure: }\end{array}$ & $\begin{array}{l}\text { Overall measure } \\
\text { of } \\
\text { ability to perform } \\
\text { behavior }\end{array}$ & $\begin{array}{l}\text { I am confident I could } \\
\text { complete food safety } \\
\text { training successfully. (Q } \\
\text { 37) disagree strongly to } \\
\text { strongly agree }\end{array}$ & $\begin{array}{l}\text { Certain I could not } \\
\text { certain } \\
\text { I could scale for } \\
\text { overall behavior. } \\
\text { Scored }-3 \text { to }+3\end{array}$ \\
\hline $\begin{array}{l}\text { Indirect } \\
\text { Measure: } \\
\text { Self-efficacy } \\
\text { belief }\end{array}$ & $\begin{array}{l}\text { Perceived ability } \\
\text { to } \\
\text { overcome each } \\
\text { facilitating or } \\
\text { constraining } \\
\text { condition }\end{array}$ & $\begin{array}{l}\text { I could complete } \\
\text { additional food safety } \\
\text { certification. (Q 38) } \\
\text { disagree strongly to } \\
\text { strongly agree }\end{array}$ & $\begin{array}{l}\text { Certain I could not } \\
\text {-certain I could } \\
\text { scale for overall } \\
\text { behavior. } \\
\text { Scored }-3 \text { to }+3\end{array}$ \\
\hline
\end{tabular}


APPENDIX B

Cover Letter for Survey - First Request 


\section{Dear Participant,}

This letter is a request for you to take part in a research project to describe food workers specifically produce processors and operations in West Virginia. This project is being conducted by Megan Govindan, a doctoral candidate in the Human \& Community Development program at West Virginia University. The primary mentor of this project is Cheryl Brown, PhD, Associate Professor in the Division of Resource Economics at WVU.

Your participation in this project is completely voluntary, and you are free to withdraw from the research at any time. You must be 18 years of age or older to participate. You may skip any question that you do not wish to answer, and you may discontinue at any time. West Virginia University's Institutional Review Board acknowledgement of this project is on file.

You will be asked to complete a survey and invited to attend a focus group. The survey will take approximately 15 minutes to complete and will be anonymous. It has 45 questions, asks questions related to demographics, food processor practices for employees and operations, marketing practices, and food safety training. The focus group will last approximately 60 minutes and will focus on identifying your needs as a fruit $\&$ vegetable local food processor accessing food safety information.

Your involvement in this project will be kept as confidential as legally possible. All data will be reported in the aggregate. You will not be asked any questions that could lead back to your identity as a participant.

Your participation is greatly appreciated. Participants will be compensated with vouchers for nutrient analysis for their participation. A \$200 value, each voucher allows for the analysis of 5 food products and will provide the processor with the full nutrient breakdown, Food \& Drug Administration Nutrition Facts Panel. Participants can receive a total of 2 vouchers, for analysis of 10 food products.

If you have any questions about this research project, please feel free to contact me at (304) 280-3429, or by email at megan.govindan@mail.wvu.edu. If you have any questions about your rights as a research participant, please contact the WVU Office of Human Research Protection by phone at 304-293-7073 or by email at IRB@mail.wvu.edu.

If you are willing to participate, this letter also serves as your consent to participate in the research. Thank you for your time and help with this important project.

Sincerely,

Megan Govindan MPH, MS, RDN, LDN and Cheryl Brown, PhD 
APPENDIX C

Cover Letter for Survey - First Follow up 


\section{Dear Participant,}

This letter is a request for you to take part in a research project to describe food workers specifically produce processors and operations in West Virginia. This project is being conducted by Megan Govindan, a doctoral candidate in the Human \& Community Development program at West Virginia University. The primary mentor of this project is Cheryl Brown, PhD, Associate Professor in the Division of Resource Economics at WVU.

Your participation in this project is completely voluntary, and you are free to withdraw from the research at any time. You must be 18 years of age or older to participate. You may skip any question that you do not wish to answer, and you may discontinue at any time. West Virginia University's Institutional Review Board acknowledgement of this project is on file.

You will be asked to complete a survey and invited to attend a focus group. The survey will take approximately 15 minutes to complete and will be anonymous. It has 45 questions, asks questions related to demographics, food processor practices for employees and operations, marketing practices, and food safety training. The focus group will last approximately 60 minutes and will focus on identifying your needs as a fruit $\&$ vegetable local food processor accessing food safety information.

Your involvement in this project will be kept as confidential as legally possible. All data will be reported in the aggregate. You will not be asked any questions that could lead back to your identity as a participant.

Your participation is greatly appreciated. Participants will be compensated with vouchers for nutrient analysis for their participation. A \$200 value, each voucher allows for the analysis of 5 food products and will provide the processor with the full nutrient breakdown, Food \& Drug Administration Nutrition Facts Panel. Participants can receive a total of 2 vouchers, for analysis of 10 food products.

If you have any questions about this research project, please feel free to contact me at (304) 280-3429, or by email at megan.govindan@mail.wvu.edu. If you have any questions about your rights as a research participant, please contact the WVU Office of Human Research Protection by phone at 304-293-7073 or by email at IRB@mail.wvu.edu.

If you are willing to participate, this letter also serves as your consent to participate in the research. Thank you for your time and help with this important project.

Sincerely,

Megan Govindan MPH, MS, RDN, LDN and Cheryl Brown, PhD 
APPENDIX D

Cover Letter for Survey - Second Follow up 


\section{Dear Participant,}

This letter is a request for you to take part in a research project to describe food workers specifically produce processors and operations in West Virginia. This project is being conducted by Megan Govindan, a doctoral candidate in the Human \& Community Development program at West Virginia University. The primary mentor of this project is Cheryl Brown, PhD, Associate Professor in the Division of Resource Economics at WVU.

Your participation in this project is completely voluntary, and you are free to withdraw from the research at any time. You must be 18 years of age or older to participate. You may skip any question that you do not wish to answer, and you may discontinue at any time. West Virginia University's Institutional Review Board acknowledgement of this project is on file.

You will be asked to complete a survey and invited to attend a focus group. The survey will take approximately 15 minutes to complete and will be anonymous. It has 45 questions, asks questions related to demographics, food processor practices for employees and operations, marketing practices, and food safety training. The focus group will last approximately 60 minutes and will focus on identifying your needs as a fruit \& vegetable local food processor accessing food safety information.

Your involvement in this project will be kept as confidential as legally possible. All data will be reported in the aggregate. You will not be asked any questions that could lead back to your identity as a participant.

Your participation is greatly appreciated. Participants will be compensated with vouchers for nutrient analysis for their participation. A \$200 value, each voucher allows for the analysis of 5 food products and will provide the processor with the full nutrient breakdown, Food \& Drug Administration Nutrition Facts Panel. Participants can receive a total of 2 vouchers, for analysis of 10 food products.

If you have any questions about this research project, please feel free to contact me at (304) 280-3429, or by email at megan.govindan@mail.wvu.edu. If you have any questions about your rights as a research participant, please contact the WVU Office of Human Research Protection by phone at 304-293-7073 or by email at IRB@mail.wvu.edu.

If you are willing to participate, this letter also serves as your consent to participate in the research. Thank you for your time and help with this important project.

Sincerely,

Megan Govindan MPH, MS, RDN, LDN and Cheryl Brown, PhD 
APPENDIX E

Survey Instrument 


\section{Section 1: Demographics}

1. Do you process and prepare fruits \& vegetables in a commercial kitchen in West Virginia?

a. Yes (please continue with survey)

b. No (Thank you for your time. Please submit the survey).

2. What is your gender?
a. Male
b. Female
c. Prefer not to answer

3. What is your age?
a. $18-24$ years old
b. $25-34$ years old
c. 35- 44 years old
d. $45-54$ years old
e. $55-64$ years
f. $65-74$ years old
g. Over 75 years old

4. What is your race and ethnicity?
a. American Indian or Alaskan Native
b. Asian
c. Black or African American
d. Native Hawaiian or Other Pacific Islander
e. White
f. Hispanic
g. Non-Hispanic

5. What is your highest level of education completed?
a. Did not complete High School
b. High School diploma/GED or alternative credential
c. 1 or more years of college, no degree
d. Associates degree (for example: AA, AS)
e. Bachelor's Degree (for example: BA, BS)
f. Master's Degree (for example: MA, MS, MBA, MPH)
g. Doctorate degree (for example PhD, EdD)
h. Other 
6. What is your title in the commercial kitchen facility?
a. Food service worker
b. Food service manager/Supervisor
c. Head chef/Cook
d. Educator/Instructor
e. Other - please specify

\section{Food Processor Practices - Employee Food Safety Training}

7. How many years of experience do you have as a food processor working in a commercial kitchen?
a. Less than 1 year
b. $1-3$ years
c. $4-6$ years
d. $7-9$ years
e. 10 or more years

8. What food safety training have you completed? Select all that apply.
a. Food Handlers Card / Food Workers Card
b. Person in charge training
c. Produce Safety Alliance
d. Better Process Control School
e. Good Agricultural Practice (GAP)
f. Current Good Manufacturing Practices (GMP)
g. ProStart graduate
h. ServSafe Manager credential
i. Professional Degree
i. Culinary
ii. Dietetics
iii. Food Science \& Technology
iv. Foodservice Management
v. Hospitality \& Tourism
vi. Other

9. Do you intend to complete BPCS training in the next year?
a. Yes
b. no

10. What is the size of the staff at your facility?
a. $0-5$ people
b. 6-10 people 
c. 11-20 people

d. $20+$ people

11. What best describes your staff? Select all that apply
a. Volunteer-based
b. Hourly wage
c. Workforce development program
i. $\quad$ ProStart ${ }^{\circledR}$ - High-School
ii. ProStart ${ }^{\circledR}$ - Community / Technical College
iii. ProStart $\AA$ - Residential Foster Care
iv. ProStart ${ }^{\circledR}$ - Juvenile Detention Education Program/ State Correctional Institution/Prison
v. ProStart ${ }^{\circledR}$ - OIEP (Institutional Education Program)
vi. Addiction/Recovery
vii. Agriculture development
d. Retail/Market
e. Culinary/Food Service Management
f. Other

12. What food safety training is required for employees/staff?
a. Food Handlers Card / Food Workers Card
b. Person in charge training
c. Produce Safety Alliance
d. Process Control
e. Better Process Control
f. Good Manufacturing Practices (GMP)
g. ProStart graduate
h. ServSafe Manager credential
i. Professional - Culinary
j. Professional - Dietetics
k. Professional - Foodservice Management
1. Professional - Hospitality \& tourism

13. What processes do the employees/staff conduct? Select all that apply

Examples of "manufacturing/processing" activities included in the definition 


\begin{tabular}{|c|c|}
\hline$\square$ & Baking \\
\hline$\square$ & Boiling \\
\hline$\square$ & Bottling \\
\hline$\square$ & Canning \\
\hline$\square$ & Cooking \\
\hline$\square$ & Cooling \\
\hline$\square$ & Cutting \\
\hline$\square$ & Distilling \\
\hline & $\begin{array}{l}\text { Drying/dehydrating RACs to } \\
\text { ate a } \\
\text { tinct commodity (such as } \\
\text { ing/dehydrating grapes to } \\
\text { duce raisins)* }\end{array}$ \\
\hline$\square$ & Evaporating \\
\hline$\square$ & Eviscerating \\
\hline$\square$ & Extracting juice \\
\hline$\square$ & Formulating \\
\hline$\square$ & Freezing \\
\hline$\square$ & Grinding \\
\hline$\square$ & Homogenizing \\
\hline$\square$ & Irradiating \\
\hline$\square$ & Labeling* \\
\hline$\square$ & Milling \\
\hline$\square$ & Mixing \\
\hline & $\begin{array}{l}\text { Packaging (including modified } \\
\text { osphere packaging)* }\end{array}$ \\
\hline$\square$ & Pasteurizing \\
\hline$\square$ & Peeling \\
\hline$\square$ & Rendering \\
\hline & $\begin{array}{l}\text { Treating to manipulate } \\
\text { ning* }\end{array}$ \\
\hline$\Gamma$ & Trimming \\
\hline & Washing \\
\hline
\end{tabular}

$\square \quad$ Bleaching (e.g., walnuts)

$\square$ Chopping

$\square$ Coating for purposes other than storage/transport (e.g., coating strawberries with chocolate)

- Coloring (e.g., adding color to the skin of oranges)

$\square$ Coring (e.g., in the production of freshcut lettuce)

$\square \quad$ Cracking (e.g., corn)

$\square$ Crushing

$\square \quad$ Extracting oils

$\square$ Extruding

$\square$ Fermenting fruits and vegetables

- Flaking

$\square$ Hulling

$\square \quad$ Infusing

$\square$ Mashing

$\square$ Pearling

a Pelleting

$\square$ Pitting

$\square$ Roasting

$\square \quad$ Salting

$\square \quad$ Shelling

$\square \quad$ Shredding

$\square$ Sifting

$\square$ Slaughtering and post-slaughter operations

$\square$ Slicing

S Smoking

$\square$ Sorting, culling, grading (e.g., as an 
$\square \quad$ Waxing

before
canning)
$\square \quad$ Using pesticides in wash water
$($ e.g., in
the production of fresh-cut lettuce)
$\square \quad$ Wafering
$\square \quad$ Weighing or conveying
ingredients to be used during
manufacturing/processing at the same
facility (e.g., weighing ingredients to
be used in the facility's production of
baked goods)




\section{Section 2: Food Processor Practices - Environment}

14. County(s) where business/organization operates?

15. Is this operation located in a rural or urban area? (Please check one)
a. Rural town (places with fewer than 2,500 people)
b. Urban (places with populations 2,500-49,999)
c. Metropolitan (places with populations greater than 49,999 people)

16. How is the kitchen facility licensed/registered ? (select all that apply)
a. Commercial Kitchen
b. County Health Department - Retail Food Establishment
c. County Health Department - Food Manufacturing Facility
d. Food Manufacturing Facility
e. FDA- Approved Manufacturing Facility
f. Other

17. What is the business structure of the operation? (check all that apply)
a. Sole-Proprietorship
b. Partnership
c. Corporation
d. Small Business Corporation (S Corporation)
e. Limited Liability Corporation (LLC)
f. Non-Profit
g. Social Enterprise
h. Other (please specify)

18. How is the processing facility/kitchen funded?
a. Grants
b. Community-support
c. Rental fees
d. Institutional support (Hospital, College \& University)
e. Public-private partnership
f. Faith-based/Religious organization
g. Other (please specify)

20. Is your operation considered a shared-use kitchen facility?

A shared use kitchen is a food facility that is used as a place of business for the purpose of providing commercial space and equipment to multiple individuals or business entities which commercially prepare or handle food that will be offered for sale" provided. 

a. Yes
b. No

21. Do you have a Food Safety Plan for your facility?
a. Yes
b. No
c. I am not sure

22. If Yes, what elements are a part of your plan?

1. Supply chain program

2. Allergen Control

3. Sanitation Control

4. Process Control

5. Hazard Analysis

6. Recall Plan

\section{Section 3: Marketing Practices}

Direct to Consumer

23. In 2020, did this operation produce and sell any processed products DIRECTLY TO CONSUMERS
a. Yes
b. No

Include

- Farmers Markets

- On-farm store or farm stand located ON this operation

- $\quad$ Roadside stand or store located off this operation

- CSA (Community Supported Agriculture)

- Online marketplace

- Other direct-to-consumer market

(pick your own, mobile market_
Exclude

- Products purchased and resold

- $\quad$ Products produced and sold directly to a retail market, institution or intermediate market.

24. In 2020, did this operation produce and sell any processed products DIRECTLY TO RETAIL MARKET? For example: Did you sell to a grocery store like Kroger or Shop and Save?
a. Yes 
b. No

Include

- $\quad$ Supermarkets or supercenters

- Restaurants or caterers

- $\quad$ Other direct-to-retail market (independently owned grocery stores, food cooperatives, small food stores, corner stores)
Exclude

- $\quad$ Products purchased and resold

- $\quad$ Products produced and sold directly to a consumer, institution, or intermediate market.

25. In 2020, did this operation produce and sell any processed products DIRECTLY TO INSTITUTION? For example: Did you work with a School Foodservice Director or Manager and receive payment from K-12 Schools, colleges, universities or hospitals?

a. Yes

b. No

Include

- $\quad$ K-12 schools

- Colleges and Universities

- Hospitals

- $\quad$ Other direct-to-institution market

(workplace cafeterias, prisons, preschools, food banks, gleaners, senior care facilities)
Exclude

- $\quad$ Products purchased and resold

- $\quad$ Products produced and sold directly to a consumer, retail market, or intermediate.

26. An intermediate market is a business or organization in the middle of the supply chain marketing locally- and/or regionally branded products. For example: Did you sell through Turnrow Appalachian Farm Collective?

In 2020, did this operation produce and sell any processed products DIRECTLY TO INTERMEDIATE MARKET? For example: Did you sell it to a wholesaler who then sold it to another business?
a. Yes
b. No 
Include

- Business or organizations in the middle of the supply chain marketing locally - and/or regionally branded products, such as distributors, food hubs, brokers, auction houses, wholesale, and terminal markets and food processors.
Exclude

- $\quad$ Products purchased and resold

- $\quad$ Products produced and sold directly to a consumer, retail market, or institution - Intermediate markets that do not market locally and/or regionally branded products

27. In 2020, what was this operation's total gross value of food sales for the food it produced and sold directly to consumers, a retail market, an institution, or an intermediate market?
a. $\$ 1-999$
b. $\$ 1,000-\$ 2,499$
c. $\$ 2,500-\$ 4,999$
d. $\$ 5,000-\$ 9,999$
e. $\$ 10,000-\$ 24,999$
f. $\$ 25,000-\$ 49,999$
g. $\$ 50,000-\$ 99,999$
h. $\$ 100,000-\$ 249,999$
i. $\$ 250,000-\$ 499,999$
j. $\$ 500,000-\$ 999,999$
k. Over $\$ 1,000,000$

28. Approximately what percent of this operation's food sales sold directly to consumers, a retail market, an institution, or an intermediate market was sold. Must equal 100\%
a. Direct to Consumer
b. Direct to Retail
c. Direct to Intermediary
d. Direct to Institution

29. Approximately what percent of this operation's food sales was sold directly to consumers, a retail market, an institution, or an intermediate market?
a. Within 100 miles or less
b. More than 100 miles but less than 400 miles
c. 400 miles or more 


\section{Section 4: Share your thoughts on advanced Food Safety Training}

30. In the past 5 have years have you attended any of the following training?
1. Food Handlers Training (_ Yes) (_No)
2. GMP: Good Manufacturing Practices (_ Yes) (_No)
3. GAP: Good Agricultural Practices (_ Yes) (_No)
4. PSR: Produce Safety Rule (_ Yes) (_No)
5. BPCS: Better Process Control School (_ Yes) (_No)

Please answer each question to indicate the extent to which you agree or disagree with the following statements.

31. In the past How likely are you to obtain additional food safety training?
a. Not likely
b. Somewhat likely
c. Very likely

32. What describes your last food safety training experience? My experience was:
a. Very good
b. Good
c. Fair
d. Poor
e. Very poor

33. Food safety training is expensive.
a. Disagree Strongly
b. Disagree
c. Slightly Disagree
d. Slightly Agree
e. Agree
f. Strongly Agree

34. Food safety training takes a lot of time.
a. Disagree Strongly
b. Disagree
c. Slightly Disagree
d. Slightly Agree
e. Agree
f. Strongly Agree 
35. It is difficult to access food safety training.
a. Disagree Strongly
b. Disagree
c. Slightly Disagree
d. Slightly Agree
e. Agree
f. Strongly Agree

36. Food safety training is beneficial to my operation.
a. Disagree Strongly
b. Disagree
c. Slightly Disagree
d. Slightly Agree
e. Agree
f. Strongly Agree

37. Most of my staff thinks I should complete advanced food safety training.
a. Disagree Strongly
b. Disagree
c. Slightly Disagree
d. Slightly Agree
e. Agree
f. Strongly Agree

38. Most of my staff thinks they should complete food safety training.
a. Disagree Strongly
b. Disagree
c. Slightly Disagree
d. Slightly Agree
e. Agree
f. Strongly Agree

39. Generally, I want to complete advanced food safety training.
a. Agree
b. Undecided
c. Disagree

40. I can complete advanced food safety training.
a. Disagree Strongly
b. Disagree 

c. Slightly Disagree
d. Slightly Agree
e. Agree
f. Strongly Agree

42. Food safety training is cost-prohibitive.
a. Disagree Strongly
b. Disagree
c. Slightly Disagree
d. Slightly Agree
e. Agree
f. Strongly Agree

43. Food safety training is difficult to complete.
a. Disagree Strongly
b. Disagree
c. Slightly Disagree
d. Slightly Agree
e. Agree
f. Strongly Agree

44. I can implement advanced food safety protocols in my operation.
a. Disagree Strongly
b. Disagree
c. Slightly Disagree
d. Slightly Agree
e. Agree
f. Strongly Agree

45. I am confident I could complete food safety training successfully.
a. Disagree Strongly
b. Disagree
c. Slightly Disagree
d. Slightly Agree
e. Agree
f. Strongly Agree

47. I could complete additional food safety certification.
a. Disagree Strongly
b. Disagree 

c. Slightly Disagree
d. Slightly Agree
e. Agree
f. Strongly Agree

48. I intend to complete BPCS training in the next 12 months.
a. Disagree Strongly
b. Disagree
c. Slightly Disagree
d. Slightly Agree
e. Agree
f. Strongly Agree 
APPENDIX F

Focus Group Facilitation Outline 


Activity description

Summarize the intent of the meeting to gather perspectives and understand the needs of food processors and food producers as it relates to food safety outreach education.

Explain the answers will be recorded and how they will be used.

Introduction/Check In:

This allows participants to speak and establish equality of participation in the group. The recorder documents a bulleted list of responses.
Facilitation guide and question

Read narrative provided. Detail ground rules

and what to expect in the focus group.

Describe the anticipated outcomes.

(8 minutes) *

Participants introduce themselves and respond to the question:

Share something you like most about processing and selling food in West Virginia. (12 minutes) * 


\section{Key Questions:}

These questions are the heart of the focus group. They will deserve thoughtful analysis.

Note: Recorder documents responses. Create a list of pressing issues (question\#2) for prioritization.
As you think about food safety outreach education:

1. How do you currently access food safety rules and regulations for food processing? (8-10 minutes) *

2. What would you say the most pressing issues for food processors are in the next year?

3. How do these issues affect your ability to process and sell food in WV?

(20 minutes) *

4. Based on your experiences processing food, what barriers have prevented us from addressing these issues?

5. What type of information or educational resources would help to address the issues?

6. What formats would you like to see used to deliver these resources? 
Closing questions:

This is an opportunity to recap information raised in the focus group. Instruct participants that they are going to prioritize issues for food safety outreach education.

Consolidate issue responses so you have a list of issues without duplication.

Utilize the Zoom poll option to survey participants. Participants will be asked to identify their top 3 long term issue priorities by using the poll anonymously.

Utilize the Zoom poll option to survey participants a second time. For this second round, ask participants to identify the issues they see as most important to address in the short term.
7. Given everything that we have discussed, what final thoughts would you add on improving food safety outreach education materials for food producers and processors in WV?

(2 minutes) *

Prioritization:

Using the numbered dots, identify what you believe are the top 3 long-term issues that are most important to address in the next 4 years.

With a second color dot, indicate the issue that is most immediate to address right away. (8 minutes) *

Wrap up: Thank participants, ask if they would like a final report of findings.

(10 minutes) * 
APPENDIX G

Initial Focus Group Codes 
Focus group codes:

- Strengthening community understanding

- Circle of life

- Emotional aspects of the work

- Empowerment and power

- Resource use: Wasted money, Wasted food

- Lack of clarity in rules and regulations

- Paralysis in advancing business

- Upward mobility

- Lack of understanding jargon

- Relationships, community and networks

- Cost, subsidy, availability

- Rural landscape and driving distance

- Smallholders

- Lack of opportunities in West Virginia

- Meeting needs of stakeholders

- Opportunities for individuals and families

- inherited knowledge

- Centralized information

- Motives and drivers of engaging in food processing labor 


\section{APPENDIX H}

Food Safety Outreach Program Development and Program Evaluation:

The House Food Safety Program for Microprocessors 


\section{Developing an Adult Education Program}

The HOUSE food safety outreach program for food processors operating in commercial kitchens, was developed using the PRECEDE-PROCEED Model (Green \& Kreuter, 2005). PRECEDE-PROCEED is an acronym for Predisposing, Reinforcing, and Enabling Constructs in Educational Diagnosis and Evaluation. Policy, Regulatory, and Organizational Constructs in Educational and Environmental Development. This programming model was selected due to its operational context engaging adult learners in professional program planning. The model is used for adult learner groups, professional program, designers and cooperative extension to focus on non-formal education. It provides guiding themes for participant-driven planned change, social system assessment and is best utilized as a framework for Extension personnel to engage participants and work backwards from desired outcomes, to determine appropriate strategies for the design, implementation and evaluation of the program (Green \& Kreuter, 2005).

PRECEDE (Predisposing, Reinforcing, and Enabling Constructs in Educational Diagnosis) outlines a diagnostic planning process to assist in the development of targeted and focused public health programs. PROCEED (Policy, Regulatory, and Organizational Constructs in Educational and Environmental Development) highlights the implementation and evaluation of the intervention designed in the PRECEDE component. The PRECEDE-PROCEED planning model informs design, anddesign and applies theory-based strategy that has the potential to be effective and sustainable in this population.

Phase 1 - Social Assessment. In this planning phase, a social assessment was completed, with multiple data collection activities including participation in focus groups with the Farmers Market Association, engagement at three annual PAD summits, and feedback from planning coordinators from Extension agents and the WV Department of Agriculture. This phase worked to articulate the community's needs and desires, and considered the community members' problem-solving capacity, strengths, resources, and readiness to change. A social assessment is the "application, through broad participation, of multiple sources of information, both objective and subjective, designed to expand the mutual understanding of people regarding their aspirations for the common good" (Green \& Kreuter, 2005, p.105). This phase identified the ultimate result $-\mathrm{a}$ food safety outreach program that builds infrastructure and upward mobility for $\mathrm{WV}$ food processors, addresses the knowledge gap in processing foods and barriers to market. Barriers identified included high start-up and input costs, high processing costs, obtaining recommended certifications, knowledge of food safety regulations, rural environments and packaging and quality control standards. 


\section{Figure 5}

The PRECEDE-PROCEED Planning Model

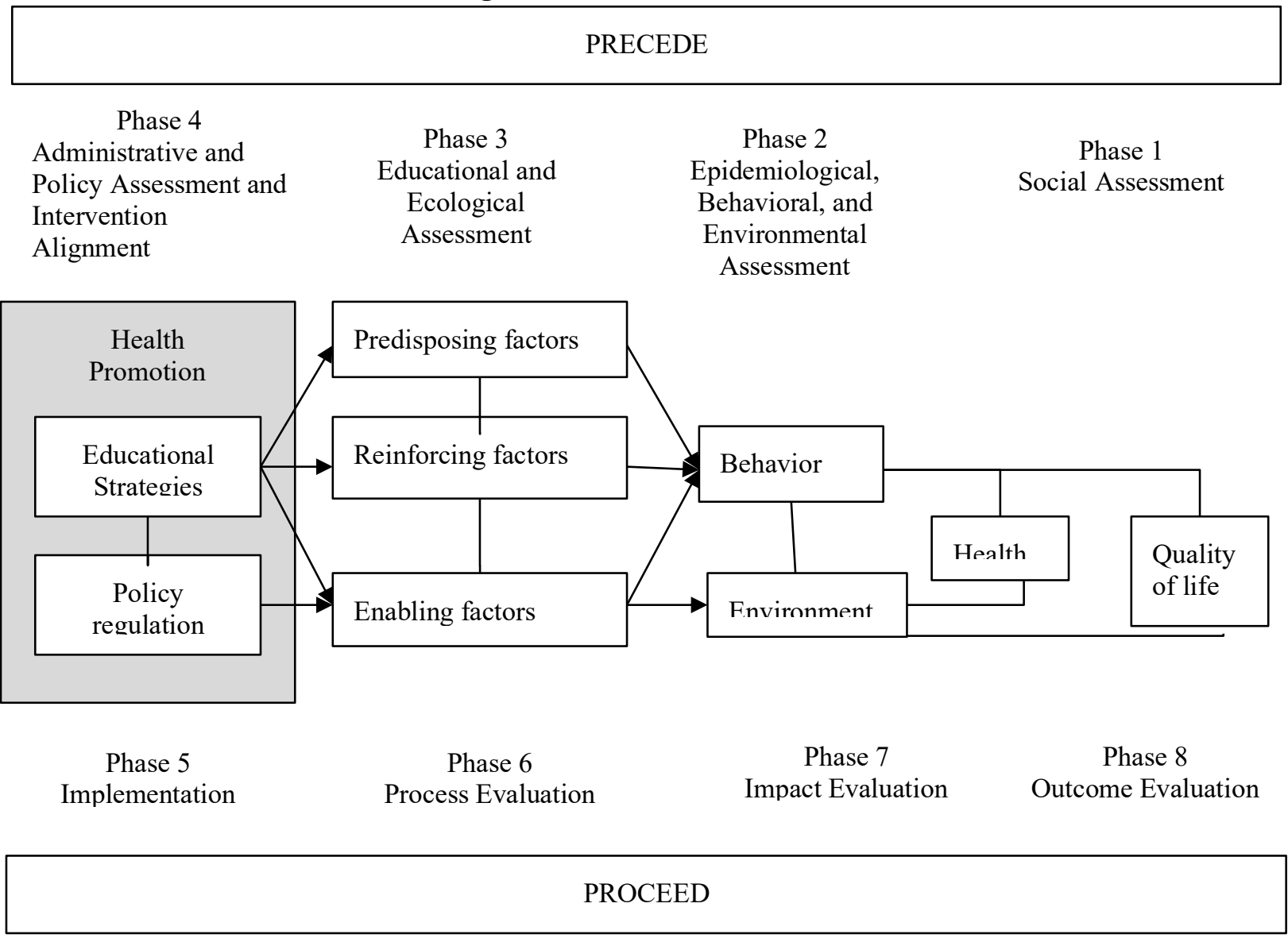

PRECEDE (Predisposing, Reinforcing, and Enabling Constructs in Educational Diagnosis) The PRECEDE portion of the model starts with activities that identify desirable outcomes or goals of the intervention, an intervention and has two main steps and four phases informing the design.

Phase 2 - Epidemiological Assessment, Behavioral Determinants and Environment. This phase set priorities, and determined epidemiological, behavioral, and environmental factors that may have an impact on the food processing and success of food processors. In this phase, the epidemiological assessment identified the problem, uncovered behavioral and environmental factors likely to influence the issue and translated those priorities into measurable objectives for the program being developed (Green and Kreuter, 2005). As the demand for locally produced foods increases in the state, producers and processors are eager to take advantage of new opportunities for income generation. Due to FSMA regulations, processors regardless of size may need to comply with FDA approved educational requirements like BPCS training. Given the federal mandates and the economic opportunity at hand from the WV Fresh Food Act, barriers to 
this behavior, such as time and perceived difficulty, must be addressed. The lack of state-specific food safety resources and Process Control authority are a limiting factor to growth of the agricultural sector. Targeting rural environments and non-profit commercial kitchens with resources can promote food safety, and safety and increase economic opportunities for food producers and processors. This program seeks to address environmental factors (lack of Process Control Authority and economic opportunity posed by WV Fresh Food Act and WV Cottage Food Act), by engaging existing food processors operating in non-profit commercial kitchens, to complete food safety training (BPCS) to process acidified and low acid foods, through open source approved processes, known as HOUSE recipes. Facilitation of the HOUSE program will lead to decreased risk of food borne illness, and increased value-added production.

Phase 3: Educational and Ecological Assessment. This phase identifies modifiable factors that can result in behavior change, and change and sustain the change process. This is done through identification of predisposing, enabling and reinforcing factors. Predisposing factors are antecedents to behavior that provide the rationale or motivation for the behavior. These include food safety education/training, understanding federal and state rules and regulations, and understanding of the implications of food borne illness outbreaks. Reinforcing factors following a behavior were also identified. These provide continuing reward or incentive for the persistence or repetition of the behavior. These include economic opportunities associated with producing value-added products, recognition in the WV Grown program, decreasing food waste, and increasing access to safe, local, nutritious foods. Enabling factors are antecedents to behavior or environmental change that allow a motivational or environmental policy to be revalued. The new skills necessary for behavioral and environmental outcomes to be realized include understanding of federal and state rules and regulations, and why these are in place to decrease the likelihood of food borne illness outbreaks. Programs and services that are necessary must provide guidance on how to be in compliance with these rules and regulations, and regulations and address the lack of services related to Better Process Control authority in the state.

Phase 4: Intervention Alignment and Administrative and Policy Assessment. This phase identified resources, organizational barriers and facilitators, and policies needed for strategy or intervention implementation and sustainability. On the MACRO level, the researcher reviewed organizational and environmental systems that can affect the desired outcomes. This included administrative and policy assessment, to identify administrative policy factors that can affect the desired outcomes. West Virginia's Fresh Food Act presents new opportunities to grow the agriculture sector by increasing institutional demand for local food products. As producers scale up to meet this demand, there is an increased need for other outlets for seconds (ungraded produce). These food products are typically processed into value- added products, and can engage co-packers using approved processes, verified by a Process Control Authority. West Virginia has one co-packer in the state, and does not have any public, shared-use rental kitchen 
facilities. The state also lacks a Process Control Authority, this directs food entrepreneurs to access these services out of the state, costing them more time and money. The West Virginia Cottage Food Act now permits home kitchens to process acidified and low acid foods provided they undergo a home-kitchen inspection and have access to approved processes verified by a Process Control Authority. The lack of the Process Control Authority in the state, and resources presents a limiting factor in the growth of the agriculture industry in the state, despite the opportunities presented by the Fresh Food and Cottage Food Act.

On the MICRO level, the researcher reviewed individuals, peers, family and others who can influence the audience's behavior more directly. These affect predisposing, reinforcing, and enabling factors. These priorities were translated into measurable objectives for the program being developed (Green and Kreuter, 2005). The West Virginia Farmers Market Association engages farmers markets across the state, and facilitates education and outreach through the Learning Information Exchange program. This connects producers, market managers, and processors with a learning community, to build upon educational programs delivered by WVU Extension and the WV Department of Agriculture. West Virginia is a rural state, and the majority of its 1.8 million residents live in communities of less than 2,500 people (source?). Approximately two-thirds of West Virginians live in rural areas, and food deserts are a growing problem as community grocery stores close and are replaced with big box stores that may require long distance travel, or stores such as Family Dollar which offer a limited supply of healthy foods. Farmers markets represent a lifeline to accessing healthy food, and utilizing resources from income-based food access programs such as SNAP. Objectives identified that seek to address predisposing, reinforcing, and enabling factors include;:

a) Identify organizational and environmental systems that could affect the desired outcomes enabling factors.

b) Identification of administrative and policy factors that influence what can be implemented is evaluated.

c) Conduct an administrative diagnosis of reviewed resources, policies, budgetary needs, and organizational situations that could hinder or facilitate the development and implementation of a strategy or program (Glanz, 2008).

\section{PROCEED (Policy, Regulatory, and Organizational Constructs in Educational and Environmental Development)}

Educational and Environmental Development. This phase involved the application of the PROCEED framework (Policy, Regulatory, and Organizational Constructs in Educational and Environmental Development). At this point of the intervention, the data collection tools were developed. The PROCEED component recognizes the importance of environmental factors as determinants of healthy behaviors. 
The aim of the HOUSE program is to provide information and guidance to new and beginning food processors in West Virginia to promote an understanding and adoption of safe food processing compliant with the Food Safety Modernization Act. This project will target food processors operating in non-profit commercial kitchens, as well as producers, who may want to understand how to process their produce themselves.

By engaging the West Virginia Farmers Market Association, the HOUSE program connects commercial kitchen environments and food processors to resources to produce value-added foods, focusing on "HOUSE" recipes. Combining food safety outreach and local food promotion, the HOUSE program represents a community of kitchens, sharing recipes, resources, experiences and mentorship. The HOUSE program accommodates the barriers food processors experience in accessing kitchen space, recipes, recipe approval by an authorized process authority, labeling, nutrition facts panel generation, and a community of learning around local food processing. By addressing these barriers, the project aims to increase access to local food in the state. House

HOUSE recipes include shelf-stable, acidified foods. Each recipe has been converted to scaleappropriate product formulations, has established appropriate food safety controls, and all product formulas have been reviewed by a regulatory Process Authority to issue a validated scheduled process for commercial use using specialty crops. In order to maintain process control, all kitchens must register and verify completion of Better Process Control School, to show they are compliant with the FDA Food Modernization Act. All processors are submitted to the WV Department of Agriculture WV Grown program on an annual basis. All products have uniform labeling and marketing using resources from the WV Farmers Market Association. Data collection tools were designed to assess the program objectives;:

- Adoption of improved food preparation, processing, and handling practices at the individual, operation and supply system levels will result in fewer incidents of food borne disease, thereby both saving lives and improving economic sustainability of operations.

- Increasing the use of locally produced food will help maximize food quality, sustainability, and safety by minimizing long distance transport.

- Improved food safety efforts will increase the access of limited-resource families and communities to local, safe, nutritious, and affordable foods.

\section{Phase 5: Implementation framework and Pilot Study}

This phase presents a description of the implementation of the educational program developed. The HOUSE program will be piloted in five counties identified by the WV Farmers Market Association. Shown in Table 17, these counties and non-profits were selected due to participating in aggregating and distribution activities, as well as having food processors that had already reported they had completed Better Process Control School. 
Table 17

HOUSE Pilot-Participating Non-Profit Organizations

\begin{tabular}{ll} 
Non-Profit Name & Location \\
\hline ACCESS WV & Wayne, WV \\
Greenville Farm Kitchen & Greenville, WV \\
Heart \& Hand House & Phillippi, WV \\
Wardensville Garden Market & Wardensville, WV \\
Wild Ramp & Huntington, WV \\
\hline
\end{tabular}

After the pilot test of the HOUSE program, the West Virginia Farmers Market Association will coordinate further recruitment and expansion of the program. Farmers Market Managers will be points of contact for the program, recruiting and advertising for the program. A logic model of the HOUSE program is shown in Figure 6, and results of application of the PRECEDEPROCEED Model is shown in Figure 7.

\section{Figure 6}

Logic Model: The HOUSE Program

\begin{tabular}{|c|c|c|c|}
\hline $\begin{array}{c}\text { Inputs } \\
\text { What we invest }\end{array}$ & $\begin{array}{c}\text { Outputs } \\
\text { Activities } \\
\text { What we do }\end{array}$ & $\begin{array}{c}\text { Outputs } \\
\text { Participants } \\
\text { Who we reach }\end{array}$ & $\begin{array}{c}\text { Outcomes } \\
\text { Impact } \\
\text { Short - medium - } \\
\text { long }\end{array}$ \\
\hline $\begin{array}{l}\text { Staff } \\
\text { WV Farmers Market } \\
\text { Association } \\
\text { WVU Extension staff } \\
\text { WV Department of } \\
\text { Agriculture } \\
\underline{\text { Time }} \\
\text {-pre/post engagement }\end{array}$ & $\begin{array}{l}\text { Engage WVU } \\
\text { Entrepreneurial Legal } \\
\text { clinic for MOUs } \\
\text { Promote outlet for } \\
\text { ungraded and seconds } \\
\text { produce }\end{array}$ & $\begin{array}{l}\text { WV Farmers Market } \\
\text { Association } \\
\text { WV Farmers Market } \\
\text { Managers }\end{array}$ & $\begin{array}{l}\text { HOUSE facilitation } \\
\text { through WVFMA } \\
\text { Learning Information } \\
\text { Exchange program } \\
\text { Targeted food safety } \\
\text { outreach } \\
\text { programming } \\
\uparrow \text { food processing } \\
\text { acknowledging food }\end{array}$ \\
\hline
\end{tabular}




\begin{tabular}{|c|c|c|c|}
\hline $\begin{array}{l}\frac{\text { Money }}{\text { - BPCS curriculum }+} \\
\text { payment of trainers } \\
\frac{\text { Materials }}{\text {-open source }} \\
\text { processes (house } \\
\text { HOUSE recipes) } \\
\text {-website } \\
\text { Equipment } \\
\text {-stockpots, jars, labels }\end{array}$ & $\begin{array}{l}\text { in state } \\
\text { Food safety training } \\
\text { verification } \\
\text { Recruit commercial } \\
\text { kitchens to engage in } \\
\text { the HOUSE program } \\
\text { Food safety training } \\
\text { on labeling, making } \\
\text { and selling low-acid, } \\
\text { acidified foods }\end{array}$ & $\begin{array}{l}\text { BPCS trained } \\
\text { processors } \\
\text { BPCS trained } \\
\text { processors and shared } \\
\text { use kitchen operators } \\
\text { BPCS trained } \\
\text { processors and shared } \\
\text { use kitchens }\end{array}$ & $\begin{array}{l}\text { safety } \\
\downarrow \text { food waste } \\
\text { increased seconds } \\
\text { market } \\
\text { increased } \\
\uparrow \text { FSMA compliant } \\
\text { processors } \\
\uparrow \text { co- packing services } \\
\text { for producers and } \\
\text { processors } \\
\uparrow \text { in BPCS food } \\
\text { processors making } \\
\text { HOUSE recipes } \\
\uparrow \text { local food sales } \\
\uparrow \text { economic growth in } \\
\text { agriculture sector }\end{array}$ \\
\hline
\end{tabular}

\section{Phase 6, 7 and 8: Process, Impact and Outcome evaluation}

The researcher proposes that the program be implemented over a 10 month10-month period, with pre and post engagement components. Recruitment and onboarding of the program will take place February - April. The program will be facilitated during the active growing months of May - September. Program evaluation and close out will occur October - November. Process evaluation activities are shown in Table 18. 


\section{Figure 7}

Application of the PRECEDE-PROCEED to food safety outreach education via the HOUSE program

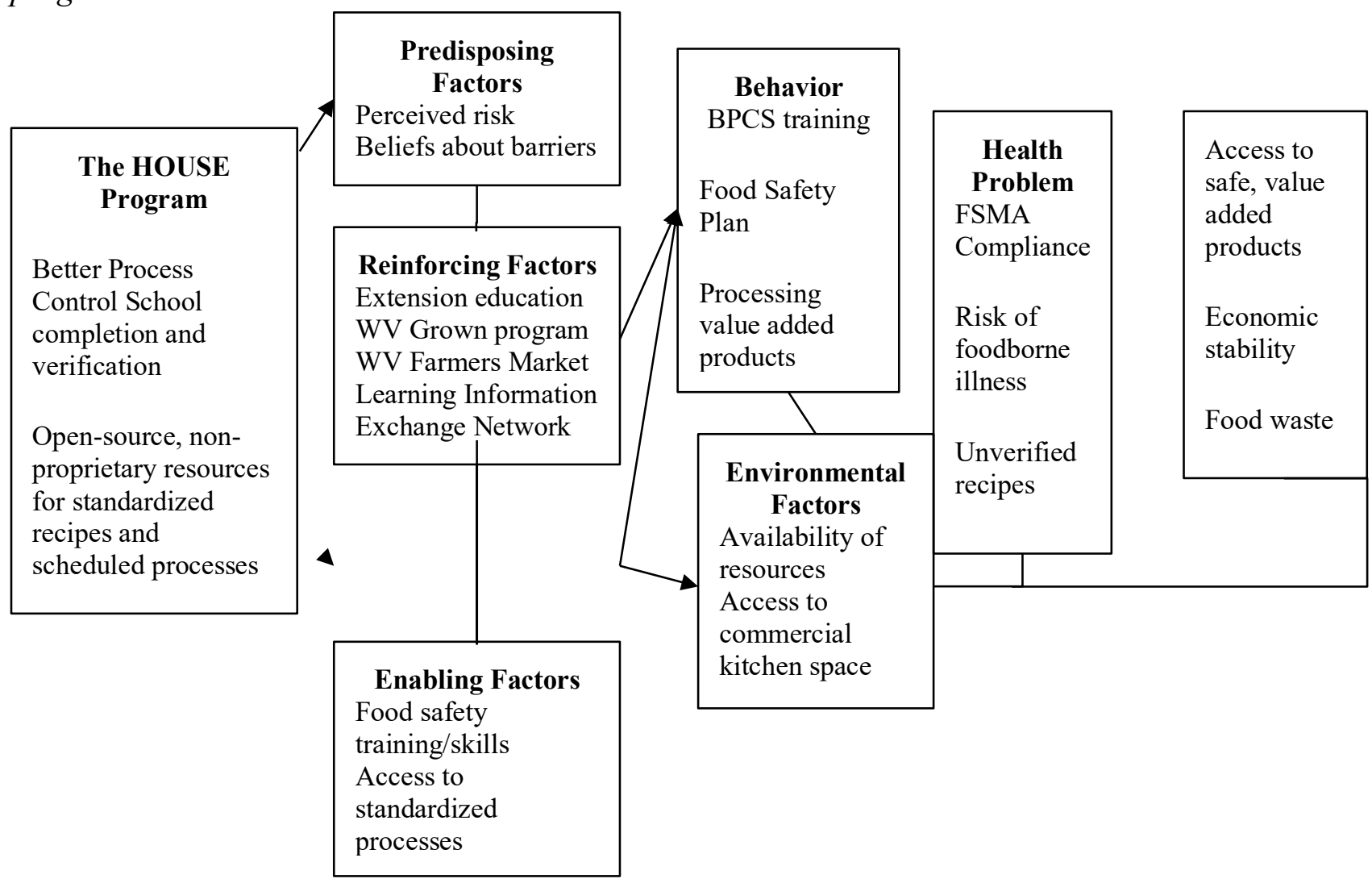




\section{Table 18}

Process Evaluation for HOUSE Program

\begin{tabular}{|c|c|c|}
\hline Pre-program (February-April) & Program (May-September) & $\begin{array}{l}\text { Post -program (October- } \\
\text { November) }\end{array}$ \\
\hline Pamphlet circulation & Product label printing & Sales record \\
\hline On-boarding survey & Monthly calls & Post-participation survey \\
\hline Recipe selection & Sales record & Production plan feedback \\
\hline Confirm food safety training & Recipe package released & \\
\hline \multicolumn{3}{|l|}{ Memorandum of } \\
\hline Understanding & & \\
\hline
\end{tabular}

At the end of the program, in December, an impact evaluation will be conducted. Impact evaluation data performance indicators are shown in Table 19. In order to understand if these impacts align with the desired outcome, an outcome evaluation will be conducted. The outcome evaluation will assess if the intervention is leading to the desired result. It will identify what the effect of the program is on participants, the environments, and the agricultural system.

\section{Table 19}

\section{Impact Evaluation and Outcome Evaluation}

Strategic objectives

Adoption of improved food preparation, processing, and handling practices at the individual, operation and supply system levels will result in fewer incidents of food borne disease, thereby both saving lives and improving economic sustainability of operations.

Increasing the use of locally produced food will help maximize food quality, sustainability, and safety by minimizing long distance transport.
Performance indicators

\# of BPCS trained processors

\# of kitchens participating

\# of sublease agreements

\# of pounds of local produce

processed

Economic Impact 
Improved food safety efforts will increase the access of limited-resource families and communities to local, safe, nutritious, and affordable foods.
\# of farmers markets participating

\# of products entered into the market

Stakeholders will be engaged in the evaluation process. Stakeholders are individuals or organizations that will be affected in some significant way by the outcome evaluation process, or that are affected by the performance of the intervention, or both. These stakeholders will be affected by the HOUSE program, and the availability of the HOUSE components shown in Table 21.

\section{Table 20}

Stakeholders of the HOUSE Program

\begin{tabular}{|c|c|}
\hline Stakeholder & Needs \\
\hline $\begin{array}{l}\text { WV Producers } \\
\text { and Food } \\
\text { Processors }\end{array}$ & $\begin{array}{l}\text { Access to kitchen facilities, second market for ungraded produce, } \\
\text { recipe processes that are approved by Better Process Control } \\
\text { Authority, access to labeling and nutrition facts panel generation. }\end{array}$ \\
\hline $\begin{array}{l}\text { WV Department } \\
\text { of Agriculture }\end{array}$ & $\begin{array}{l}\text { Inform policy related to Cottage Food Law and WV Fresh Food Act. } \\
\text { Support farmers, food entrepreneurs, and food processors with WV } \\
\text { Grown program and agriculture marketing division. Verifies process } \\
\text { control documents for WV Grown program and pays for cost share of } \\
\text { BPCS training. Staff participates in the state Food Safety Team. }\end{array}$ \\
\hline WVU Extension & $\begin{array}{l}\text { Develop, deliver and evaluate education and outreach for producers, } \\
\text { processors and agri-service providers. Provides FSMA compliance } \\
\text { training in conjunction with WVDA for FDA Produce Safety Rule. } \\
\text { Staff participates in the state Food Safety Team. }\end{array}$ \\
\hline $\begin{array}{l}\text { Food } \\
\text { Procurement } \\
\text { Agents }\end{array}$ & $\begin{array}{l}\text { Purchase food for institutions, identify products and quantities in } \\
\text { demand. }\end{array}$ \\
\hline $\begin{array}{l}\text { WV Farmers } \\
\text { Market } \\
\text { Association }\end{array}$ & $\begin{array}{l}\text { Education and outreach to producers, processors through the Learning } \\
\text { Information Exchange program, and facilitate direct to consumer } \\
\text { markets across the state. }\end{array}$ \\
\hline
\end{tabular}


HOUSE Components and Recipes

\section{Recipe Package}

1. Scheduled Process Review Letter

2. FDA Food Process Filing for acidified food

3. Standard Operating Procedure

4. Standardized Recipe

5. Customized Label: Includes processing information, ingredient list, and Nutrition Facts Panel

6. Memorandum of Understanding

\section{Current Recipes}

1. Grammy McIntyre's Apple Butter

2. Baker's Bread \& Butter Pickles

3. Harry's Diced Tomatoes

4. Dr. Brown's Hot Sauce

5. Rockin' Ruthie's Dill Relish

6. Dr. Debby's Pickled Beets

7. Tom's Dilly Beans

8. Ida \& Matt's Pickled Radish

9. Patti's Pickled Turnip

10. Ani's Pickled Zucchini 


\section{VITA}

\section{Megan Govindan MPH, MS, RD, LD}

Govindan.Megan@gmail.com

\section{EDUCATION}

PhD, Human \& Community Development, 2021

Examining the perceptions of produce processors operating in non-profit commercial kitchens in West Virginia

Davis College of Agriculture, Natural Resources \& Design

West Virginia University - Morgantown, WV

\section{M.P.H. Public Health - Social \& Behavioral Sciences, 2009}

Practicum: Developing a nutrition education program for low income mothers

School of Public Health

West Virginia University - Morgantown, WV

\section{R.D. Registered Dietitian, 2008}

Commission on Dietetic Registration

Dietetic Internship - West Virginia University - Morgantown, WV

\section{M.S. Animal \& Nutritional Sciences, 2008}

Thesis: Youth health promotion in West Virginia: The Helping H.A.N.D. Program

Davis College of Agriculture, Natural Resources \& Design

West Virginia University - Morgantown, WV

B.S. Family \& Consumer Sciences, Human Nutrition \& Foods, 2006

Davis College of Agriculture, Natural Resources \& Design

West Virginia University - Morgantown, WV

\section{PROFESSIONAL APPOINTMENTS}

Director of Community Leadership \& Social Action August 2019 - present

Director of the Health Equity Lab

Service Instructor

Center for Resilient Communities

Eberly College of Arts \& Sciences

West Virginia University

Teaching Associate Professor, Human Nutrition \& Foods August 2013 - June 2019 Davis College of Agriculture, Natural Resources \& Design

West Virginia University

Summer Visiting Assistant Professor - Hospitality \& Tourism June 2013 - 2018 John Chambers College of Business \& Economics

West Virginia University 
Director, Didactic Program in Dietetics

January 2012- August 2017

Davis College of Agriculture, Natural Resources \& Design

West Virginia University

Director - Individualized Supervised Practice Pathway

Davis College of Agriculture, Natural Resources \& Design

West Virginia University

Teaching Assistant Professor, Human Nutrition \& Foods

Davis College of Agriculture, Natural Resources \& Design

West Virginia University

Graduate Teaching Assistant - Human Nutrition \& Foods August 2006-May 2008

School of Agriculture \& Food

Davis College of Agriculture, Natural Resources \& Design

West Virginia University

May 2012-August 2015

August 2008 - July 2013

August 2006-May 2008

\section{TEACHING EXPERIENCE}

A primary pedagogical goal of mine is to integrate lessons with service-learning experiences to allow students the opportunity to go beyond the book. I have demonstrated teaching effectiveness in-person and online and through small and large lecture format at a 4/4/4 course load. Course descriptions shown below.

Professional Field Experience - Geography: Prearranged experiential learning program, to be planned, supervised, and evaluated for credit by faculty and field supervisors. Involves temporary placement with public or private enterprise for professional competence development.

Community Research and Social Action; Seminar and field experience for students in the Community Leadership \& Social Action Fellowship. Leadership development, applied action research with community partners.

Orientation to Human Nutrition \& Foods: Engages students in active learning strategies that enable effective transition to college life at WVU. Students will explore school, college and university programs, policies and services relevant to academic success. Provides active learning activities that enable effective transition to the academic environment.

Introduction to Nutrition: Nutrient structure, metabolism, integrated function and their importance to human well-being during all stages of the life cycle. Current concerns and those of special interest to college students in meeting nutrient needs.

Honors - Introduction to Nutrition: Students in Honors Program and consent by the honors director. Independent reading, study or research.

Community Nutrition: Beginning planning for community nutrition to individuals and families 
at various stages of the life cycle. Roles of concerned agencies and professional groups. Clinical experience in community facilities.

Contemporary Issues In Nutrition. Contemporary issues in nutrition including a critical review of food practices and recent trends in nutrition.

Dietetic Internship Application Course. Understanding dietetic internship match and the profession of dietetics.

Foodservice Systems Management: Principles of quantity food production management: production schedules, portion control, financial management, layout and equipment planning, evaluation of alternative systems, and computer applications.

Independent Study: Faculty supervised study of topics not available through regular course offerings.

Nutrition Lab Experimentation. Nutrient analysis and introduction to nutrition experimentation; nutritional assessment.

Professional Field Experience in Nutrition: Prearranged experiential learning program, to be planned, supervised, and evaluated for credit by faculty and field supervisors. Involves temporary placement with public or private enterprise for professional competence development.

Senior Seminar in Nutrition: The course provides an integrative approach to various topics related to the practice of dietetics by challenging students to read, critique/evaluate, present, and discuss current research.

\section{CURRICULUM DEVELOPMENT}

I have spearheaded curriculum development at the undergraduate, graduate and professional levels, designing courses, minors, field experience rotations and professional educational tracks.

Geography Engagement Program- Immersive professional development opportunities for undergraduate students with community-based preceptors.

Community Leadership \& Social Action Fellowship - Preparation for social action research, with applied action research focus engaging grassroots organizations in Appalachia.

Introduction to Supervised Practice - Dietetic Internship preparation course for onsite and offsite interns.

Integrative and Functional Nutrition - Curriculum design for online course.

Nutrition Across The Lifecycle - Developed curriculum, student learning outcomes and assessment for online delivery. 
Nutrition \& Physical Assessment - Redesigned face to face course for online delivery.

Food Systems Practicum - Developed field experiences related to food manufacturing, food processing, labeling, and marketing local foods.

Sports Nutrition Practicum - Developed field experience with campus partners for foodservice management and nutrition education.

Culinary \& Lifestyle Medicine Track - Assisted in the development of Liaison Committee on Medical Education track for culinary and lifestyle medicine for WVU Medicine.

Minor in Nutrition \& Food Studies - Developed minor, student learning outcomes and curriculum assessment map.

Minor in Food Service Management. Developed minor, student learning outcomes and curriculum assessment map.

\section{COMPETITIVE GRANT FUNDING AWARDED}

2020 \$500,000 United States Department of Agriculture - National Institute of Food and Agriculture, Rapid Response to Novel Coronavirus (SARS-COV2): Innovating Formal and Non-Formal Educational Experience in Food and Agricultural Sciences During the Time of Social Distancing AFRI Priority Area Program - Primary Investigator

2018 \$148,462 United States Department of Agriculture - National Institute of Food and Agriculture - Food Safety Outreach Grant. The Commercial Home and Incubator Kitchens and Food Producers Projects - Primary Investigator

$2016 \quad \$ \mathbf{\$ 1 0 , 0 0 0}$ CSX Transportation Healthy Food Grant

2016 \$4,000 Share our Strength: Cooking Matters at the Store Grant

2013 \$1,000 West Virginia University - Choose to Change Mini-Grant

$2012 \$ \mathbf{\$ 5 0 0} \quad$ American Dietetic Association - Kids Eat Right Grant

$2011 \quad \$ \mathbf{5 0 0} \quad$ American Dietetic Association - Kids Eat Right Grant

2008 \$10,000 General Mills Champions for Healthy Kids Grant 
(2020-present).

President, West Virginia Academy of Nutrition \& Dietetics (2019-2020).

President-Elect, West Virginia Academy of Nutrition \& Dietetics (2018-2019).

President of the Board, Conscious Harvest Cooperative (2019-present).

Executive Committee, West Virginia Academy of Nutrition \& Dietetics (2018-present)

Committee Member, National Farm to Institution Collaborative Steering Committee, (2018-present).

Steering Committee Member, West Virginia Farm to School Strategic Plan, (2018-present).

West Virginia Food Safety Team Member, West Virginia University Extension, West Virginia State Extension, and WV Department of Agriculture (2018-present).

Summer Faculty Member, West Virginia Health Sciences \& Technology Academy (June 2013 - present).

Committee Member - Carnegie Service Classification Committee at West Virginia University (2018-2019)

Accreditation Lead, West Virginia University Didactic Program in Dietetics for program accreditation through the Accreditation Council for Education in Nutrition \& Dietetics (20082017).

Dietetic Internship Preceptor, West Virginia University, Culinary Medicine, Community Nutrition, Institutional Food service, Sustainable, Resilient, Healthy Food and Water Systems rotations. (2015-2019).

Dietetic Internship Preceptor, Community Nutrition, Institutional Food service, Sustainable, Resilient, Healthy Food and Water Systems rotations. Marshall University (2017-2019).

Trainee, Whole Measures for Community Food Systems Training, facilitated by Value Cluster Chain Initiative (2017).

Faculty Steering Committee - Center for Service \& Learning at West Virginia University (2014-present).

Faculty Advisor, West Virginia University - Community of Practice Group - Culinary and Lifestyle Medicine (2017-2019).

Faculty Advisor, West Virginia University - Food Recovery Network (2017-present).

Faculty Advisor, West Virginia University -Student Association of Nutrition \& Dietetics (2008- 
2019).

Faculty Advisor, West Virginia University -Phi Upsilon Omicron - Lambda Chapter (20082019).

Mid-Block Instructor, Culinary Medicine - Med Chef Rotation, West Virginia University School of Medicine (2014-2018).

Council on Professional Issues West Virginia Academy of Nutrition \& Dietetics (2017-2018).

Committee Member - Diversity Committee at West Virginia University Davis College of Agriculture, Natural Resources \& Design (2014-2018).

Council on Professional Issues - Elect, West Virginia Academy of Nutrition \& Dietetics (2016-2017).

Committee Member - H.E. Kidder Scholarship Committee at West Virginia University Davis College of Agriculture, Natural Resources \& Design (2008-2017).

Student Relations/Career Guidance Chair - West Virginia Academy of Nutrition \& Dietetics (2015-2016).

Chair of National Nutrition Month Committee, West Virginia Academy of Nutrition \& Dietetics (2012-2016).

Nominating Committee Chair - Academy of Nutrition \& Dietetics - Nutrition Educators of Health Professionals. (2012-2013).

\section{HONORS AND AWARDS}

2019 West Virginia University - I Heart Demo Day - 3rd place - Conscious Harvest

2019 West Virginia University - Nick Evans Faculty Advising Excellence Award Nominee

2017 Academy of Nutrition and Dietetics - Marianne Smith Edge Award

2017 Academy of Nutrition and Dietetics - Hunger and Environmental Didactic Practice Group - Award for Leadership in Hunger and Environmental Nutrition

2017 Empty Bowls Monongalia County - Service Award

2017 West Virginia University - Climb Higher Nominee

2016 West Virginia University - Women and Gender Studies: Alma and Claude Rowe Excellence through Equity Award

2016 West Virginia University - Nick Evans Faculty Advising Excellence Award Nominee

2016 Hunger and Environmental Nutrition Didactic Practice Group - Speakers 
Bureau Award

2011 West Virginia University - Davis College of Agriculture, Natural Resources and Design - Outstanding Teacher Award

2010 President's Volunteer Service Award

2008 West Virginia Dietetic Association's Outstanding Dietetic Intern

2008 West Virginia Dietetic Association Educational Scholarship

FOOD SAFETY TRAINING

2019 Produce Safety Alliance - PSA Grower Training Course

2019 Good Manufacturing Practices

2018 Food Safety Preventive Controls Alliance: Preventative Controls for Human Foods

2018 Canned Foods, Principles of Thermal Process Control, Acidification and Container Closure for Acidified Foods, Glass. Flexible \& semi rigid containers.

2010 National Restaurant Association Education Foundation - ServSafe Manager and ManageFirst Instructor and Proctor

\section{FOOD ACCESS TRAINING}

2019 WVU Food Justice Lab - Nourishing Networks Training Course

2016 WVU Food Justice Lab - Nourishing Networks Mapping Workshop

\section{PROFESSIONAL AFFILIATIONS}

Member of the Academy of Nutrition \& Dietetics

Member of the West Virginia Academy of Nutrition \& Dietetics

Member of the Dietitians in Integrative and Functional Nutrition

Member of Hunger and Environmental Nutrition Didactic Practice Group

Member of Phi Upsilon Omicron - Lambda Chapter

\section{INVITED ENGAGEMENTS}

2020 WVU Extension Small Farms Conference: February 21, 2020

- Cooking up opportunity in cottage Foods, Commercial Kitchens, and Incubator Kitchens

2018 WVU Extension Small Farms Conference: February 22, 2018

- Outlets for lower grade products - from seconds to success

- Food is Medicine

2017 WVU Food System Symposium: September 25th, 2017

- Farm to Institution

2017 West Virginia Academy of Nutrition \& Dietetics - Annual Conference: April 2017

- Opportunities in Culinary Medicine 


\section{WVU Food System Symposium: September 14th, 2016}

- Food Systems efforts on campus

\section{West Virginia Small Farm Conference}

- Food recovery opportunities for small farmers in West Virginia

\section{MEDIA}

2019 Public Health undergraduate students complete more than 1,600 field experience hours https://www.hsc.wvu.edu/news/story?headline=public-health-undergraduate-studentscomplete-more-than-1-600-field-experience-hours

2018 WVU Faculty to develop food safety education and outreach program for food producers https://wvutoday.wvu.edu/stories/2018/11/15/wvu-faculty-to-develop-food-safetyeducation-and-outreach-program-for-food-producers

2017 WVU to host 2nd Annual Food Symposium https://enews.wvu.edu/articles/2017/09/22/2nd-annual-food-system-symposium

2017 Climb Higher Nominee:

https://climbhigher.wvu.edu/nominees

2016 100-mile Dinner returns to WVU Cafe Evansdale http://wvutoday-archive.wvu.edu/n/2016/10/10/100-mile-dinner-returns-to-cafevansdale.html

2016 Deliteful Success https://www.davis.wvu.edu/featured-stories/delite-ful-success

2015 WVU to host 100 Mile Dinner https://issuu.com/wvudavis/docs/davis_mag_spring2015_v2_digital

2014 WVU To host 100 Mile Dinner http://wvutoday-archive.wvu.edu/n/2014/10/20/wvu-to-host-100-mile-dinner.html\#sthash

2014 Nutrition staff give culinary demo and tasting at market http://connections.wvumedicine.org/news/story?headline=nutrition-staff-give-culinarydemo-and-tasting-at-market 
2014 Program will train WVU students to be top C.H.E.F.s. http://wvutoday-archive.wvu.edu/n/2014/01/23/program-will-train-wvu-students-to-betop-c-h-e-f-s.html

2013 Student group to host "food Week" to focus on healthy choices http://wvutoday-archive.wvu.edu/n/2013/10/17/wvu-student-group-to-host-food-week-tofocus-on-healthy-choices.html

2013 Gifts to WVU Business College to fund cross-campus collaboration https://www.wvnews.com/theet/news/gifts-to-wvu-business-college-to-fund-crosscampus-collaboration/article 6f0bd970-c811-11e2-bd7d-001a4bcf887a.html

2013 WVU Business School Hospitality \& Tourism support provide six internships http://wvutoday-archive.wvu.edu/n/2013/05/28/wvu-business-school-hospitality-andtourism-support-funds-provide-six-internships.html

2012 Taziki's WVU partners with Ag School on Food Allergens Project https://business.wvu.edu/about/news/features/2012/10/30/-tazikis-wvu-partners-with-agschool-on-food-allergens-project

2012 Govindan to lead WVU's dietetic education program http://wvutoday-archive.wvu.edu/n/2012/01/31/govindan-to-lead-wvu-s-dieteticeducation-program.html

\section{CLINICAL EXPERIENCE}

Registered Dietitian

2008-2009

HealthSouth Mountainview Rehabilitation Hospital - Morgantown, WV

\section{PUBLICATIONS}

Berry, M. Govindan, M, Verlinden, S. Taylor, R. Investigation into Composting Efforts at West Virginia University. West Virginia University, ProQuest Dissertations Publishing, 2018.

Fink, D. Govindan, M. You, J. Taylor, R. The Effect of an Interdisciplinary Healthcare Team on the Nutritional Status of Elderly Patients in Acute and Post-Acute Care. West Virginia University, ProQuest Dissertations Publishing, 2018.

Haney, J. Govindan, M. Boone, D. Blemings, K. Managing diabetes in children with disabilities: best practices \& barriers. West Virginia University, ProQuest Dissertations 
Publishing, 2008.

Bulian, K. Govindan, M. Blemings, K. Barnes, K. Successful aspects of nutrition-focused social marketing campaigns. West Virginia University, ProQuest Dissertations Publishing, 2014. Govindan M. Youth Health Promotion in West Virginia: The Helping H.A.N.D. (Health Awareness \& Nutritious Decisions) program. West Virginia University, ProQuest Dissertations Publishing, 2008.

Govindan M. Developing a nutrition education program for low-income mothers: The Helping H.A.N.D. Cooking Club. West Virginia University, ProQuest Dissertation Publishing, 2009.

\section{POSTER PRESENTATIONS}

2011 West Virginia University Community Medicine MPH Practicum Presentations at the Robert C. Byrd Health Sciences Center in Morgantown, WV: May $4^{\text {th }}, 2011$

- Nutrition education programs for women: A Review of selected approaches and models. M. Govindan

2009 West Virginia University Community Medicine MPH Practicum Presentations at the Robert C. Byrd Health Sciences Center in Morgantown, WV: December $7^{\text {th }}, 2009$.

- Revision and expert review of the Dining with Diabetes curriculum for use with the general public. M. Govindan MPH Candidate

2008 American Dietetic Association's Food \& Nutrition Conference \& Expo (FNCE) McCormick Place West in Chicago, Ill: October $25^{\text {th }}-28^{\text {th }}, 2008$.

- Youth Health Promotion in West Virginia: Helping H.A.N.D. (Health Awareness \& Nutritious Decisions) C. Fitch, PhD, RD, M. Govindan MS, LD-P

2008 West Virginia University Community Medicine Student Poster Presentation at the Robert C. Byrd Health Sciences Center in Morgantown, WV: April $24^{\text {th }}, 2008$.

- Agricultural groundwater contamination and campylobacter resistance M. Govindan MS

2007 University of South Florida $8^{\text {th }}$ Annual Conference on Obesity at the Sheraton Sand Key Resort in Clearwater Beach, Fl: September $7^{\text {th }}-^{\text {th }}, 2007$

- Promoting health awareness and nutrition education to low-income children in West Virginia: Helping H.A.N.D. (Health Awareness \& Nutritious Decisions) C. Fitch, PhD, RD, M. Govindan, BS, E. Vongxaiburana, MABMH

2007 West Virginia University Extension Service Diabetes Symposium and Workshop at 
Embassy Suites in Charleston, WV: October $2^{\text {th }}-26^{\text {th }}, 2007$.

- Healthy $i$ Diabetes Conversation Maps - diabetes educator training. 